\title{
Morphological control of multifunctionalized mesoporous silica nanomaterials for catalysis applications
}

\author{
by \\ Seong Huh \\ A dissertation submitted to the graduate faculty \\ in partial fulfillment of the requirements for the degree of \\ DOCTOR OF PHLOSOPHY \\ Major: Inorganic Chemistry \\ Program of Study Committee: \\ Victor S. -Y. Lin, Major Professor \\ James H. Espenson \\ Nenad M. Kostic \\ Nicola L. Pohl \\ Brent H. Shanks
}

Iowa State University

Anes, Iowa

2004 
Graduate College

Iowa State University

This is to certify that the doctoral dissertation of

Seong Huh

has met the dissertation requirements of Iowa State University

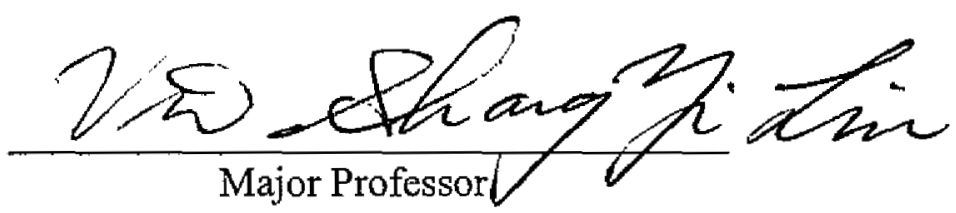

For the Major Program 
iii

To my parents, and brothers Hyun and Hoon 


\section{TABLE OF CONTENTS}

ABSTRACT

CHAPTER 1. GENERAL INTRODUCTION 1

Introduction $\quad 1$

Dissertation Organization $\quad 1$

Literature Review 3

References 8

CHAPTER 2. ORGANIC FUNCTIONALIZATION AND MORPHOLOGY CONTROL OF MESOPOROUS SILICAS VIA A CO-CONDENSATION SYNTHESIS METHOD $\quad 14$

$\begin{array}{ll}\text { Abstract } & 14\end{array}$

Introduction $\quad 15$

$\begin{array}{ll}\text { Experimental Section } & 17\end{array}$

Results and Discussion $\quad 20$

$\begin{array}{ll}\text { Conclusions } & 26\end{array}$

Acknowledgement $\quad 26$

References $\quad 42$

CHAPTER 3. TUNING OF PARTICLE MORPHOLOGY AND PORE

PROPERTIES IN MESOPOROUS SILICAS WITH MULTIPLE ORGANIC FUNCTIONAL GROUPS

Abstract

Introduction

Experimental Section $\quad 47$

$\begin{array}{ll}\text { Results and Discussion } & 48\end{array}$

Conclusions $\quad 51$

Acknowledgement $\quad 51$

References $\quad 56$

Supporting Information $\quad 58$

CHAPTER 4. CONTROLLING THE SELECTIVITY OF COMPETITIVE

NITROALDOL CONDENSATION BY USING A BIFUNCTIONALIZED

MESOPOROUS SILICA NANOSPHERE-BASED CATALYTIC SYSTEMS $\quad 75$

Abstract $\quad 75$

$\begin{array}{ll}\text { Introduction } & 76\end{array}$

$\begin{array}{ll}\text { Experimental Section } & 77\end{array}$

$\begin{array}{ll}\text { Results and Discussion } & 77\end{array}$

Acknowledgement $\quad 80$

References $\quad$. 85

Supporting Information $\quad 87$ 
CHAPTER 5. COOPERATIVE CATALYSIS BY GENERAL ACID AND BASE

BIFUNCTIONALIZED MESOPOROUS SILICA NANOSPHERE CATALYSTS Abstract

Introduction

101

Results and Discussion

102

Conclusions

102

Acknowledgement

106

References

106

Supporting Information

112

113

CHAPTER 6. GENERAL CONCLUSIONS 
vi

\begin{abstract}
I found an efficient method to control the morphology of the organically monofunctionalized mesoporous silica materials by introducing different types of organoalkoxysilanes in a base-catalyzed co-condensation reaction. The monofunctionalized materials exhibit different particle morphologies relative to the pure MCM-41 material. The concentration dependence of the morphology is a critical factor to determine the final particle shape. A proposed mechanism of the shape evolution is also offered. After understanding the role of organoalkoxysilanes in producing various well-shaped nanomaterials, I also obtained a series of bifunctional mesoporous silica materials with certain particle morphology. A series of bifunctional mesoporous silica nanospheres (MSNs) whose physicochemical properties was investigated via solid state NMR techniques and $\mathrm{Cu}^{2+}$ adsorption capacity tests. The ratio of two different organic groups inside of mesopores of these MSNs could be fine-tuned. These MSNs serve as a useful model system to study substrate selectivity in catalytic reactions and sorption phenomena. For example, the $\mathrm{Cu}^{2+}$ adsorption capacity of these materials was dictated by the chemical nature of the mesopores generated by the different organic functional groups.
\end{abstract}

An investigation of the substrate selectivity of the bifunctionalized MSNs in a competitive nitroaldol reaction using an equimolar amount of two competing 4nitrobenzaldehyde derivatives was performed. Shape-controlled bifunctional MSNs were employed as the catalysts. The properties of the MSNs were investigated using various spectroscopic methods and electron microscopy. The more hydrophobic the surface organic groups are, the higher the ratio of hydrophobic final product. This is the first example to 
vii

demonstrate the selection of substrate using physicochemical nature of the mesopore surface other than the conventional shape selection in zeolite systems.

I also created a cooperative dual catalyst system that is capable of activating two different substrates in aldol reaction, Henry reaction and cyanosilylation. One catalytic group activates the nucleophile, another organic group simultaneously activates the electrophile to enhance the total reaction rate. I systematically varied the amount of two organic groups and performed the three model reactions to compare rate enhancements. 


\section{CHAPTER 1. GENERAL INTRODUCTION}

\section{Introduction}

Since the first discovery of the mesoporous silica materials a decade ago, such as MCM- $41 / 48^{1,2}$ and SBA- $15,{ }^{3,4}$ numerous methods for the synthesis of mesostructured siliceous and nonsiliceous materials have been reported. ${ }^{5,6}$ These mesostructured materials usually exhibit well-ordered hexagonal, cubic or lamellar phases according to their synthetic conditions. In addition, highly disordered channel structures have been observed when neutral amine templates were applied to give MSU type of materials. ${ }^{7}$ The major synthetic parameters include temperature, $\mathrm{pH}$, aging time, stirring rate, types of templates and the concentration of surfactant. Particle morphology of the mesostructured materials is also a critical factor for various reasons. ${ }^{8}$

\section{Dissertation Organization}

This thesis is consisted of four main chapters with three published papers, ${ }^{9-11}$ one submitted paper, and two chapters including a general introduction and a general conclusion chapter. Chapter 1 includes an overview about the synthesis and functionalization of mesoporous materials. Chapter 2 describes the morphology control of the organically monofunctionalized mesoporous silica materials by introducing different types of organoalkoxysilanes in a base-catalyzed co-condensation reaction. ${ }^{9}$ The monofunctionalized materials exhibit different particle morphologies relative to the pure MCM-41 material. I also observed concentration dependence of the morphology which is a critical factor to determine 
the final particle shape. A proposed mechanism of the shape evolution is also offered in this chapter. After understanding the role of organoalkoxysilanes in producing various wellshaped nanomaterials, I also obtained a series of bifunctional mesoporous silica materials with certain particle morphology. Chapter 3 deals with a series of bifunctional mesoporous silica nanospheres (MSNs) whose physicochemical properties were investigated via solid state NMR techniques and $\mathrm{Cu}$ (II) adsorption capacity tests. ${ }^{10}$ The ratio of two different organic groups inside of mesopores of these MSNs could be fine-tuned. These MSNs serve' as a useful model system to study substrate selectivity in catalytic reactions and sorption phenomena. For example, the $\mathrm{Cu}(\mathrm{II})$ adsorption capacity of these materials was dictated by the chemical nature of the mesopores generated by the different organic functional groups.

Chapter 4 entails an investigation of the substrate selectivity of the bifunctionalized MSNs in a competitive nitroaldol reaction using an equimolar amount of two competing 4nitrobenzaldehyde derivatives. ${ }^{\text {ll }}$ Shape-controlled bifunctional MSNs were employed as the catalysts. The properties of the MSNs were investigated using various spectroscopic methods and electron microscopy. The more hydrophobic the surface organic groups are, the higher the ratio of hydrophobic final product. This is the first example to demonstrate the selection of substrate using physicochemical nature of the mesopore surface other than conventional shape selection in zeolite systems.

In Chapter 5,1 try to expand the basic concept developed in Chapter 4 to create a cooperative dual catalyst system that is capable of activating two different substrates in aldol reaction, Henry reaction and cyanosilylation. One catalytic group activates the nucleophile, the other organic groups simultaneously activate the electrophile to enhance the total reaction 
rate. I systematically varied the amount of two organic groups systematically and performed the three model reactions to compare rate enhancements.

\section{Literature Review}

Mesoporous silica materials prepared by numerous templating approaches open a new era to exceed the pore size limit of zeolites. The hexagonal MCM-41 and cubic MCM-48 were synthesized using a traditional soft sol-gel chemistry using a quarternary ammonium surfactant as an ionic template, such as $\mathrm{CTAB} .{ }^{1,2}$ Charge-matching has been recognized as the most critical factor in governing the final phases and stability. Stucky introduced nonionic surfactants in acidic condition to produce thick-wall large pore size hexagonal mesoporous silica SBA-15., The SBA-15 usually has mesopores and micropores together evidenced by BET isotherm and TEM study. In general, almost every organic molecule can be used as a soft template to lead hard inorganic porous materials in solution state. One is able to freely alter the pore organization (hexagonal, cubic or lamellar) and a pore size as well. Disordered mesostructured siliceous or nonsiliceous materials were also synthesized by Pinnavaia et al. through a neutral amine templating. ${ }^{\text {? }}$

These materials provide new research opportunities in catalysis, ${ }^{11-13}$ delivery of biologically important molecules, ${ }^{14,15}$ immobilizations of enzymes, ${ }^{16,17}$ and remediation of toxic compounds. ${ }^{18-20}$ Recent progress in preparation of mesoporous carbon materials takes advantage of the predefined silica structure as a template for replication by carbonaceous sources. ${ }^{21-23}$ Mesoporous carbons are also important for their potential applications to sorption, fuel cells, and drug delivery. 
Another novel class of mesoporous organic/inorganic hybrid materials is a periodic mesoporous organosilica (PMO) developed by three different independent research groups at the same time. ${ }^{24-26}$ The PMOs have quite different physicochemical properties from typical mesoporous silicas because the surface wall is consisted of both organic and inorganic moieties. Different types of organoalkoxysilanes have been employed to form well structured PMOs. ${ }^{27-29}$ The PMOs having an atomic scale periodicity have been also reported by Inagaki et al $^{30-32}$ Recently 3D macroporous PMO materials bearing hybrid groups have been achieved using a polystyrene crystalline phase as a macroporous template. ${ }^{33}$ Aminefunctionalized PMOs have been prepared through a co-condensation method. ${ }^{34}$

Mesostructured films were successfully obtained via an evaporation-induced self assembly (EISA) process developed by Brinker et al. ${ }^{35}$ In addition to the preparation of high quality mesoporous silica films, they demonstrated patterned mesoporous silica films using photolytically polymerizable diacetylenic surfactants. ${ }^{36}$ Mesostructured silica thin films prepared in supercritical fluids are also important low dielectric materials with a strong mechanical strength. ${ }^{37} \mathrm{~A}$ hierarchically arranged mesostructured silica film has been also realized by using a standard PDMS patterning method. ${ }^{5}$ They applied a mesoporous silica precursor solution as an ink for the PDMS stamping.

The functionalization of the pore surface of the mesoporous materials has been intensively investigated. ${ }^{38}$ There are two major ways to decorate the surface wall, a postgrafting and a co-condensation. ${ }^{39}$ Although the post-grafting method is straightforward to introduce any organic functionalities using organoalkoxysilane or organosilyl chloride precursors in a refluxing toluene solution, the distribution of functional groups tends to be 
inhomogeneous. Compared with the post-grafting method, the co-condensation is able to give homogeneously distributed organic groups on the entire inner pore surfaces and no poreblockage or shrinkage problems have been reported. Even though bulky organoalkoxysilane precursors often perturb the original textural properties of the systems, we and others have been developing methods to decorate the surface wall efficiently while maintaining the mesoprous structure.9, 10

Recently, small shape-controlled mesoporous material particles have attracted much attention owing to their superior properties in a variety of applications. ${ }^{10,11,14}$ Controlling of particle morphology as well as mesostructure is an emerging research area which is closely related to the biomineralization process in nature. If the mesostructure is a primary structure, the particle morphology is a hierarchical secondary structure. The complex forms of diatoms are good examples. ${ }^{40}$ There are many sophisticated methods to prepare shape-controlled pure mesoporous siliceous materials. Ozin has demonstrated that the particle morphology of the surfactant micelle-templated mesoporous silica materials could be manipulated via an acid synthesis $\left(\mathrm{S}^{+} \mathrm{XT}^{+}\right)$route. ${ }^{41}$ This synthetic method is based on different hierarchical orderings of individual micellar rods as mentioned by Ozin. ${ }^{42}$ Several other synthetic strategies have also been reported in the literature for the morphological control of various mesoporous silica materials, including hollow tubular silica materials whose wall consists of MCM-41 type of mesoporous structure, ${ }^{43}$ fluorine anion induced hierarchical ordering of SBA type of materials ${ }^{44}$ rod-shaped mesoporous materials obtained from rapid $\mathrm{pH}$ change of sodium metasilicate and cationic surfactant mixture, ${ }^{45}$ bacterial thread-templated mesoporous silica rod, ${ }^{46}$ mesoporous fibers from the rubbing treated polyimide film, ${ }^{47}$ ultrastable mesoporous 
silica vesicles prepared via a neutral gemini surfactant template method, ${ }^{48}$ hydrothermal transformation of MCM-41 silica spheres into rod-shaped particles ${ }^{49}$ and hollow mesoporous fibers and spheres prepared by a spray drying. ${ }^{50}$ Twisted mesoporous silica particles were prepared with the use of enantiopure templates having an amino acid head group. ${ }^{51}$ Despite much inspiring progress in fine tuning the particle morphology of pure inorganic mesoporous silica materials, the quest for synthetic pathways that could combine the particle morphology control with surface functionalization to create uniformly shaped and sized mesoporous materials with various organic functionalities has just begun. ${ }^{9-11}$

During my research, two independent groups reported shape-controlled organically functionalized nanomaterials through a co-condensation method. Walcarius used a traditional Stöber method to synthesize mercaptopropyl- and aminopropyl-functionalized mesoporous silica spheres. ${ }^{52}$ Detailed textural properties were also investigated. In fact, this method is an extension of the Unger's work ${ }^{53,54}$ to prepare micron-sized spherical mesoporous silicas based on the Stöber method. ${ }^{55}$ Their internal channel structures were further investigated in detail by a transmission electron microscopy (TEM) ${ }^{56}$ Mann et al. invented a method to produce organically functionalized spherical and rod-shaped particles. ${ }^{57}$ They used a dilution/neutralization process to control the size of the final particles. ${ }^{58}$ However, there are still remaining questions to be answered about the role of organic group (the starting form of organoalkoxysilane) during shape evolution and the effect of two or more different organic groups during the condensation. ${ }^{10,11}$

Zhao et al. reported a very interesting observation during the preparation of bulk mercaptopropyl-functionalized materials. ${ }^{59}$ In the presence of a certain amount of 
mercaptopropyltrimethoxysilane (MPTMS), the original hexagonal phase of the material was partly transformed into a cubic phase. This phenomenon is relevant to my observation during my synthetic conditions.

The preparation method for micron-sized pure siliceous mesoporous materials via a low concentration of CTAB has been reported by Cai et al.$^{60} \mathrm{Because}$ of the broad range of critical micelle concentration (CMC) of CTAB, they chose the lower limit of the $\mathrm{CMC}$ value and successfully obtained small hexagonally arranged mesoporous silicas. This approach is a similar way of preparing small mesoporous particles like the dilution/neutralization method proposed by Mann et al ${ }^{57}$ It is clear that low concentration of ammonium surfactants easily induces small size of micelle aggregates.

Because of their high surface area and large pore size, mesostructured materials frequently employed as catalyst support for immobilization of precious metal catalysts. ${ }^{61}$ Highly crystalline polyethylene nanofibers were prepared by using covalently anchored $\operatorname{Ti}(\mathrm{IV})$ complexes on the inner surface of the fibrous mesoporous silica. ${ }^{62}$ They proposed the polymerization/extrusion mechanism from the hexagonally aligned mesopores which is similar to the biosynthesis of crystalline cellulose. Conducting graphite-type carbon polymer encapsulated mesoporous silica nanocomposites were made through a pyrolysis of polymerized acrylonitrile inside of the mesopores by Bein et al. ${ }^{63,64}$ The periodic arrangement of mesopores manifested the role of a nanocontainer for an efficient nanocomposite formation. Jones et al. developed an ingenious way to graft the organic functional groups on the mesoporous silica surface by using a labile protecting group at the terminal aminopropyl groups. ${ }^{65,66}$ The resulting site-isolated organometallic catalyst is 
known to be a very active catalytic system. Acid-labile surfactant has been synthesized and successfully employed as a template for the preparation of MCM-41 type of materials. ${ }^{67}$ After hydrocarbon tail cleavage by a simple acid hydrolysis, the as-made materials were changed into amino acid functionalized mesoporous materials. Even though this approach always requires sophisticated design of template molecules, the resultant surface coverage is exceptionally high and functional groups are well defined.

\section{References}

1. Kresge, C. T.; Leonowicz, M. E.; Roth, W. J.; Vartuli, J. C.; Beck, J. S., Nature (London) 1992, 359, 710-712.

2. Beck, J. S.; Vartuli, J. C.; Roth, W. J.; Leonowicz, M. E.; Kresge, C. T.; Schmitt, K. D.; Chu, C. T. W.; Olson, D. H.; Sheppard, E. W., J. Am. Chem. Soc. 1992, ll4, 10834-10843.

3. Zhao, D.; Feng, J.; Huo, Q.; Melosh, N.; Frederickson, G. H.; Chmelka, B. F.; Stucky, G. D., Science (Washington, D. C.) 1998, 279, 548-552.

4. Zhao, D.; Huo, Q.; Feng, J.; Chmelka, B. F.; Stucky, G. D., J. Am. Chem. Soc. 1998, $120,6024-6036$

5. Yang, P.; Deng, T.; Zhao, D.; Feng, P.; Pine, D.; Chmelka, B. F.; Whitesides, G. M.;

Stucky, G. D., Science (Washington, D. C.) 1998, 282, 2244-2247.

6. Yang, P.; Zhao, D.; Margolese, D. I.; Chmelka, B. F.; Stucky, G. D., Nature (London) $1998,396,152-155$. 
7. Bagshaw, S. A.; Prouzet, E.; Pinnavaia, T. J., Science (Washington, D. C.) 1995, 269, 1242-1244.

8. Ciesla, U.; Schuth, F., Micropor. Mesopor. Mater. 1999, 27, 131-149.

9. Huh, S.; Wiench, J. W.; Yoo, J.-C.; Pruski, M.; Lin, V. S. Y., Chem. Mater. 2003, 15, $4247-4256$.

10. Huh, S.; Wiench, J. W.; Trewyn, B. G.; Song, S.; Pruski, M.; Lin, V. S. Y., Chem. Commun. 2003, 2364-2365.

11. Huh, S.; Chen, H.-T.; Wiench, J. W.; Pruski, M.; Lin, V. S. Y., J. Am. Chem. Soc. $2004,126,1010-1011$.

12. Tanev, P. T.; Chibwe, M.; Pinnavaia, T. J., Nature (London) 1994, 368, 321-323.

13. Xia, Y.; Mokaya, R, Angew. Chem., Int. Ed. 2003, 42, 2639-2644.

14. Lai, C.-Y.; Trewyn, B. G.; Jeftinija, D. M.; Jeftinija, K.; Xu, S.; Jeftinija, S.; Lin, V. S. Y., J. Am. Chem. Soc. 2003, 125, 4451-4459.

15. Han, Y.-J.; Stucky, G. D.; Butler, A., J. Am. Chem. Soc. 1999, 121, 9897-9898.

16. Lei, C.; Shin, Y.; Liu, J.; Ackerman Eric, J., J. Am. Chem. Soc. 2002, 124, $11242-$ 11243.

17. Fan, J.; Yu, C.; Gao, F.; Lei, J.; Tian, B.; Wang, L.; Luo, Q.; Tu, B.; Zhou, W.; Zhao, D., Angew. Chem. Int. Ed. 2003, 42, 3146-3150.

18. Yoshitake, H.; Yokoi, T.; Tatsumi, T., Chem. Mater. 2003, 15, 1713-1721.

19. Yoshitake, H.; Yokoi, T.; Tatsumi, T., Chem. Mater. 2002, 14, 4603-4610.

20. Feng, X.; Fryxell, G. E.; Wang, L. Q.; Kim, A. Y.; Liu, J.; Kemner, K. M., Science (Washington, D. C.) 1997, 276, 923-926. 
21. Ryoo, R.; Joo, S. H.; Kruk, M.; Jaroniec, M., Adv. Mater. 2001, 13, 677-681.

22. Lee, J.-S.; Joo, S. H.; Ryoo, R., J. Am. Chem. Soc. 2002, 124, 1156-1157.

23. Joo, S. H.; Choi, S. J.; Oh, I.; Kwak, J.; Liu, Z.; Terasaki, O.; Ryoo, R., Nature (London) 2001, 414, 169-172.

24. Asefa, T.; MacLachlan, M. J.; Coombs, N.; Ozin, G. A., Nature (London) 1999, 402, $867-871$.

25. Inagaki, S.; Guan, S.; Fukushima, Y.; Ohsuna, T.; Terasaki, O., J. Am. Chem. Soc. $1999,121,9611-9614$.

26. Melde, B. J.; Holland, B. T.; Blanford, C. F.; Stein, A., Chem. Mater. 1999, 11, 33023308.

27. Kapoor, M. P.; Yang, Q.; Inagaki, S., Chem. Mater. 2004, 16, 1209-1213.

28. Landskron, K.; Hatton Benjamin, D.; Perovic Doug, D.; Ozin Geoffrey, A., Science (Washington, D. C.) 2003, 302, 266-269.

29. Temtsin, G.; Asefa, T.; Bittner, S.; Ozin, G. A., J. Mater. Chem. 2001, 11, 32023206.

30. Inagaki, S.; Guan, S.; Ohsuna, T.; Terasaki, O., Nature (London) 2002, 416, 304-307.

31. Kapoor Mahendra, P.; Yang, Q.; Inagaki, S., J. Am. Chem. Soc. 2002, 124, 1517615177 .

32. Yang, Q.; Kapoor Mahendra, P.; Inagaki, S., J. Am. Chem. Soc. 2002, 124, 96949695.

33. Zhou, Z.; Bao, X.; Zhao, X. S., Chem. Commun. 2004, 1376-1377. 
34. Burleigh, M. C.; Markowitz, M. A.; Spector, M. S.; Gaber, B. P., Chem. Mater. 2001, $13,4760-4766$.

35. Lu, Y.; Ganguli, R.; Drewien, C. A.; Anderson, M. T.; Brinker, C. J.; Gong, W.; Guo, Y.; Soyez, H.; Dunn, B.; Huang, M. H.; Zink, J. I., Nature (London) 1997, 389, 364368.

36. Lu, Y.; Yang, Y.; Sellinger, A.; Lu, M.; Huang, J.; Fan, H.; Haddad, R.; Lopez, G.; Burns, A. R.; Sasaki, D. Y.; Shelnutt, J.; Brinker, C. J., Nature (London) 2001, 410, 913-917.

37. Pai, R. A.; Humayun, R.; Schulberg, M. T.; Sengupta, A.; Sun, J.-N.; Watkins, J. J., Science (Washington, D. C.) 2004, 303, 507-511.

38. Stein, A.; Melde, B. J.; Schroden, R. C., Adv. Mater. 2000, 12, 1403-1419.

39. Lim, M. H.; Stein, A., Chem. Mater. 1999, 11, 3285-3295.

40. Mann, S.; Ozin, G., Nature (London) 1996, 382, 313-318.

41. Yang, H.; Coombs, N.; Ozin, G. A., Nature (London) 1997, 386, 692-695.

42. Ozin; G. A., Chem. Commun. 2000, 419-432.

43. Lin, H.-P.; Mou, C.-Y., Science (Washington, D. C.) 1996, 273, 765-768.

44. Schmidt-Winkel, P.; Yang, P.; Margolese, D. I.; Chmelka, B. F.; Stucky, G. D., Adv. Mater, 1999, 11, 303-307.

45. Shio, S.; Kimura, A.; Yamaguchi, M.; Yoshida, K.; Kuroda, K., Chem. Commun. $1998,2461-2462$.

46. Davis, S. A.; Burkett, S. L.; Mendelson, N. H.; Mann, S., Nature (London) 1997, 385, $420-423$. 
47. Miyata, H.; Kuroda, K., Adv. Mater. 2001, 13, 558-561.

48. Kim, S. S.; Zhang, W.; Pinnavaia, T. J., Science (Washington, D. C.) 1998, 282, 1302-1305.

49. Mokaya, R., Chem. Commun. 2001, 933-934.

50. Lu, Y.; Fan, H.; Stump, A.; Ward, T. L.; Rieker, T.; Brinker, C. J., Nature (London) $1999,398,223-226$.

51. Che, S.; Liu, Z.; Ohsuna, T.; Sakamoto, K.; Terasaki, O.; Tatsumi, T., Nature (London) 2004, 429, 281-284.

52. Etienne, M.; Lebeau, B.; Walcarius, A., New J. Chem. 2002, 26, 384-386.

53. Gruen, M.; Lauer, I.; Unger, K. K., Adv. Mater. 1997, 9, $254-257$.

54. Schumacher, K.; Du Fresne von Hohenesche, C.; Unger, K. K.; Ulrich, R.; Du Chesne, A.; Wiesner, U.; Spiess, H. W., Adv. Mater. 1999, II, 1194-1198.

55. Stoeber, W.; Fink, A.; Bohn, E., J. Colloid Interface Sci. 1968, 26, 62-69.

56. Pauwels, B.; Van Tendeloo, G.; Thoelen, C.; Van Rhijn, W.; Jacobs, P. A., Adv. Mater. 2001, 13, 1317-1320.

57. Sadasivan, S.; Khushalani, D.; Mann, S., J. Mater. Chem. 2003, 13, 1023-1029.

58. Fowler, C. E.; Khushalani, D.; Lebeau, B.; Mann, S., Adv. Mater. 2001, 13, 649-652.

59. Che, S.; Garcia-Bennett, A. E.; Liu, X.; Hodgkins, R. P.; Wright, P. A.; Zhao, D.; Terasaki, O.; Tatsumi, T., Angew. Chem. Int. Ed. 2003, 42, 3930-3934.

60. Cai, Q.; Luo, Z.-S.; Pang, W.-Q.; Fan, Y.-W.; Chen, X.-H.; Cui, F.-Z., Chem. Mater. $2001,13,258-263$.

61. Clark, J. H., Acc. Chem. Res. 2002, 35, 791-797. 
62. Kageyama, K.; Tamazawa, J.-I.; Aida, T., Science (Washington, D. C.) 1999, 285, 2113-2115.

63. Wu, C. G.; Bein, T., Science (Washington, D. C.) 1994, 264, 1757-1759.

64. Wu, C.-G.; Bein, T., Science (Washington, D. C.) 1994, 266, 1013-1015.

65. McKittrick, M. W.; Jones, C. W., J. Am. Chem. Soc. 2004, 126, 3052-3053.

66. Yu, K.; McKittrick, M. W.; Jones, C. W., Organometallics 2004, 23, 4089-4096.

67. Zhang, Q.; Ariga, K.; Okabe, A.; Aida, T., J. Am. Chem. Soc. 2004, 126, 988-989. 


\title{
CHAPTER 2. ORGANIC FUNCTIONALIZATION AND MORPHOLOGY CONTROL OF MESOPOROUS SILICAS VIA A CO-CONDENSATION SYNTHESIS METHOD
}

\author{
A paper published in Chemistry of Materials ${ }^{1}$
}

Seong Huh, Jerzy W. Wiench, Ji-Chul Yoo, Marek Pruski and Victor S. -Y. Lin

\begin{abstract}
A series of new mesoporous silica materials with MCM-41 type of structure containing a homogeneous layer of organic functional groups inside the pores was prepared using a co-condensation method under low surfactant concentration condition. This reproducible synthetic approach resulted in high surface coverage with several functional groups such as a primary amine, secondary amine, urea, isocyanate, vinyl, and nitrile. In addition, the presence of organoalkoxysilane precursors during the base catalyzed condensation greatly influenced the final particle shape. By changing the precursor or its concentration, the particle morphology was tuned to various shapes, including spheres, tubes, and rods of various dimensions. The synthetic procedures that gave rise to the specific particle morphologies were investigated and the mechanism responsible for shape control was postulated. The structure and functionality of these materials were characterized by the field-emission scanning electron microscopy, transmission scanning microscopy, solid state
\end{abstract}

\footnotetext{
' Reprinted with permission of Chem. Mater. 2003, 15, 4247-4256. Copyright 2003, American Chemical Society.
} 
NMR spectroscopy, thermogravimetric analysis, and nitrogen adsorption and desorption studies (BET isotherms and BJH pore size distribution measurements).

\section{Introduction}

Ever since the discovery of surfactant micelle-templated synthesis of mesoporous silica materials, such as MCM-41/48, ${ }^{1,2}$ SBA- $15,{ }^{3}$ MSU- $n,{ }^{4} \mathrm{KIT}-1,{ }^{5}$ and FSM-16, ${ }^{6}$ many research efforts have focused on (i) preparing the organic/inorganic hybrids through functionalization of the exterior and/or interior surfaces and (ii) controlling the particle morphology. The success of such investigations will prompt the utilization of these materials in separation, ${ }^{7}$ sensor design, ${ }^{8}$ catalysis, ${ }^{9}$ and drug delivery. ${ }^{10}$

Although numerous synthetic approaches have been pursued and significant progress has been made in functionalization of the MCM silicas with various organic groups, the current state-of-the-art methods, such as post synthesis grafting ${ }^{11}$ and organosiloxane/siloxane co-condensation, ${ }^{12}$ need to be improved in order to control the amount and location of the incorporated functional groups. For example, the post synthesis grafting method typically results in inhomogeneous surface coverage because the introduced organic moieties congregate near the entries to the mesoporous channels and on the exterior surfaces. ${ }^{13}$ While many organically functionalized mesoporous materials were prepared via co-condensation, ${ }^{13-27}$ only few very recent investigations reported that spherical or tubular MCM-41 type silicas could be synthesized via incorporation of either mercaptopropyl, allyl, or aminopropyl functional groups. ${ }^{28}$ Also, the previously reported co-condensation methods usually result in breakup of the structural integrity and long-range periodicity at surface coverages exceeding $25 \%$. 
Herein, we report and analyze a new synthetic method that could combine efficient organic functionalization of mesoporous silicas with the control of particle morphology. The degree of functionalization and particle morphology were dictated by the concentration, molecular size and hydrophilicity/hydrophobicity of the organoalkoxysilane precursors. Our strategy involved a co-condensation method based on sodium hydroxide-catalyzed reactions of tetraethoxysilane (TEOS) with various organoalkoxysilanes in the presence of a low concentration of cetyltrimethylammonium bromide (CTAB) surfactant. The organoalkoxysilanes included 3-aminopropyltrimethoxysilane (APTMS), $N$-(2-aminoethyl)3-aminopropyltrimethoxysilane (AAPTMS), 3-[2-(2-aminoethylamino)ethylamino]propyltrimethoxysilane (AEPTMS), ureidopropyltrimethoxysilane (UDPTMS), 3 isocyanatopropyltriethoxy-silane (ICPTES), 3-cyanopropyltriethoxysilane (CPTES), and allyltrimethoxysilane (ALTMS). In contrast to the Stöber process ${ }^{29}$ or the recently reported. controlled quenching method, ${ }^{28}$ our approach did not involve any organic co-solvents or instantaneous neutralization of alkaline solutions during the co-condensation reaction, respectively. By systematically varying the type and the amount of organoalkoxysilanes, we obtained a series of nanoparticles in form of spheres, rods, and hexagonal tubes. Throughout this paper, we will refer to these materials as X-MP, where $\mathrm{X}$ describes the organoalkoxysilane precursor and MP stands for mesoporous particle. To examine the different mechanistic effects of the organoalkoxysilane-induced shape transformation, we analyzed the structures of these mesoporous organic/inorganic hybrid materials by powder X-ray diffraction (XRD) spectroscopy, field-emission scanning electron microscopy (FESEM), nitrogen adsorption-desorption surface analysis (BET isotherms and BJH pore size distributions), and thermogravimetric analysis (TGA). The incorporation of the organic 
functional groups was quantitatively studied by solid state NMR spectroscopy of ${ }^{13} \mathrm{C}$ and

${ }^{29} \mathrm{Si}$. Based on the observations of the morphological structures and the degree of organic functionalization, we proposed a formation mechanism of mesoporous silica nanoparticles with different morphologies that relies on the interaction between organoalkoxysilanes and CTAB micelles.

\section{Experimental Section}

The organoalkoxysilane precursors used for our co-condensation reactions contain a common trimethoxysilyl or triethoxysilyl terminal group and different organic functional groups, as depicted in Scheme 1. APTMS, AAPTMS, AEPTMS, UDPTMS, ICPTES, CPTES, ALTMS, TEOS and CTAB were purchased from Aldrich and used as received. The reaction mixture contained $1.0 \mathrm{CTAB}: 8.16 \mathrm{TEOS}: 1.05$ organotrialkoxysilane of choice (unless specified otherwise): $2.55 \mathrm{NaOH}: 4857 \mathrm{H}_{2} \mathrm{O}$ based on the molar ratio. For example, in the case of AP-MP, the mixture of CTAB $(2.0 \mathrm{~g}, 5.49 \mathrm{mmol}), 2.0 \mathrm{M}$ of $\mathrm{NaOH}(\mathrm{aq})(7.0$ $\mathrm{mL}, 14.0 \mathrm{mmol})$ and $\mathrm{H}_{2} \mathrm{O}(480 \mathrm{~g}, 26.67 \mathrm{~mol})$ was heated at $80^{\circ} \mathrm{C}$ for 30 min to reach $\mathrm{pH}$ 12.3. To this clear solution, TEOS ( $9.34 \mathrm{~g}, 44.8 \mathrm{mmol})$ and APTMS (1.03 g, $5.75 \mathrm{mmol})$ were added sequentially and rapidly via injection. Following the injection, a white precipitation was observed after $3 \mathrm{~min}$ of stirring at $c a .550 \mathrm{rpm}$. The reaction temperature was maintained at $80^{\circ} \mathrm{C}$ for $2 \mathrm{~h}$. The products were isolated by a hot filtration, washed with copious amount of water and methanol and dried under vacuum. The reaction yields of asmade products varied with respect to the choice of organoalkoxysilane and ranged from $38 \%$ to $65 \%$ of the starting weight of TEOS. An acid extraction was performed in methanol (100 $\mathrm{mL})$ mixture of concentrated hydrochloric acid $(1.0 \mathrm{~mL})$ and as-made materials $(1.0 \mathrm{~g})$ at 60 
${ }^{\circ} \mathrm{C}$ for $6 \mathrm{~h}$. Resulting surfactant-removed solid products were filtered and washed with water and methanol and then dried under vacuum. Pure MCM-41 samples were prepared as reference using the same experimental conditions. The as-synthesized sample containing the surfactant will be referred to as s-MCM-41, while the sample with CTAB removed will be simply denoted as MCM-41.

Particle morphology of these materials was determined by scanning electron microscopy (SEM) using a Hitachi S4700 FE-SEM system with $10 \mathrm{kV}$ accelerating voltage and $0.005 \mathrm{nA}$ of beam current for imaging. For transmission electron microscopy (TEM) studies, a small aliquot was taken from a suspension of methanol and placed in a lacey carbon coat TEM grid, which was pulled through the suspension and allowed to dry in air. Thin sections of samples embedded in epoxy resin were obtained with ultramicrotomy (60-80 $\mathrm{nm})$. The resulting sample was examined with a Philips model CM-30 TEM operated at 300 $\mathrm{kV}$. The specimen was given no further treatment, as it appeared stable under beam bombardment.

Powder XRD experiments were performed on a Scintag XDS 2000 diffractometer using a $\mathrm{Cu} \mathrm{K} \alpha$ radiation source. Low angle diffraction with a $2 \theta$ range of 1 to $10^{\circ}$ was used to investigate the long-range order of the materials. The surface area and median pore diameter were measured using $\mathrm{N}_{2}$ adsorption/desorption measurements in a Micromeritics ASAP 2000 BET surface analyzer system. The data were evaluated using the BrunauerEmmett-Teller (BET) and Barrett-Joyner-Halenda (BJH) methods to calculate the surface area and pore volumes/pore size distributions, respectively. Samples were prepared by degassing at $90^{\circ} \mathrm{C}$ for $1 \mathrm{~h}$ and then at $150^{\circ} \mathrm{C}$ for $4 \mathrm{~h}$. TGA curves were recorded using a TA 
Instruments TGA 2950 thermogravimetric analyzer with a temperature ramp of $5^{\circ} \mathrm{C} / \mathrm{min}$ under continuous flow of nitrogen $(100 \mathrm{~mL} / \mathrm{min})$.

Solid-state nuclear magnetic resonance (NMR) experiments were performed on a Varian/Chemagnetics Infinity spectrometer at the frequencies of 79.5, 100.6 and $400.0 \mathrm{MHz}$ for ${ }^{29} \mathrm{Si},{ }^{13} \mathrm{C}$ and ${ }^{1} \mathrm{H}$ nuclei, respectively. ${ }^{13} \mathrm{C}$ and ${ }^{29} \mathrm{Si}$ nuclei were observed using direct polarization (DP) or by cross polarization ${ }^{30}(\mathrm{CP})$ from the neighboring ${ }^{1} \mathrm{H}$ nuclei. The samples were placed in $5 \mathrm{~mm}$ zirconia rotors and spun at $10 \mathrm{kHz}$ in a doubly tuned Chemagnetics probe. The saturation recovery experiment, carried out for AL-MP and ICP-MP samples, yielded the ${ }^{29} \mathrm{Si}$ longitudinal relaxation times in the range of 30 to $65 \mathrm{~s}$. In spite of slow relaxation, ${ }^{29} \mathrm{Si}$ DPMAS measurements were performed to obtain quantitative spectra for all samples. These experiments used excitation with a single $90^{\circ}$ pulse of $2.1 \mu \mathrm{s}$ followed by data acquisition under continuous wave $(\mathrm{CW})^{1} \mathrm{H}$ decoupling at $65 \mathrm{kHz}$. Typically 270 scans were completed using pulse delay of $300 \mathrm{~s}$.

The variable amplitude CPMAS scheme ${ }^{31}$ was used to enhance the polarization of observed nuclei and increase the repetition rate of data acquisition. During each cross polarization period, the ${ }^{1} \mathrm{H}$ rf field was ramped between 16 and $40 \mathrm{kHz}$ using $2.4 \mathrm{kHz}$ increments, whereas the ${ }^{29} \mathrm{Si}$ (or ${ }^{13} \mathrm{C}$ ) rf field was maintained at a constant level of approximately $36 \mathrm{kHz}$. The maximum ${ }^{1} \mathrm{H} \rightarrow{ }^{29} \mathrm{Si}$ polarization transfer was achieved using a contact time of approximately $10 \mathrm{~ms}$, which is in agreement with previous studies performed for silicas. ${ }^{32}$ For ${ }^{13} \mathrm{C}$ nuclei, shorter contact times of $0.4 \sim 1.5 \mathrm{~ms}$ were used. The ${ }^{1} \mathrm{H}$ rf magnetic fields of $90 \mathrm{kHz}$ and $65 \mathrm{kHz}$ were used for initial excitation and decoupling, respectively. The values of ${ }^{1} \mathrm{H}$ longitudinal relaxation time encountered in all mesoporous samples examined in this study did not exceed $1 \mathrm{~s}$, which allowed for repetition time of $1.2 \mathrm{~s}$ 
to be used in the CPMAS experiments. Typically, $4 \mathrm{~K}$ scans were accumulated for ${ }^{1} \mathrm{H} \rightarrow{ }^{29} \mathrm{Si}$ CPMAS, whereas ${ }^{1} \mathrm{H} \rightarrow{ }^{13} \mathrm{C}$ experiments required between $1 \mathrm{~K}$ and $10 \mathrm{~K}$ scans per spectrum. All chemical shifts were referenced to $\mathrm{SiMe}_{4}$.

\section{Results and Discussion}

Organic functionalization. To simplify the analysis, we initially prepared a series of samples in which the amount of organoalkoxysilane used for the preparation was fixed at $12.8 \mathrm{~mol} \%$ of the amount of TEOS. The ${ }^{1} \mathrm{H} \rightarrow{ }^{13} \mathrm{C}$ CPMAS spectra of these samples, shown in Figure 1, provide clear evidence that they were indeed functionalized as intended. The observed chemical shifts, listed in Table 1, agreed well with those observed in homogeneous solutions of the corresponding precursors and were easily assigned. For example, the resonances at 6.5 , and $45.3 \mathrm{ppm}$ in the spectrum of APTMS dissolved in $\mathrm{CDCl}_{3}$ (not shown) corresponded to those at $9.1 \mathrm{ppm}(\mathrm{C} 1)$ and $42.3 \mathrm{ppm}(\mathrm{C} 3)$ observed in AP-MP. The resonance at $28 \mathrm{ppm}$ representing $\mathrm{C} 2$ exhibited a larger shift change toward higher field relative to the liquid state (20.6 ppm). The CPMAS spectrum of s-MCM-41 sample (Figure 1h) consisted of several resonances due to $\mathrm{CTAB}$, among which the peak at around $30 \mathrm{ppm}$, corresponding to carbons $\mathrm{C} 3$ through $\mathrm{C} 14$, is most intense. Two samples, $\mathrm{CP}-\mathrm{MP}$ and $\mathrm{AL}$ MP, contained detectable resonances from CTAB (marked with asterisks in spectra $f$ and $g$ ), which comprised just a few $\%$ of the total ${ }^{13} \mathrm{C}$ intensity.

The functionalization of silicas was further studied by TGA and solid state NMR of

${ }^{29} \mathrm{Si}$ (Figure 2 and Table 2). In general, three or four distinct weight loss TGA profiles were found, including methanol, organic functional groups, and a small weight loss due to the dehydration of the surface hydroxyl groups. While the TGA data provided evidence of the 
existence of organic functional groups inside the pores, a direct, quantitative measure of the organic functionalization was provided by ${ }^{29}$ Si DPMAS spectra shown in the left column of Figure 2. The resonances at around -59 and $-68 \mathrm{ppm}$ represented silicon atoms in positions $(\equiv \mathrm{SiO})_{2} \mathrm{Si}(\mathrm{OH}) \mathrm{R}$ and $(\equiv \mathrm{SiO})_{3} \mathrm{SiR}$, which are denoted $\mathrm{T}^{2}$ and $\mathrm{T}^{3}$, respectively. ${ }^{33-36}$ These silicon species were better observed using the ${ }^{29} \mathrm{Si}$ CP-MAS NMR method (see Figure 2, right column), which detected only the nuclei located within $2-3$ bond lengths from the nearest hydrogen atoms. Note that the presence of $\mathrm{T}^{3}$ and $\mathrm{T}^{2}$ functionalities confirmed the existence of the covalent linkage between the organic groups and the silica surface. The resonance lines representing $\mathrm{Q}^{4}$ (siloxane, $\left.(\equiv \mathrm{SiO})_{4} \mathrm{Si}\right), \mathrm{Q}^{3}$ (single silanol, $\left.(\equiv \mathrm{SiO})_{3} \mathrm{SiOH}\right)$ and $\mathrm{Q}^{2}$ (geminal silanol, $(\equiv \mathrm{SiO})_{2} \mathrm{Si}(\mathrm{OH})_{2}$ ) silicons were also observed in their usual spectral positions. ${ }^{32-36}$ The relative concentrations of all silicon sites were obtained by deconvolution of DPMAS spectra (see Table 2). Assuming that all $\mathrm{Q}^{3}$ and $\mathrm{Q}^{2}$ sites decorated the interior walls of mesoporous silicas, the surface coverage (SC) of the mesopores with organic moieties could be estimated as $\mathrm{SC}=\left(\mathrm{T}^{2}+\mathrm{T}^{3}\right) /\left(\mathrm{Q}^{2}+\mathrm{Q}^{3}+\mathrm{T}^{2}+\mathrm{T}^{3}\right)$. As shown in Table 2 , the SC values varied between $13 \%$ for UDP-MP and $33 \%$ for AL-MP. The measured loading efficiencies of the MP's synthesized with the organoalkoxysilanes containing hydrophobic functional groups, such as CPTES and ALTMS, were higher than those that contained the hydrophilic precursors, such as AAPTMS and AEPTMS. These results suggested that the organoalkoxysilanes with hydrophobic functional groups could better orient themselves around the water/micelle interface and intercalate these groups to the hydrophobic regions of the CTAB micelles during the co-condensation reactions.

Morphology control. The morphology and mesoporous structure of the organically functionalized MP materials were studied using FE-SEM and powder X-ray diffraction. The 
FE-SEM micrographs demonstrated a variety of particle shapes and sizes. For example, the AP-MP material showed a curved hexagonal shaped tubular morphology, as depicted in Figure 3a. Interestingly, upon replacing the APTMS with other structurally similar organoalkoxysilanes, such as AAPTMS and AEPTMS (Figure 3b, c), the shapes transformed into twisted columns and micrometer-sized spheres, respectively. In contrast to smooth particle surface of AEP-MP, UDP-MP (Figure 3d) exhibited micron-sized spherical particles with raspberry-like bumpy rough surfaces. The ICP-MP material (Figure 3e) consisted of smallest spherical particles with diameters ranging from 100 to $500 \mathrm{~nm}$. In the synthesis of CP-MP (Figure 3f) and AL-MP materials (Figure 3g), hexagonal rod-shaped particles of different lengths and diameters were observed. The average particle size of CP-MP ( $1 \mu \mathrm{m}$ in length and $500 \mathrm{~nm}$ in diameter) is larger than that of AL-MP (500 nm and $50 \mathrm{~nm}$, respectively). As a rule, the particle sizes of materials prepared with the hydrophobic organoalkoxysilane precursors, such as ICPTES, CPTES, and ALTMS, appear significantly smaller than pure MCM-41 (Figure 3h), whereas the materials synthesized using more hydrophilic organoalkoxysilanes, such as AAPTMS, AEPTMS, and UDPTMS, yielded larger particles. Note that the co-condensation reactions took place in a basic aqueous . solution $(\mathrm{pH}=12.3$ ), therefore the trialkoxysilyl groups of these organoalkoxysilanes were hydrolyzed and converted to the trihydroxysilyl group, which is always hydrophilic. The other end of the molecule can be either hydrophilic or hydrophobic depending on the water solubility of the organic functional group involved.

The surface areas, pore volumes and pore size distributions of the MP materials were analyzed by the nitrogen adsorption-desorption techniques. As shown in Figure 4, all silicas exhibited characteristic Type IV BET isotherms consistent with the presence of cylindrical 
meso-scale pores. However, as outlined in Table 3, the BJH average pore diameters were different depending on the types of the incorporated organic functional groups. Again, utilization of the hydrophobic precursors yielded smaller pores. The powder XRD spectra of these materials (Figure 5) featured an intense (100) reflection peak corresponding to lattice spacings in the range of 33.7 to $43.7 \AA$. Even though (210) peaks were not observed, the well resolved diffraction patterns characteristic of hexagonal MCM-41 silicas, ${ }^{37}$ including $(100),(110)$, and $(200)$ peaks with the spacing ratio of $1: \sqrt{3}: \sqrt{4}$, were observed in AP-MP, AAP-MP, CP-MP, ICP-MP and AL-MP. On the other hand, AEP-MP and UDP-MP (Figure $5 \mathrm{c}, \mathrm{d})$ appeared to be disordered as evidenced by a broad peak at $4.52^{\circ}$ and $4.10^{\circ}$, respectively, representing superimposed (110), and (200) patterns. The TEM micrographs of these samples shown in Figures $6 \mathrm{a}$ and $6 \mathrm{~d}$ are consistent with this observation. In contrast, the TEM micrographs of materials prepared with hydrophobic organoalkoxysilanes, such as CPTES, showed well-organized mesopores packed in hexagonal symmetry as evidenced in Figure 6b, c.

Mechanism responsible for the shape formation. As discussed earlier, similar organic precursors can yield very different particle morphologies, e.g., AAP-MP showed tubular-shaped particles (Figure 3b) while the AEP-MP exhibited exclusively spherical particles (Figure 3c). Clearly, several different interactions, such as electrostatic attraction/repulsion, hydrogen bonding, and hydrophobic interaction, between the organoalkoxysilanes and surfactant molecules at the micelle/water interface could contribute cooperatively to the observed drastic changes in particle morphology. We undertook an approach of deconvoluting some of these factors by investigating how the concentration of a selected organoalkoxysilane (AEPTMS) could influence the resulting particle shape and size. 
The molar ratio of AEPTMS/TEOS was systematically varied from 1.28 to $12.8 \mathrm{~mol} \%$, while the concentrations of all the other chemicals introduced to the co-condensation reaction were fixed at the previously described levels. The incorporation of AEP was quantitatively determined by DPMAS and CPMAS ${ }^{29} \mathrm{Si}$ NMR (Figure 7a,b). As discussed earlier, the DPMAS spectra provided quantitative measure of the relative concentrations of $Q^{n}$ and $T^{n}$ functionalities. However, due to low concentration of $\mathrm{T}^{\mathrm{n}}$ species the $\mathrm{SC}$ values were not directly measured in this series of samples. Instead, we used the CPMAS spectra to evaluate the relative change of $T^{n}$ intensities versus the concentration of AEPTMS. The results, plotted in Figure $7 \mathrm{c}$ in reference to the sample with 1.28 mol\% of AEPTMS, showed that the concentration of AEP increased almost linearly as the initial AEPTMS/TEOS molar ratio changed from 1.28 to $12.8 \mathrm{~mol} \%$. The particle morphology and mesoporous structure of the resulting materials were analyzed by FE-SEM and TEM. The FE-SEM micrographs of Figure 8 showed a concurrent transformation of the particle morphology from small kidney bean shaped rods to spheres, with elongated rods and ellipsoidal particles being observed at intermediate concentrations of AEPTMS. Furthermore, a noticeable increase of the average particle sizes of these materials could be observed at higher concentrations of AEPTMS. The TEM micrographs (Figure 9a,b) of the AEP-MP materials with low degrees of functionalization ( 1.28 and $6.43 \mathrm{~mol} \%$, respectively) revealed that the mesopores are uniformly aligned along the long axes of MP's despite of their different particle sizes. This is in contrast to the randomly oriented mesopores observed in the spherical AEP-MP's with the higher degree of functionalization (Figure 6a).

Based on these results, the following mechanism is proposed to account for the formation of different particle shapes and sizes. To facilitate the ensuing discussion, we 
present Scheme 2 where $R_{1}$ and $R_{2}$ represent the hydrophilic and hydrophobic functional groups, respectively. In the case of the more hydrophobic organoalkoxysilane precursors, such as CPTES and ALTMS, the aforementioned strong interaction between their non-polar groups $\left(\mathrm{R}_{2}\right)$ and the hydrophobic hydrocarbon tails of the CTAB molecules could likely stabilize the formation of long individual cylindrical micelles by intercalating their hydrophobic groups to the micelles, as shown in Scheme $2 \mathrm{~b}$. The uniform organization of the trialkoxysilyl group at the Gouy-Chapman region of the surface of micelles and their increased length would assist in the rapid cross-linking/condensation between the "micelleoriented" trialkoxysilyl groups in the basic $\mathrm{NaOH}$ aqueous solution, as depicted in Scheme 2c. The resulting "side-on" packing of the silicate-coated cylindrical micelles would give rise to small rod-like nanoparticles. Similar phenomenon has been observed by Cai $e t \mathrm{al}^{38}$ while utilizing $\mathrm{NaOH}$ and $\mathrm{NH}_{4} \mathrm{OH}$ as catalysts to manipulate the particle morphology of the MCM-41 silicas without organic functional groups. The above mechanism would not be operable for more hydrophilic organoalkoxysilane precursors, such as AAPTMS, AEPTMS, and UDPTMS, because their $\mathrm{R}_{1}$ functional groups are not favored by the interaction with the surfactant molecules (Scheme 2a). This would inhibit the formation of long micelles and reduce their tendency toward side-on condensation. The difference in rate of condensation between silicate-coated micelles versus that of the free silicate (TEOS) molecules would be small. Due to the lack of thermodynamic incentives for the silicate-coated micelles to pack in an ordered fashion, such co-condensation reactions should yield particles with randomly oriented pore structures. This hypothesis was supported by our study of synthesizing AEPMP's with different concentrations of AEPTMS. The fact that the spherical-shaped AEP-MP obtained with $12.8 \mathrm{~mol} \%$ AEPTMS showed disordered mesoporous structure indicated that 
the amount of hydrophilic precursors introduced was perhaps high enough to disturb the sideon growth mechanism. A similar phenomenon was recently reported by Mann and coworkers, ${ }^{28}$ who observed the growth of the mesoporous silica particle in the direction that is perpendicular to the pore-alignment upon the introduction of amine-containing organoalkoxysilanes. At lower concentrations of AEPTMS, rod-shaped materials were generated with small average particle sizes, which indicated that the disruption of the packing mechanism was indeed minimized.

\section{Conclusions}

In this study, we have demonstrated that a series of organically functionalized MCM41 type mesoporous silicas with various particle morphologies could be synthesized by a cocondensation method. The co-condensation reactions used various amounts of organoalkoxysilanes with different functional groups as structure-directing reactants. The mechanism responsible for the observed changes in particle morphology and pore alignment has been proposed. Further studies of this mechanism, which will also include the size effect of the organoalkoxysilane precursors, will be performed. Better understanding of such synthetic strategies and the underlying mechanisms of functionalization and morphology control will lead to construction of various sophisticated organic/inorganic hybrid nanomaterials for heterogeneous sensors and/or catalysts with high selectivity and efficiency.

\section{Acknowledgement}

V. S.-Y. Lin thanks the Green Chemistry Catalysis Laboratory (GCCL) of the USDOE Ames Laboratory for financial support of this work. This research was also supported 
at Ames Laboratory by the U.S. Department of Energy, Office of Basic Energy Sciences, Division of Chemical Sciences, under Contract W-7405-Eng-82. 
Figure 1. ${ }^{1} \mathrm{H} \rightarrow{ }^{13} \mathrm{C}$ CPMAS spectra of AP-MP (a), AAP-MP (b), AEP-MP (c), UDP-MP (d), ICP-MP (e), CP-MP (f), AL-MP (g), and s-MCM-41 (h) using CP contact time of 0.4 (spectra a-c and $\mathrm{h}$ ) or $1.5 \mathrm{~ms}$ (spectra d-g). Asterisks mark positions of residual surfactant carbons present in spectra $f$, and $g$. Note that spectrum (e) represents the propyl-carbamic acid group formed during the synthesis of ICP-MP by base-catalyzed hydrolysis of isocyanopropyl group.

(a) AP-MP<smiles>CC(CCN)CC(C)[Si](C)(C)C</smiles>

(b) AAP-MP<smiles>CC(CCNCCN)[Si](C)(C)C</smiles>

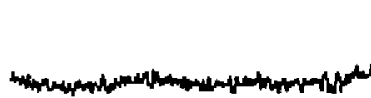

(c) AEP-MP

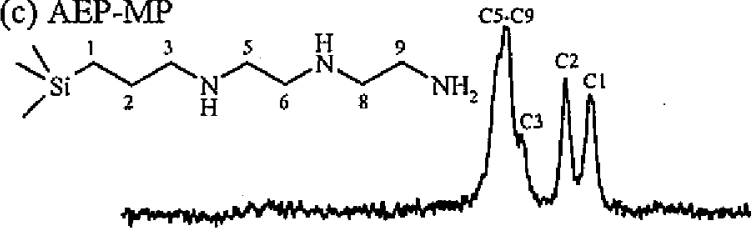

(d) UDP-MP

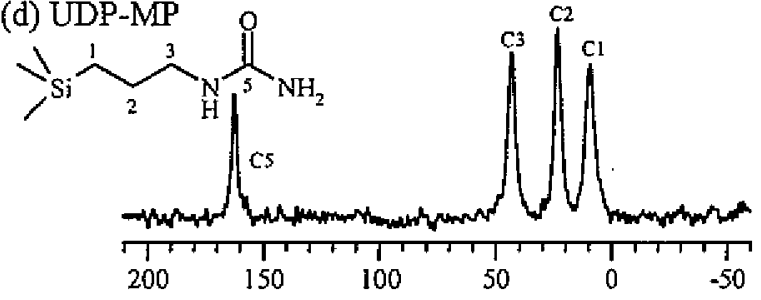

(e) ICP-MP
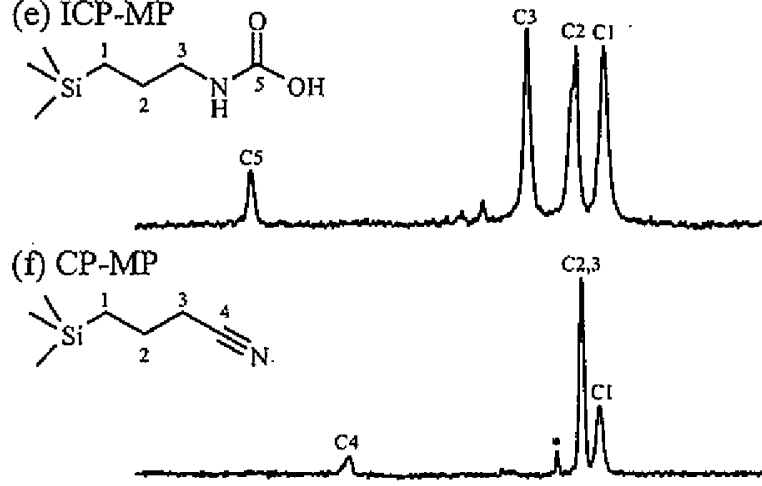

(g) AL-MP<smiles>C=CC(C)[Si](C)(C)C</smiles>

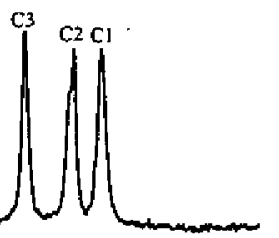

$\mathrm{C}_{2,3}$ mthesized MCM-41

(h) as-synthesized $\mathrm{MCM}$
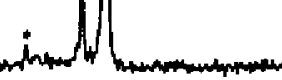

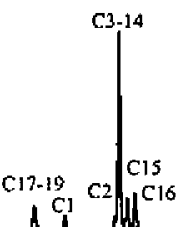

$\mathrm{Cl}^{\mathrm{C}} \mathrm{Ll}^{\mathrm{C}}$

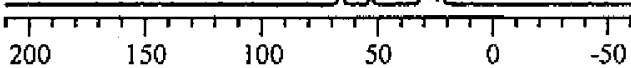


Figure $2 .{ }^{29} \mathrm{Si}$ DPMAS (left) and ${ }^{1} \mathrm{H} \rightarrow{ }^{29} \mathrm{Si}$ CPMAS (right) spectra of AP-MP (a), AAP-MP (b), AEP-MP (c), UDP-MP (d), ICP-MP (e), CP-MP (f), AL-MP (g), s-MCM-41 (h), and MCM-41 after the extraction of surfactant (i).

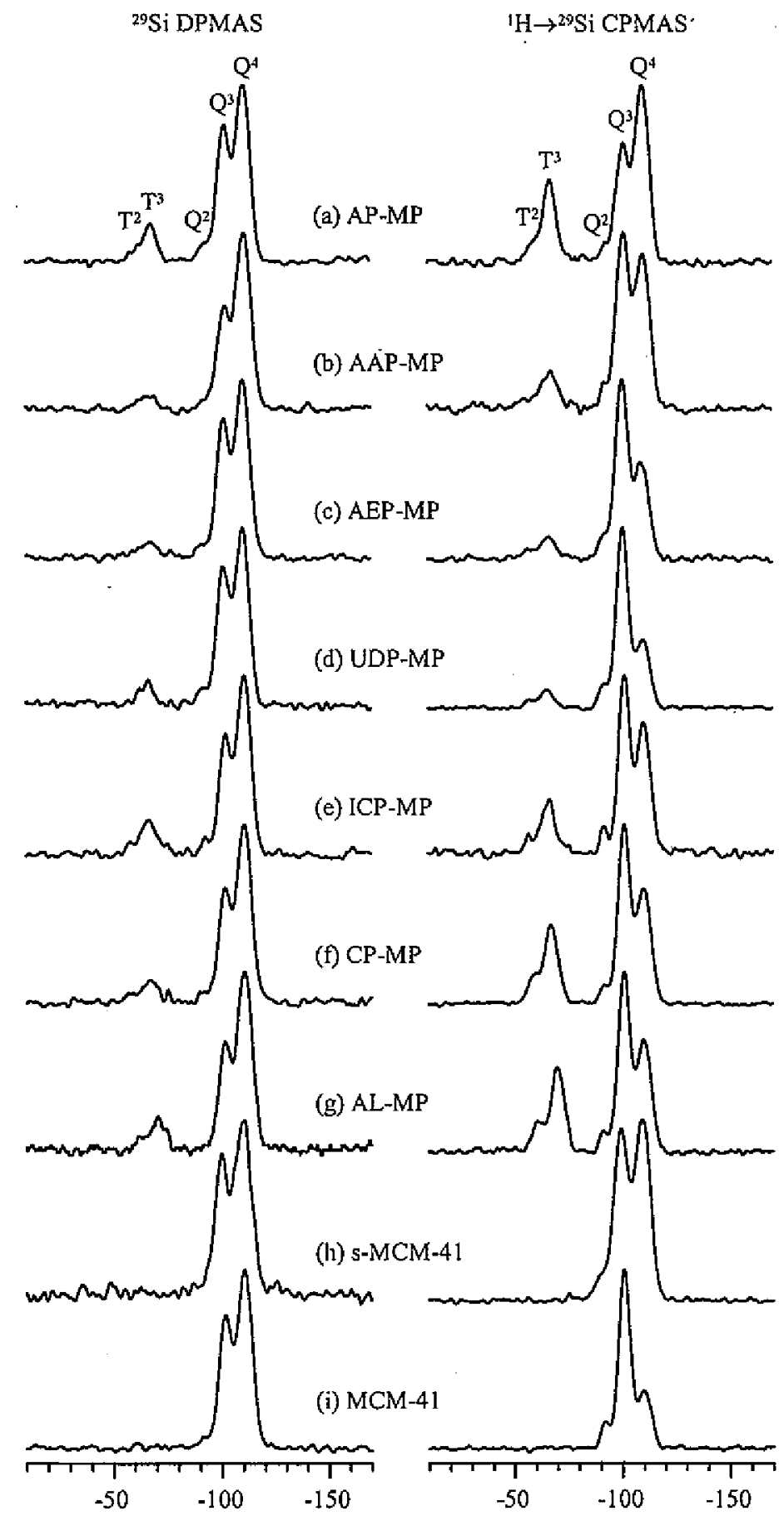


Figure 3. FE-SEM Images of AP-MP (a), AAP-MP (b), AEP-MP (c), UDP-MP (d), ICP-MP (e), CP-MP (f), AL-MP (g), and pure MCM-41 silica (h) synthesized via our condensation reaction condition without adding any organic functional group. All images are presented using the same scale, with the scale bar $=3 \mu \mathrm{m}$.
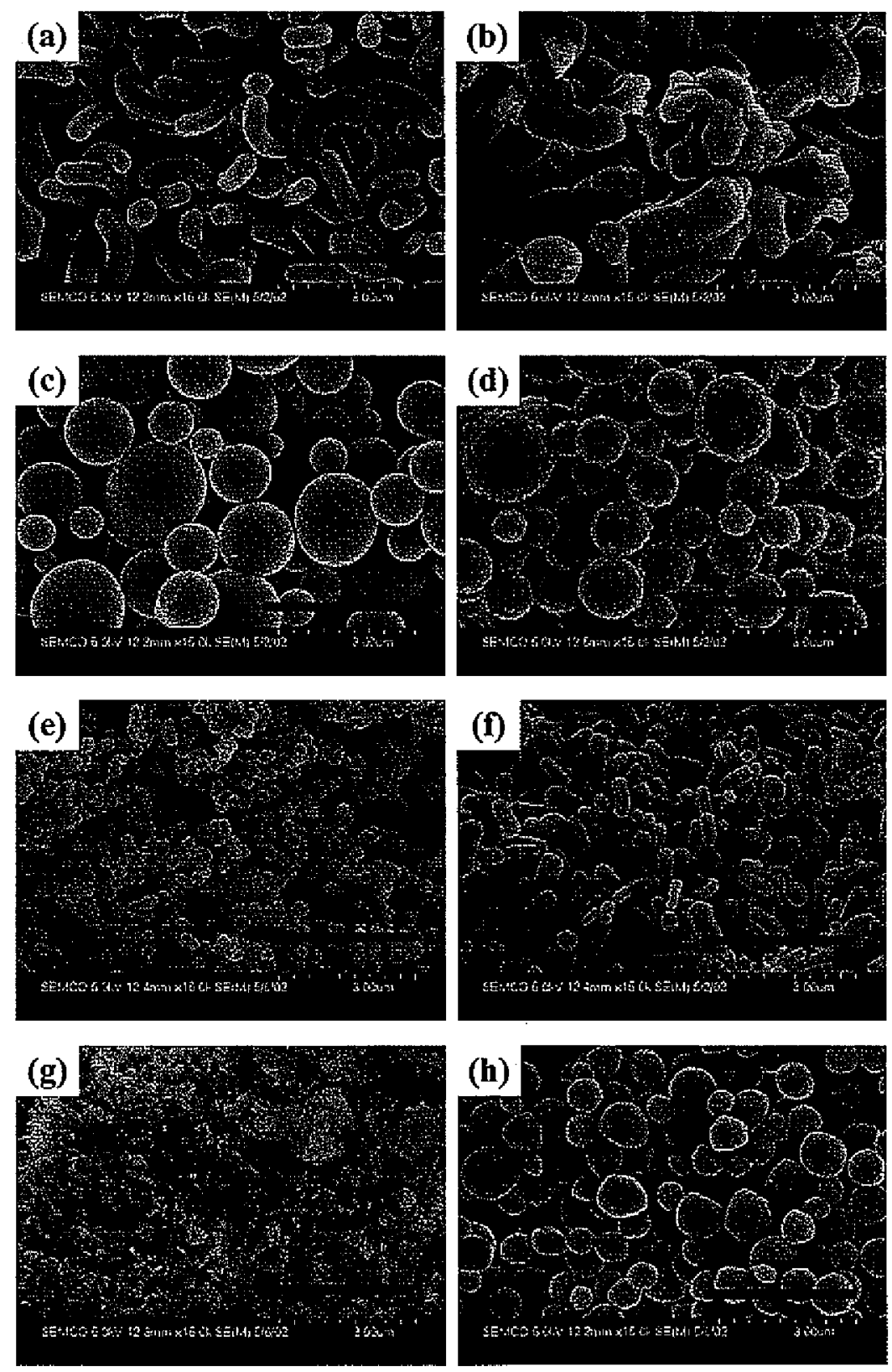
Figure 4. BET isotherms and BJH pore size distributions (insets) of AP-MP (a), AAP-MP (b), AEP-MP (c), UDP-MP (d), ICP-MP (e), CP-MP (f), AL-MP (g) and pure MCM-41 silica (h) materials.
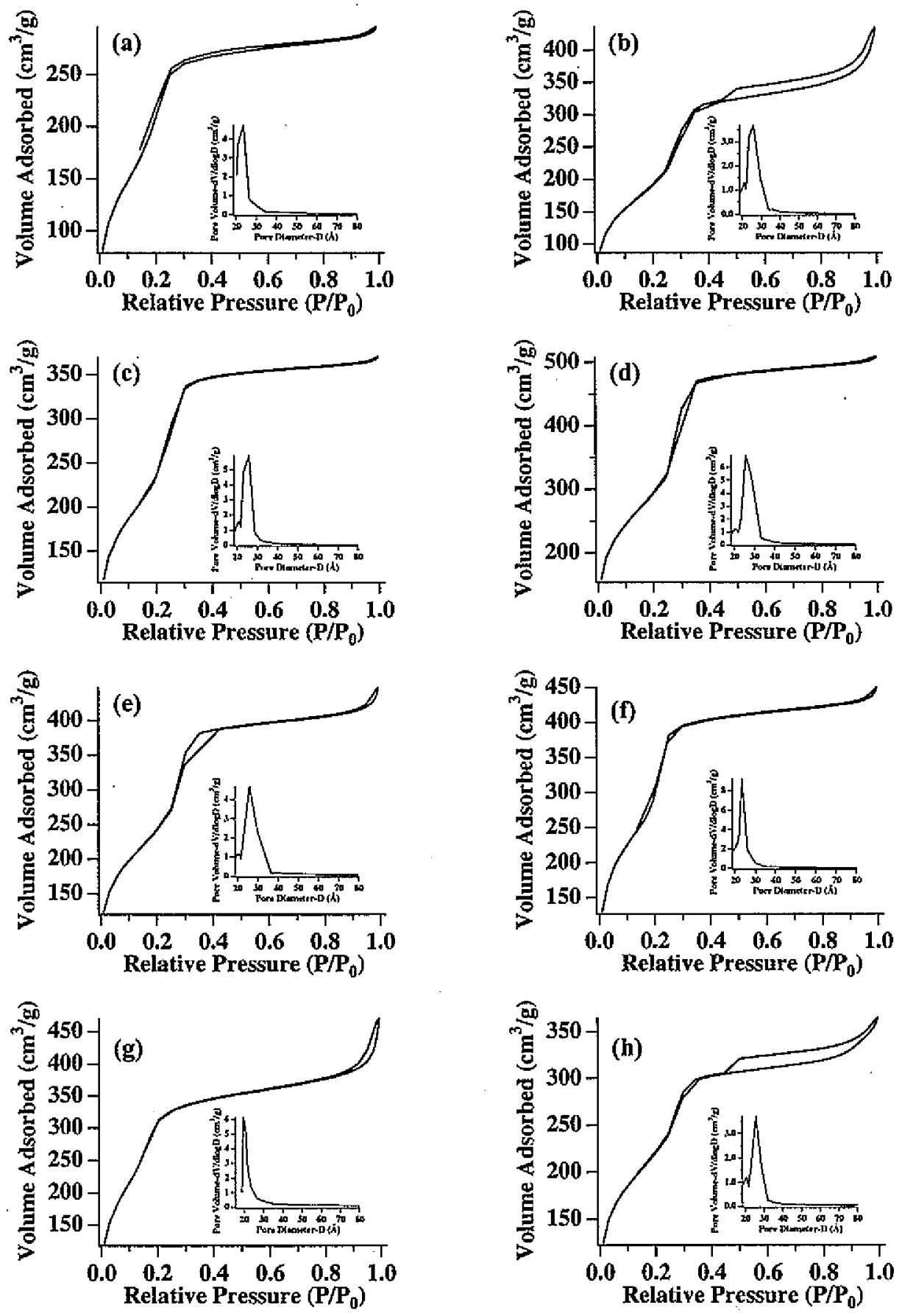
Figure 5. XRD spectra of the surfactant-removed AP-MP (a), AAP-MP (b), AEP-MP (c), UDP-MP (d), AL-MP (e), CP-MP (f) and ICP-MP (g).

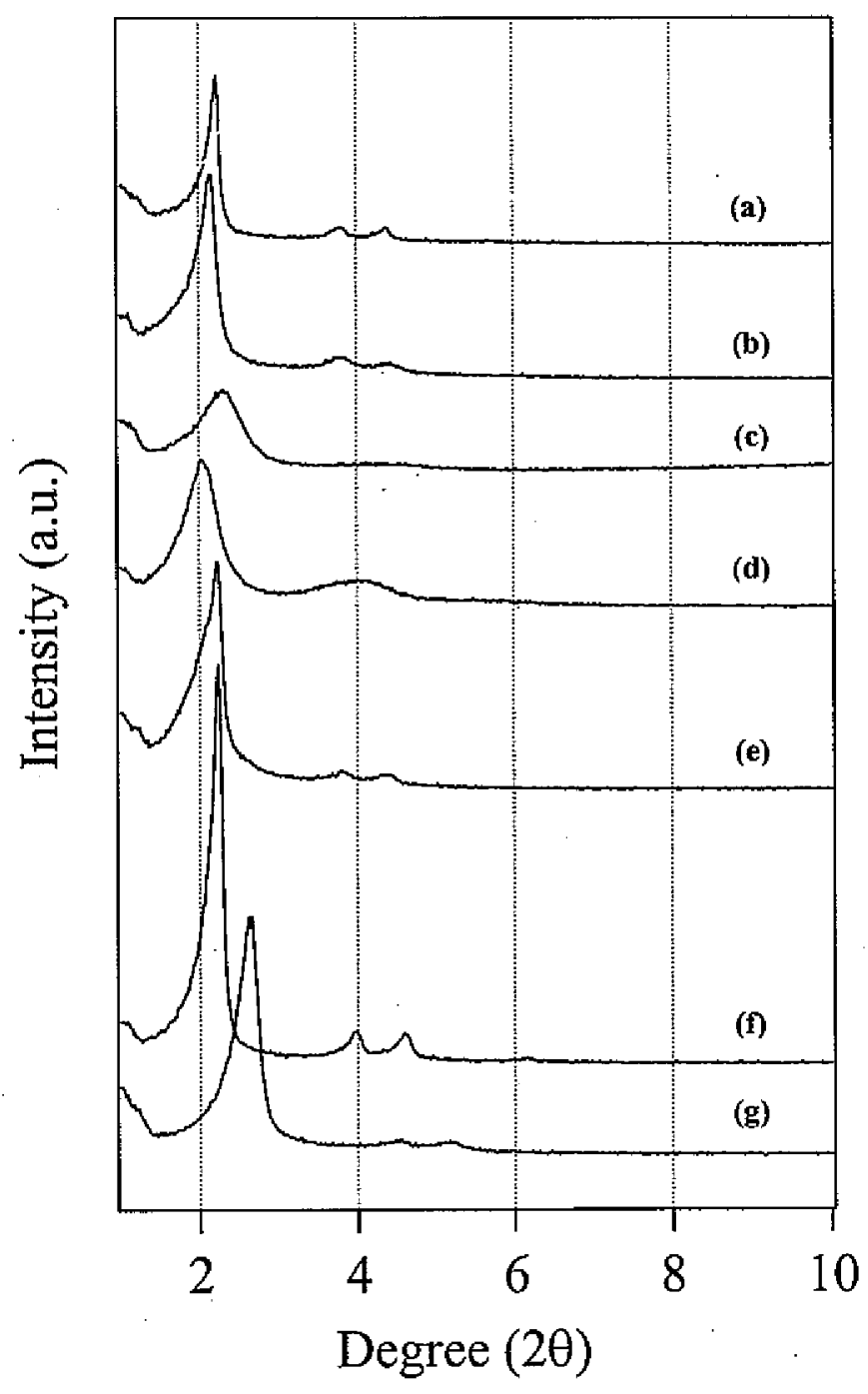


Figure 6. TEM micrographs of AEP-MP (a), CP-MP (b, c), and UDP-MP (d) materials. Images $(a)$ and (b) represent ultramicrotomed samples (scale bar $=100 \mathrm{~nm}$ ).

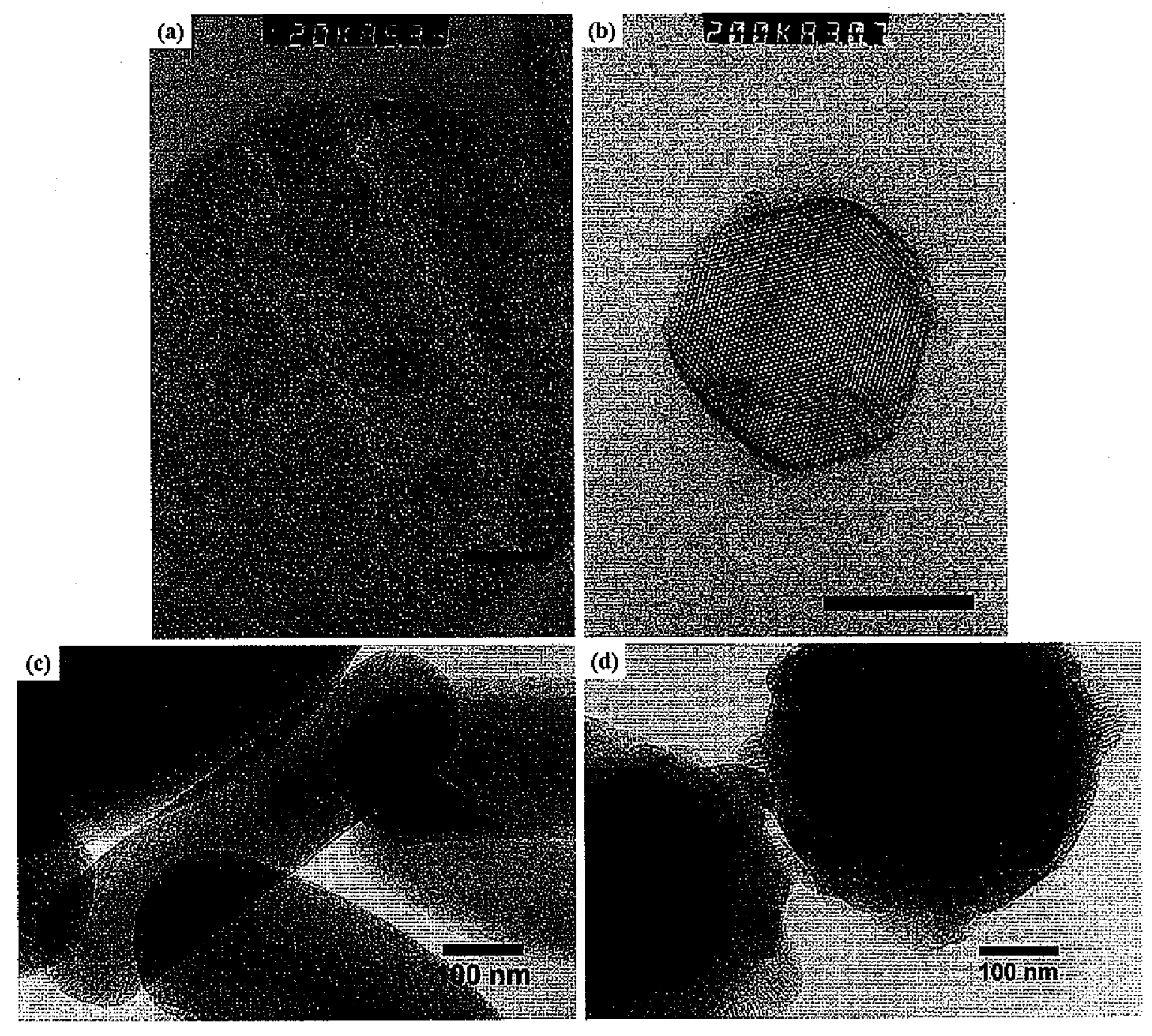


Figure 7. ${ }^{29} \mathrm{Si}$ DPMAS (a) and ${ }^{1} \mathrm{H} \rightarrow{ }^{29} \mathrm{Si}$ CPMAS (b) spectra of functionalized mesoporous materials with various amounts of AEPTMS. A contact time of $1 \mathrm{~ms}$ was used during cross polarization period. (c) The relative increase of functionalization versus the concentration of AEPTMS estimated from CPMAS.

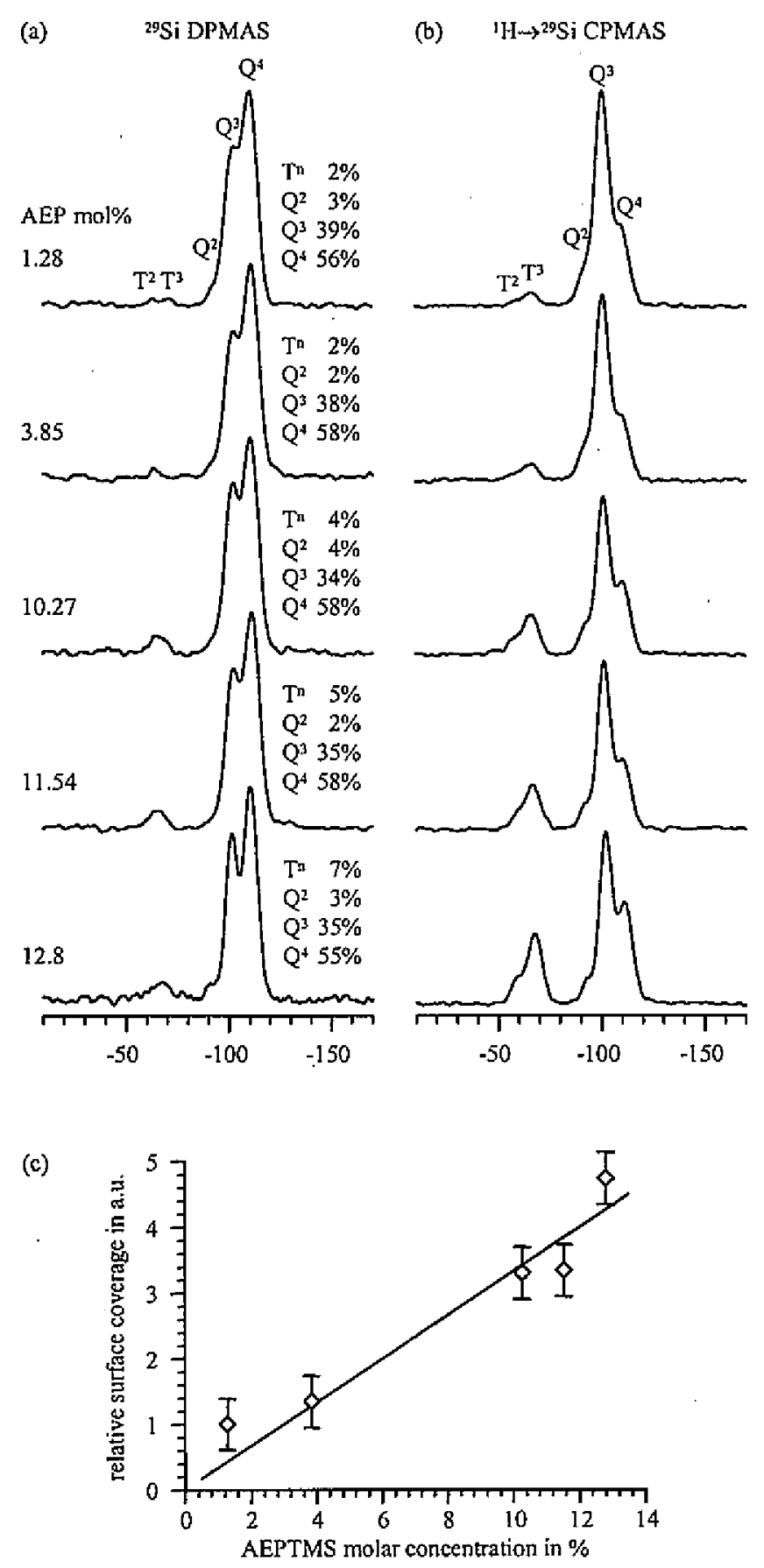


Figure 8. FE-SEM Images of AEP-MP's with different initial loadings of AEPTMS: 1.28 mol\% (a), $3.85 \mathrm{~mol} \%$ (b), $6.43 \mathrm{~mol} \%$ (c), $10.27 \mathrm{~mol} \%$ (d), $11.54 \mathrm{~mol} \%$ (e), and $12.80 \mathrm{~mol} \%$ (f). All images are presented using the same scale, with the scale bar $=3 \mu \mathrm{m}$.
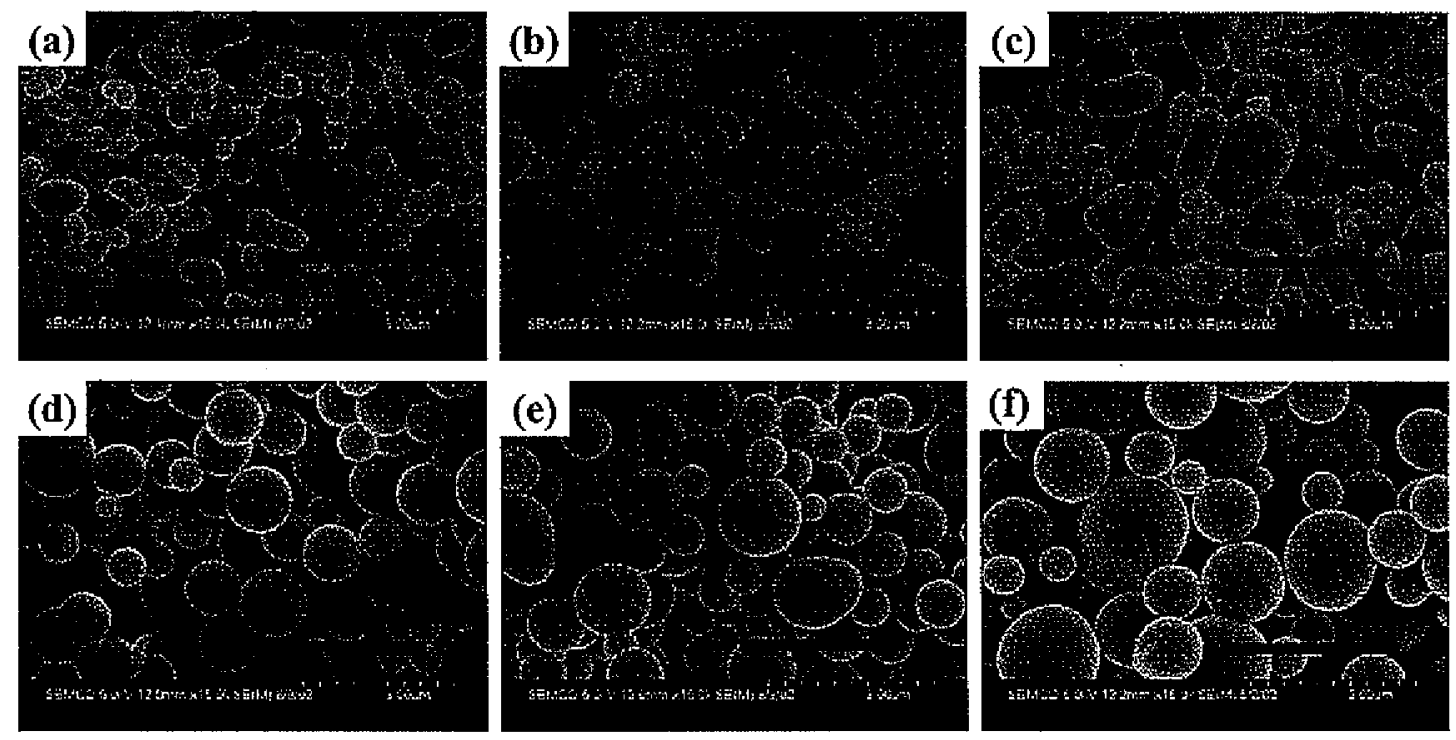
Figure 9. TEM images of ultramicrotomed AEP-MP's with $1.28 \mathrm{~mol} \%$ (a) and $6.43 \mathrm{~mol} \%$ (b) AEPTMS (scale bar $=100 \mathrm{~nm}$ ).
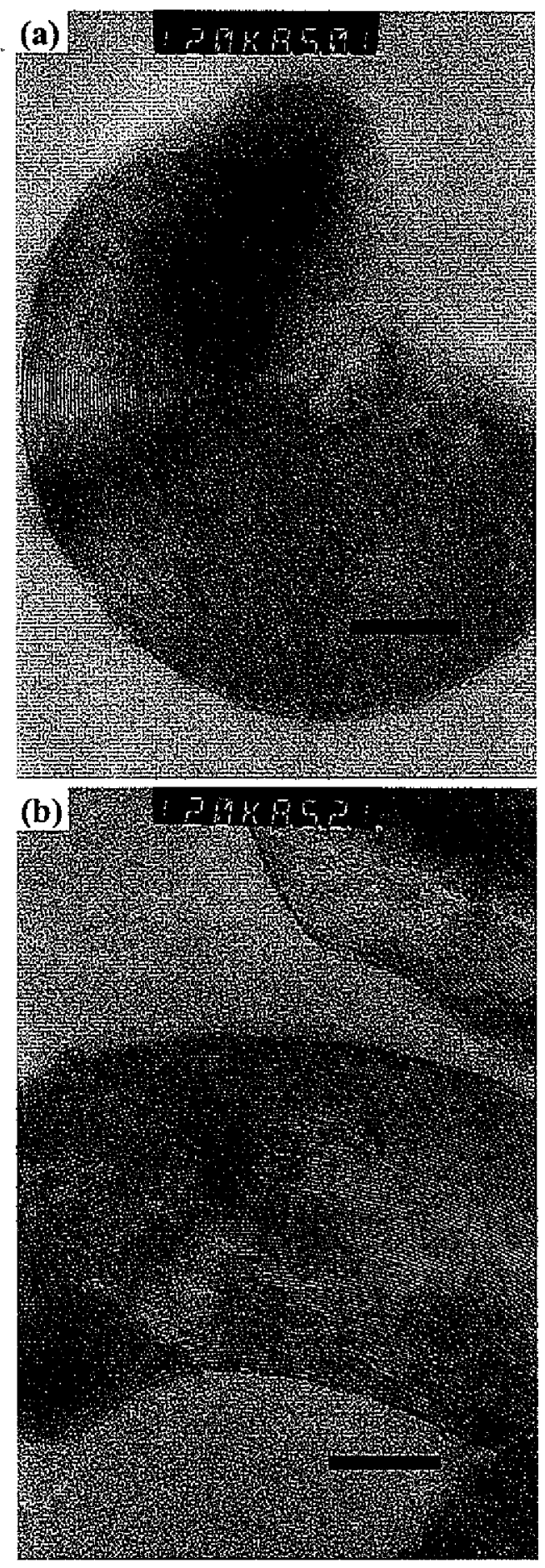


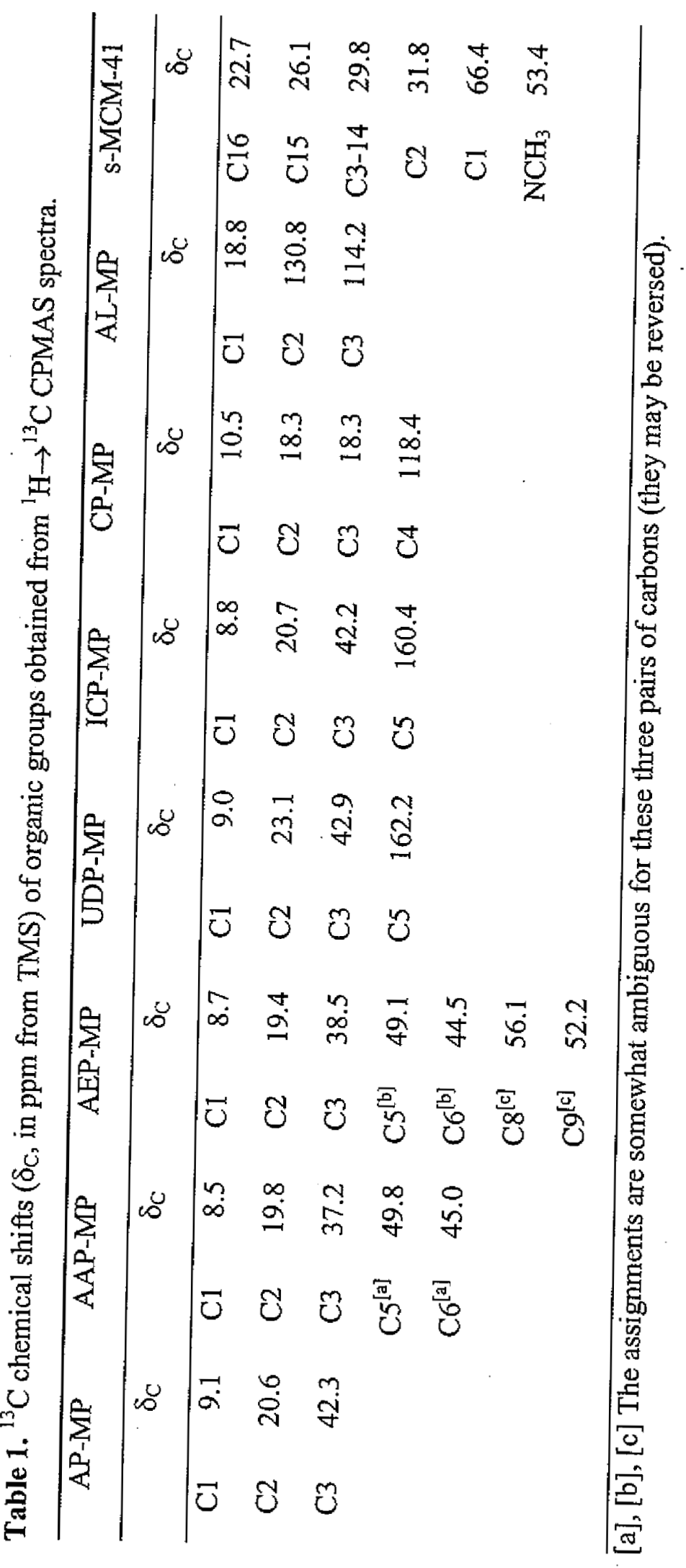




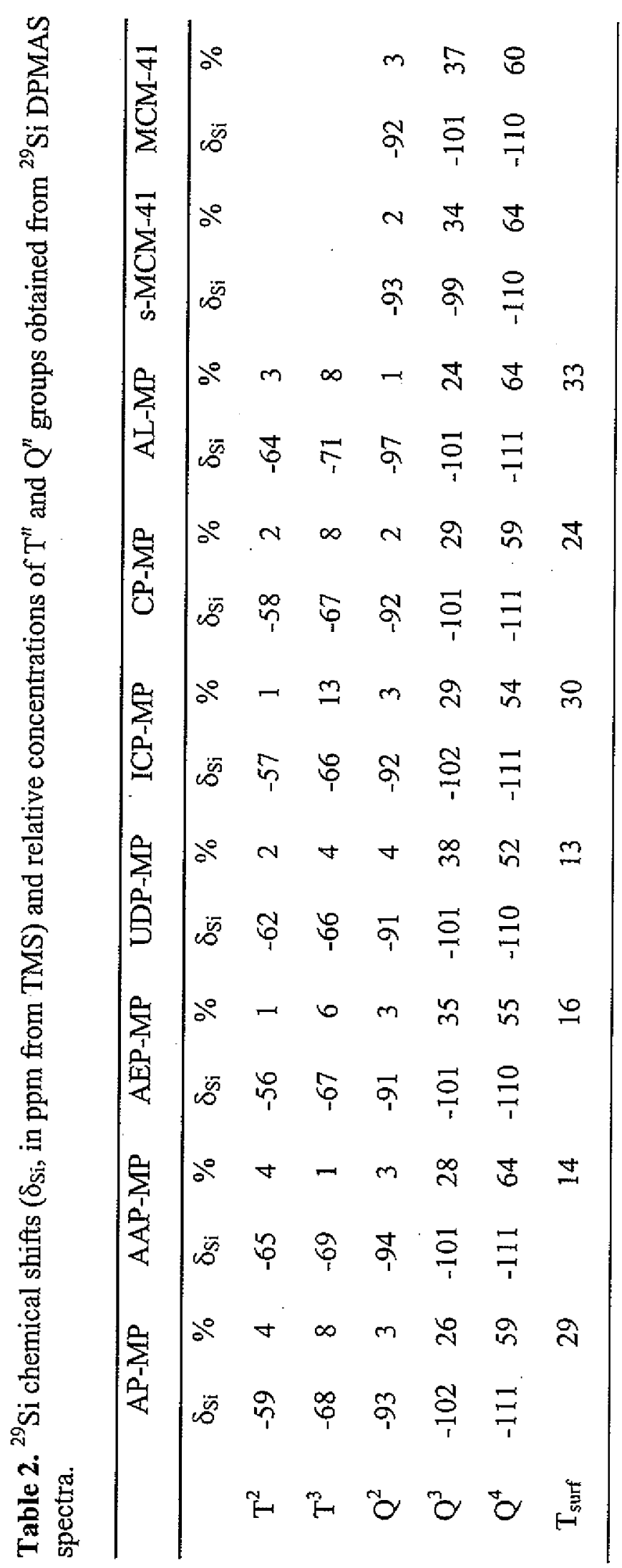


39

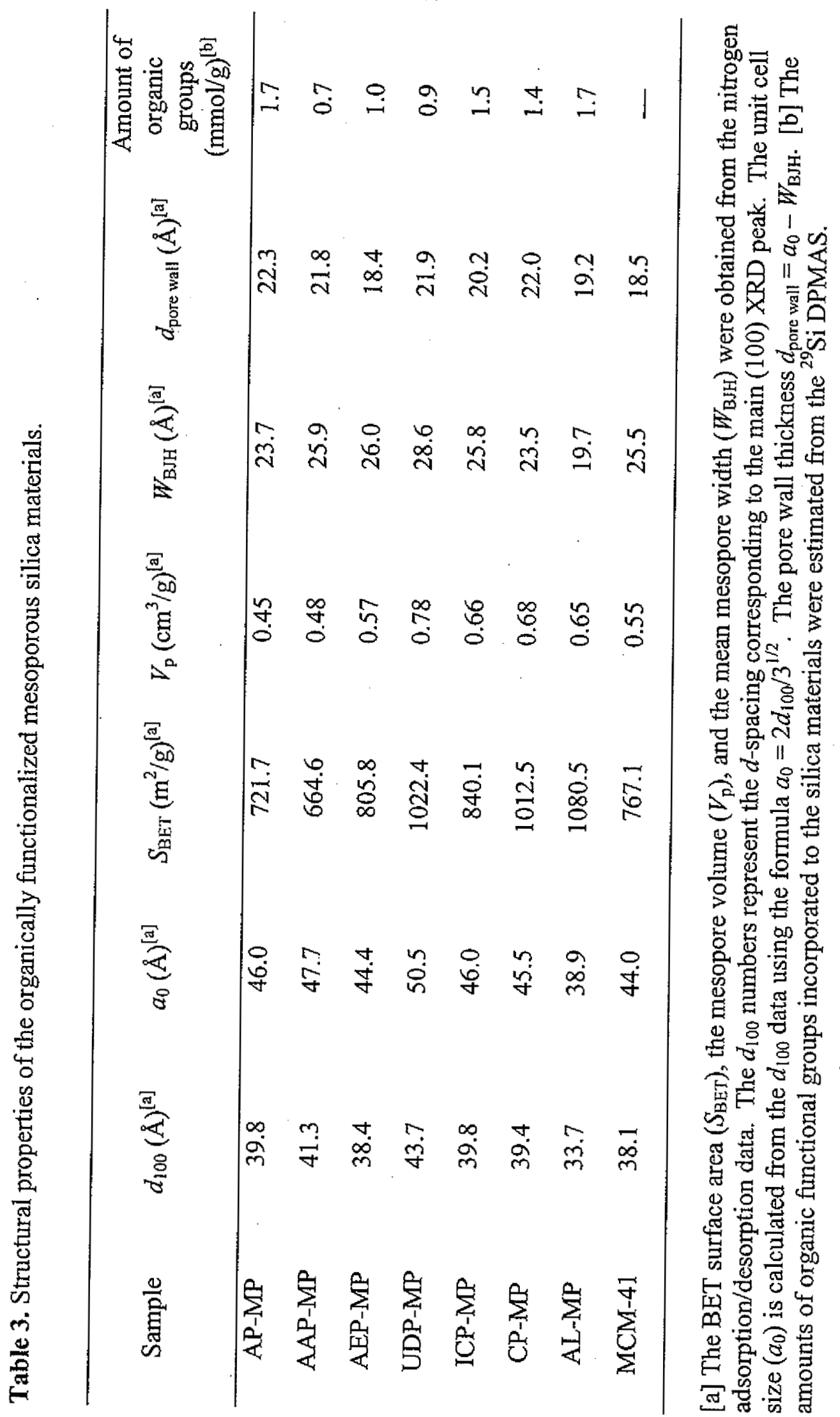


Scheme 1

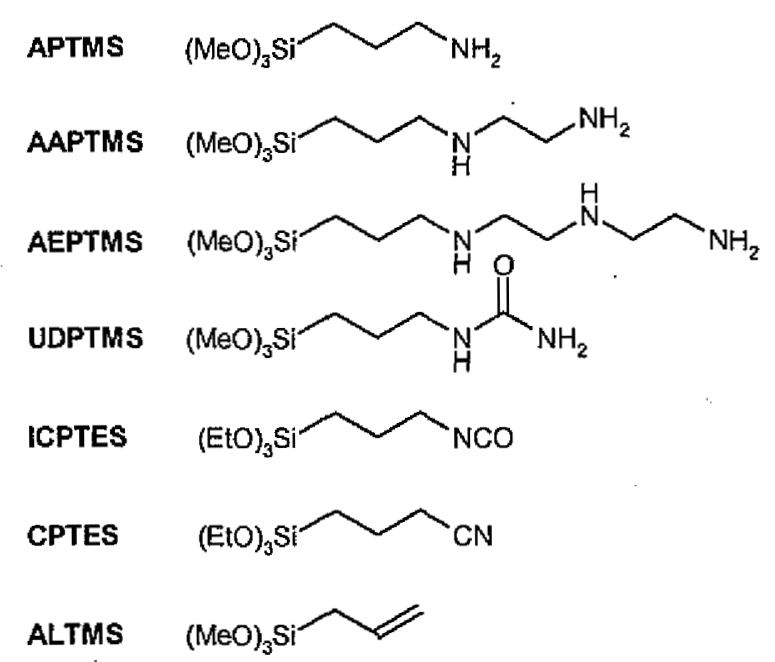




\section{Scheme 2}

Condensation

(a)
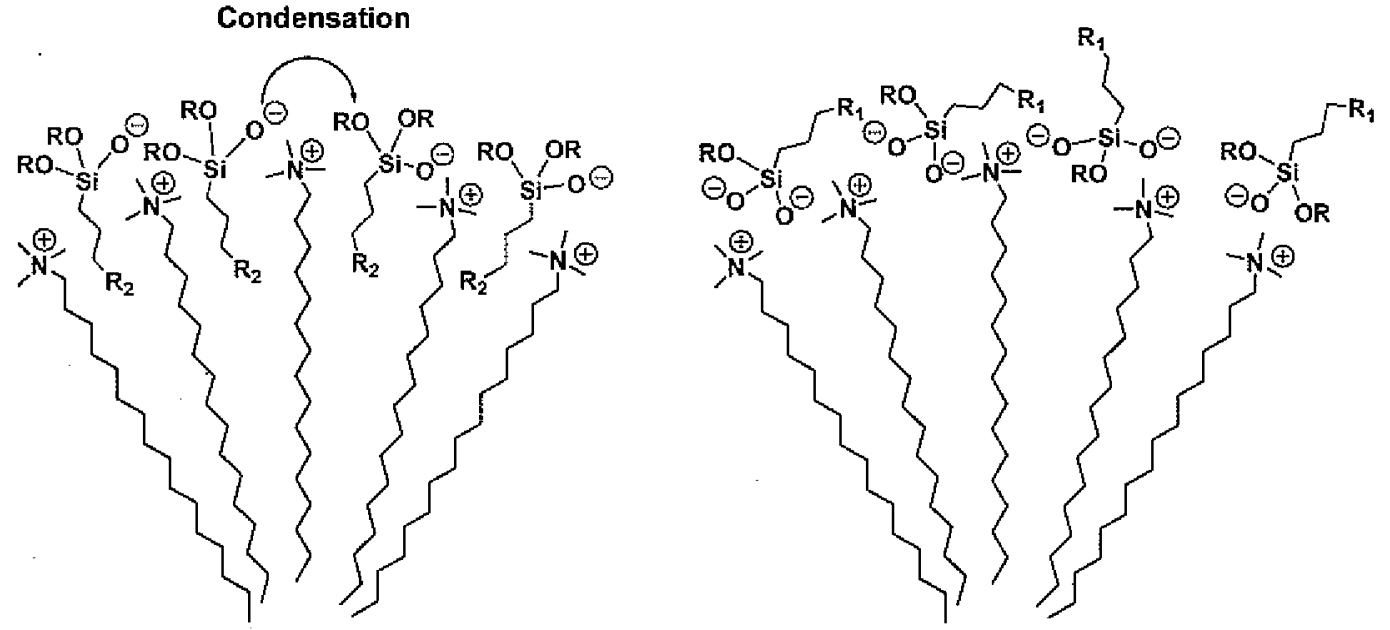

(b)
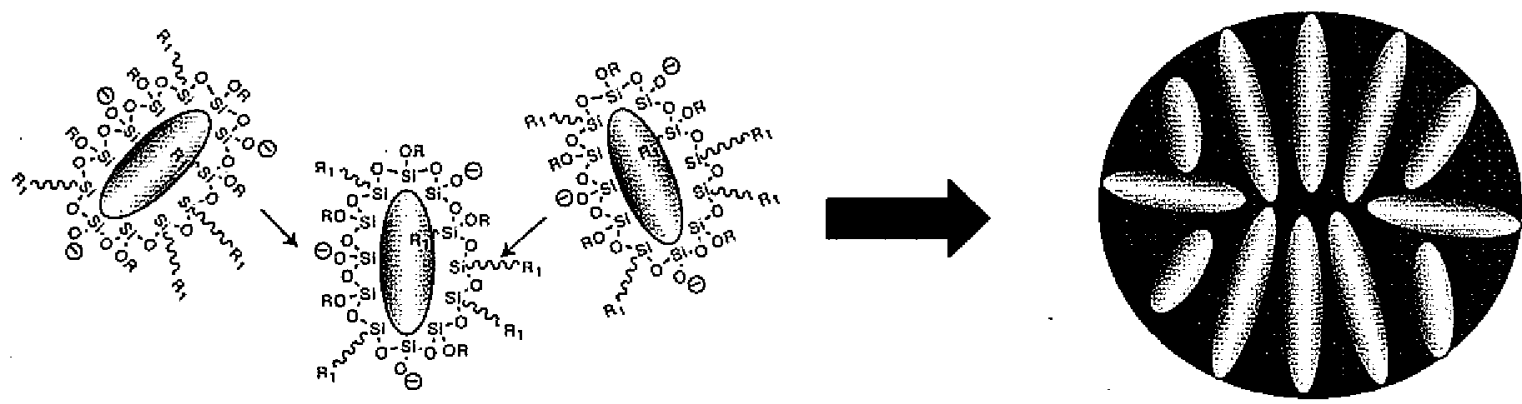

(c)
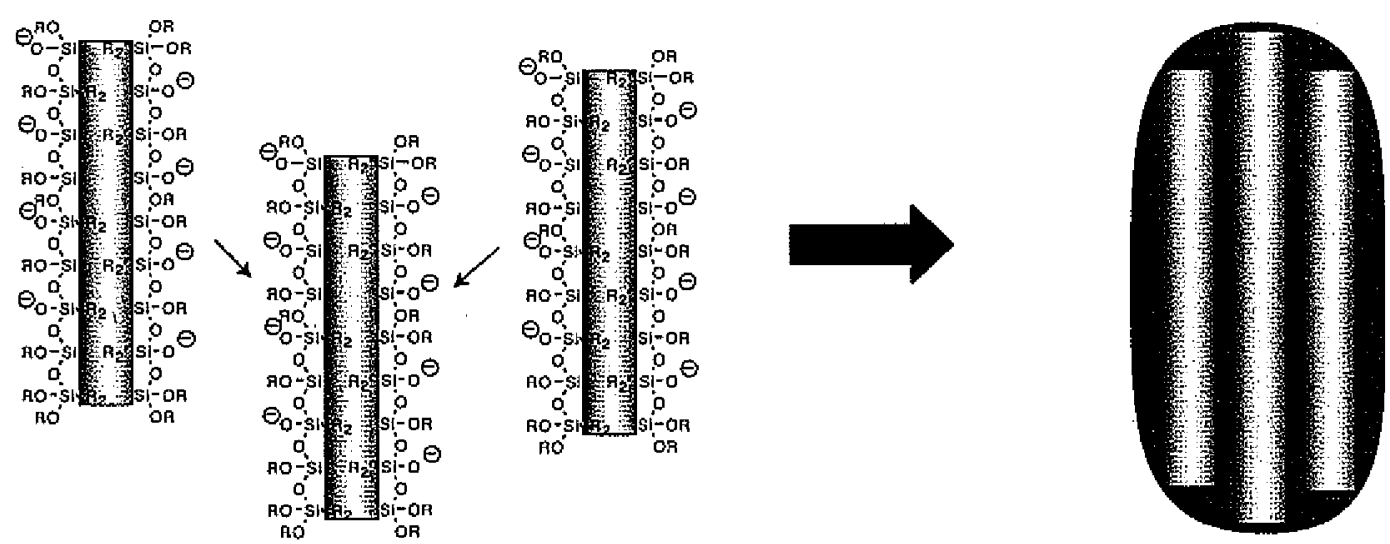


\section{References}

1. Beck, J. S.; Vartuli, J. C.; Roth, W. J.; Leonowicz, M. E.; Kresge, C. T.; Schmitt, K. D.; Chu, C. T. W.; Olson, D. H.; Sheppard, E. W.; et al. J. Am. Chem. Soc. 1992, 114, 10834-10843.

2. Kresge, C. T.; Leonowicz, M. E.; Roth, W. J.; Vartuli, J. C.; Beck, J. S. Nature (London) 1992, 359, 710-712.

3. Zhao, D.; Feng, J.; Huo, Q.; Melosh, N.; Frederickson, G. H.; Chmelka, B. F.;

Stucky, G. D. Science (Washington, D. C.) 1998, 279, 548-552.

4. Bagshaw, S. A.; Prouzet, E.; Pinnavaia, T. J. Science (Washington, D. C.) 1995, 269, $1242-1244$.

5. Ryoo, R.; Kim, J. M.; Ko, C. H.; Shin, C. H. J. Phys. Chem. 1996, 100, 17718-17721.

6. Inagaki, S.; Koiwai, A.; Suzuki, N.; Fukushima, Y.; Kuroda, K. Bull. Chem. Soc. Jpn. $1996,69,1449-1457$.

7. (a) Dai, S.; Burleigh, M. C.; Shin, Y.; Morrow, C. C.; Barnes, C. E.; Xue, Z. Angew. Chem., Int. Ed. Engl. 1999, 38, 1235-1239. (b) Lin, Y.; Fryxell, G. E.; Wu, H.;

Engelhard, M. Environ. Sci. Technol.2001, 35, 3962-3966. (c) Yoshitake, H.; Yokoi, T.; Tatsumi, T. Chem. Mater. 2003, 15, 1713-1721. (d) Yoshitake, H.; Yokoi, T.; Tatsumi, T. Bull. Chem. Soc. Jpn. 2003, 76, 847-852. (e) Hossain, K. Z.; Mercier, L. Adv. Mater. (Weinheim, Ger.) 2002, 14, 1053-1056.

8. (a) Lin, V. S. Y.; Lai, C.-Y.; Huang, J.; Song, S.-A.; Xu, S. J. Am. Chem. Soc. 2001, 123, 11510-11511. (b) Burleigh, M. C.; Dai, S.; Hagaman, E. W.; Lin, J. S. Chem. Mater. 2001, 13, 2537-2546. 
9. (a) Soler-Illia Galo, J. d. A. A.; Sanchez, C.; Lebeau, B.; Patarin, J. Chem. Rev. 2002, 102, 4093-4138. (b) Stein, A. Adv. Mater. (Weinheim, Ger.) 2003, 15, 763-775. (c) Davis, M. E. Nature (London) 2002, 417, 813-821. (d) Corma, A. Chem. Rev. 1997, 97, 2373-2419. (e) Price, P. M.; Clark, J. H.; Macquarrie, D. J. Dalton 2000, 101110. (f) Ying, J. Y.; Mehnert, C. P.; Wong, M. S. Angew. Chem., Int. Ed. Engl. 1999, 38, 56-77. (g) Sayari, A. Chem. Mater. 1996, 8, 1840-1852. (h) Moller, K.; Bein, T. Chem. Mater. 1998, 10, 2950-2963.

10. Lai, C.-Y.; Trewyn, B. G.; Jeftinija, D. M.; Jeftinija, K.; Xu, S.; Jeftinija, S.; Lin, V. S. Y.J. Am. Chem. Soc. 2003, 125, 4451-4459.

11. Liu, J.; Shin, Y.; Nie, Z.; Chang, J. H.; Wang, L.-Q.; Fryxell, G. E.; Samuels, W. D.; Exarhos, G. J. J. Phys. Chem. A 2000, 104, 8328-8339.

12. Stein, A.; Melde, B. J.; Schroden, R. C. Adv. Mater. (Weinheim, Ger.) 2000, 12, 1403-1419.

13. Lim, M. H.; Stein, A. Chem. Mater. 1999, 11, 3285-3295.

14 Fowler, C. E.; Khushalani, D.; Lebeau, B.; Mann, S. Adv. Mater. (Weinheim, Ger.) 2001, 13, 649-652.

15. MacLachlan, M. J.; Asefa, T.; Ozin, G. A. Chem.-Eur. J. 2000, 6, 2507-2511.

16. Fowler, C. E.; Burkett, S. L.; Mann, S. Chem. Commun. 1997, 1769-1770.

17. Fowler, C. E.; Mann, S.; Lebeau, B. Chem. Commun. 1998, 1825-1826.

18. Hall, S. R.; Fowler, C. E.; Mann, S.; Lebeau, B. Chem. Commun. 1999, 201-202.

19. Zub, Y. L.; Seredyuk, I. V.; Chuiko, A. A.; Jaroniec, M.; Jones, M. O.; Parish, R. V.; Mann, S. Mendeleev Commun. 2001, 208-210.

20. Lim, M. H.; Blanford, C. F.; Stein, A. Chem. Mater. 1998, 10, 467-470. 
21. Lim, M. H.; Blanford, C. F.; Stein, A. J. Am. Chem. Soc. 1997, 119, 4090-4091.

22. Babonneau, F.; Leite, L.; Fontlupt, S. J. Mater. Chem. 1999, 9, 175-178.

23. Moller, K.; Bein, T.; Fischer, R. X. Chem. Mater. 1999, 11, 665-673.

24. Sayari, A.; Hamoudi, S. Chem. Mater. 2001, 13, 3151-3168.

25. Inagaki, S.; Guan, S.; Ohsuna, T.; Terasaki, O. Nature (London) 2002, 416, 304-307.

26. Burleigh, M. C.; Markowitz, M. A.; Spector, M. S.; Gaber, B. P. J. Phys. Chem. B 2001, 105, 9935-9942.

27. Burleigh, M. C.; Markowitz, M. A.; Spector, M. S.; Gaber, B. P. Chem. Mater. 2001, $13,4760-4766$.

28. Sadasivan, S.; Khushalani, D.; Mann, S. J. Mater. Chem. 2003, 13, 1023-1029.

29. Stoeber, W.; Fink, A.; Bohn, E. J. Colloid Interface Sci. 1968, 26, 62-69.

30. Pines, A.; Gibby, M. G.; Waugh, J. S. J. Chem. Phys. 1973, 59, 569-590.

31. Peersen, O. B.; Wu, X.; Kustanovich, I.; Smith, S. O. J. Magn. Reson. A 1993, 104, 334-339.

32. Maciel, G. E.;'Sindorf, D. W. J. Am. Chem. Soc. 1980, 102, 7606-7607.

33. Sindorf, D. W.; Maciel, G. E. J. Am. Chem. Soc. 1983, 105, 3767-3776.

34. Maciel, G. E. In Encyclopedia of Nuclear Magnetic Resonance; Grant, D. M., Harris, R. K., Eds.; John Wiley \& Sons Ltd: Chichester, 1996; Vol. 7, pp 4370-4386.

35. Engelhardt, G.; Michel, D. High-Resolution Solid-State NMR of Silicates and Zeolites; John Wiley \& Sons: Chichester, 1987.

36. Lindner, E.; Schneller, T.; Auer, F.; Mayer, H. A. Angew. Chem., Int. Ed. Engl. 1999, $38,2155-2174$. 
37. Gulik, A.; Delacroix, H.; Krischner, G.; Luzzati, V. J. de Physique II 1995, 5, 445464.

38. Cai, Q.; Luo, Z.-S.; Pang, W.-Q.; Fan, Y.-W.; Chen, X.-H.; Cui, F.-Z. Chem. Mater. 2001, $13,258-263$. 


\title{
CHAPTER 3. TUNING OF PARTICLE MORPHOLOGY AND PORE PROPERTIES IN MESOPOROUS SILICAS WITH MULTIPLE ORGANIC FUNCTIONAL GROUPS
}

\author{
A paper published in Chemical Communications ${ }^{I}$
}

Seong Huh, Jerzy W. Wiench, Brian G. Trewyn, Seahn Song, Marek Pruski, and Victor S.-Y. Lin

\begin{abstract}
A synthetic method has been developed that can control both multifunctionalization and morphology of the mesoporous organic/inorganic hybrid materials by introducing different molar ratios of organoalkoxysilane precursors to a base-catalyzed co-condensation of silicate.
\end{abstract}

\section{Introduction}

Recent advances in synthesizing organically functionalized mesoporous silica materials ${ }^{1}$ have highlighted the promising potential of utilizing these materials as building blocks to construct multifunctional microdevices for selective catalysis, ${ }^{1 \mathrm{~b}, 2}$ adsorption, ${ }^{3}$ and sensor $^{4}$ applications. Further progress in such applications will rely on the ability to tune the extent of functionalization with multiple organic moieties and to control the particle morphology in order to direct the mass-transport properties of the resulting organic/inorganic hybrid materials. Morphology control of inorganic mesoporous silicas has

\footnotetext{
${ }^{1}$ Reprinted with permission of Chem. Commun. 2003, 2364-2365. Copyright 2003, Royal Society of Chemistry.
} 
been studied intensively ever since the first report of MCMs family a decade ago. The desired particle shapes were prepared via $\mathrm{pH}$ control, ${ }^{5}$ utilization of base catalysts, ${ }^{7}$ and by the use of co-solvents, ${ }^{6}$ e.g. in a modified Stoeber process. ${ }^{6, d}$ We describe herein a new approach, in which various organoalkoxysilane precursors introduced during the cocondensation reactions, rather than the co-solvents, are used for morphology control. An added advantage of this method is that it results in simultaneous anchoring of multiple functional groups to the mesopores (multifunctionalization). The roles and quantities of these moieties may be tailored independently and/or cooperatively for various applications, such as gatekeeping. To the best of our knowledge, the synthetic pathway that controls both multifunctionalization and morphology of the mesoporous organic/inorganic hybrid material has not been reported prior to this communication.

\section{Experimental Section}

The FE-SEM images of two mesoporous silicas functionalized through the introduction of 3-[2-(2-aminoethylamino)ethylamino]propyl (AEP) and 3-cyanopropyl (CP) as organoalkoxysilane precursors, are shown in Figure $1 \mathrm{a}$ and $\mathrm{b}$, respectively. ${ }^{8}$ In contrast to the pure MCM-41 synthesized under the same conditions, which exhibits irregular spherical shape, ${ }^{8}$ monofunctionalization with AEP or CP resulted in different particle shapes and sizes,

i.e., spheres with an average particle diameter $\sim 3 \mu \mathrm{m}$ and rods with an average particle size: $\mathrm{L} \times \mathrm{W}=1 \times 0.2 \mu \mathrm{m}$. These materials were prepared by sodium hydroxide-catalyzed condensation reactions of tetraethoxysilane (TEOS) with AEP-trimethoxysilane (AEPTMS) or CP-triethoxysilane (CPTES), in the presence of a low concentration of cetyltrimethylammonium bromide (CTAB) surfactant, under stirring $(550 \mathrm{rpm})$ at $80^{\circ} \mathrm{C}$ for 2 
h. The reaction mixture molar ratio was $1.00 \mathrm{CTAB}: 8.16 \mathrm{TEOS}: 1.05$ total organoalkoxysilanes : $2.55 \mathrm{NaOH}: 4857 \mathrm{H}_{2} \mathrm{O}$. Surfactant-free materials were obtained with an acid extraction. ${ }^{8}$ The observed difference in particle morphology prompted us to synthesize a series of bifunctional materials in which the molar ratio between the AEPTMS and CPTES was varied systematically from $100 \%$ AEPTMS to $100 \%$ CPTES. During the synthesis, the total amount of the organoalkoxysilanes (AEPTMS + CPTES) relative to TEOS was fixed at the level of $12.8 \mathrm{~mol} \%$ in all samples. In this Communication, we will refer to the monofunctionalized microparticle (MP) as AEP-MP (CP-MP) and to the bifunctionalized materials as AEP/CP-MP.

\section{Results and Discussion}

As depicted in Figure 1c, d, and e, the FE-SEM micrographs of the bifunctional AEP/CP-MP materials synthesized with different molar ratios of AEPTMS/CPTES showed only spherical particles. In contrast to the micron-sized AEP-MP, the average particle diameters of the bifunctional AEP/CP-MP spheres decreased as the relative ratio of AEPTMS/CPTES changed from $5 / 5$ to $1 / 9$. It is interesting to note that even in the $1 / 9$ case (1.28 $\mathrm{mol} \%$ of AEPTMS and $11.52 \mathrm{~mol} \%$ of CPTES, Figure 1e), no rod-like particles were observed, which is in stark contrast with CP-MP sample (12.8 mol \% of CPTES, Figure $1 \mathrm{~b}$ ). Evidently, the presence of AEPTMS precursor in the co-condensation reaction played a crucial role in governing the particle shape of the resulting bifunctional materials.

To investigate the influence of the organoalkoxysilanes on the pore properties and structure, we measured the powder XRD diffraction patterns of the bifunctional samples. As shown in Figure $2 \mathrm{a}$ and in the Supporting Information, the observed patterns exhibited a 
strong $\mathrm{d}_{100}$ peak and a broad peak derived from the combination of $\mathrm{d}_{110}$ and $\mathrm{d}_{200}$ diffractions, most likely due to a disordered wormhole-like porous structure. This observed diffraction pattern is very similar to that of the AEP-MP material. Also, the TEM micrographs ${ }^{8}$ revealed the disordered, wormhole pore structure in both AEP-MP and AEP/CP-MP. Interestingly, the XRD (Figure 2a) and TEM measurements of the CP-MP rods showed a typical MCM-41 type of hexagonal symmetry of the mesopores packed in a parallel fashion along the long axis of the rod-shaped particles. These observations provided further evidence that the sample morphology is very sensitive to the presence of AEPTMS during co-condensation. ${ }^{13} \mathrm{C}$ solid-state NMR was used to (i) obtain spectroscopic evidence for the presence of the organic functional moieties in the mesopores, (ii) confirm their chemical structure, and (iii) measure their relative concentration in bifunctionalized samples. The spectra were obtained at $9.4 \mathrm{~T}$ on a Varian/Chemagnetics Infinity spectrometer, using ${ }^{1} \mathrm{H}-{ }^{13} \mathrm{C}$ cross polarization with magic angle spinning (CPMAS). ${ }^{9}$ The spectra, shown in Figure $2 \mathrm{~b}$, demonstrated that the mesopores were indeed functionalized as intended.

Measurements of the "build-up" of carbon magnetization during cross-polarization revealed details about the molecular motions of both functional groups and allowed to measure their relative concentration in all samples. ${ }^{8}$ In AEP-MP, all $\mathrm{CH}_{2}$ carbons were polarized with a time constant $\tau_{\mathrm{CH}}$ on the order of $60 \mu \mathrm{s}$, which is typical for such functional groups when they are sufficiently rigid (in this case, do not undergo motions on a $\mathrm{kHz}$ scale). A similar time constant has been found for the $\mathrm{C} 1$ carbon in CP-MP. However, the evolution of resonance at $19 \mathrm{ppm}$ assigned to the $\mathrm{C} 2$ and $\mathrm{C} 3$ groups in this sample involved two time constants of approximately 100 and $700 \mu$ s. This result showed that the $\mathrm{C} 2-\mathrm{H}_{2}$ and $\mathrm{C} 3-\mathrm{H}_{2}$ groups in CP-MP experienced increasing mobility, which weakened the ${ }^{1} \mathrm{H}_{-}{ }^{13} \mathrm{C}$ dipolar 
coupling and inhibited the cross polarization process. The $\tau_{\mathrm{CH}}$ value of $5 \mathrm{~ms}$ observed for carbon $\mathrm{C} 4$ was consistent with the nitrile end of CP-MP being the most mobile.

Our measurements also showed that in the AEP/CP-MP'samples the cross polarization dynamics was the same, within the experimental error, as for the corresponding carbon species in AEP-MP and CP-MP. This allowed us to use the physical mixture of AEP-MP with CP-MP in a known molar ratio as the intensity standard for quantitative analysis of the spectra of bifunctionalized samples, which are shown in Figure 3. Two unique resonances, at around 48 ppm in AEP (carbons C4-C7) and at 120 ppm in CP (carbon C4), offered best indicators of both functionalities. The exact procedure used for quantitative measurements is described in the Supporting Information. ${ }^{8}$

In order to investigate the chemical accessibility of the organic functional groups, we examined the $\mathrm{Cu}^{2+}$ adsorption capacity of representative samples. ${ }^{10}$ Because of the chelate effect of the diethylene triamine moiety of the AEP group, we anticipated significantly higher $\mathrm{Cu}^{2+}$ adsorption capacities for the materials with higher amount of AEP. Indeed, our results indicated that the AEP-MP and CP-MP materials showed adsorptivities of 0.284 and 0.017 $\mu \mathrm{mol} / \mathrm{m}^{2}$, respectively (Figure 4 ). The corresponding values for bifunctional $5 / 5$ and $1 / 9$ AEP/CP-MP silicas were 0.073 and $0.028 \mu \mathrm{mol} / \mathrm{m}^{2}$. We note, however, that the $\mathrm{Cu}^{2+}$ adsorption capacity increased by a factor of only 2.6 between the $1 / 9$ to $5 / 5$ AEP/CP-MP samples, whereas solid state NMR showed an 8-fold increase of the relative AEP/CP ratio in these materials. Given that the total loading of both organic groups was fixed at $12.8 \mathrm{~mol} \%$, these results indicated that the chemical accessibility of organic functional groups did not increase linearly with the amount of AEP groups in bifunctional silicas. The CP 
functionality, which is hydrophobic in nature, might have played an active role in decreasing the adsorption capacity per AEP group.

\section{Conclusions}

In conclusion, we have prepared a series of bifunctional mesoporous silica materials with the ability to control the particle morphology and the degree of multifunctionalization. This new synthetic approach proved useful in preparation of other bifunctionalized mesoporous materials in our laboratory. We envision that these materials could be used in selective catalysis and other applications.

\section{Acknowledgement}

This research was supported at Ames Laboratory by the U.S. DOE, Office of Basic Energy Sciences, Division of Chemical Sciences, under contract W-7405-Eng-82. 
Figure 1. FE-SEM images of (a) AEP-MP, (b) CP-MP, (c) 5/5 AEP/CP-MP (d) 3/7 AEP/CP$\mathrm{MP}$, (e) $1 / 9 \mathrm{AEP} / \mathrm{CP}-\mathrm{MP}$. Scale bar $=1 \mu \mathrm{m}$ for all the micrographs.
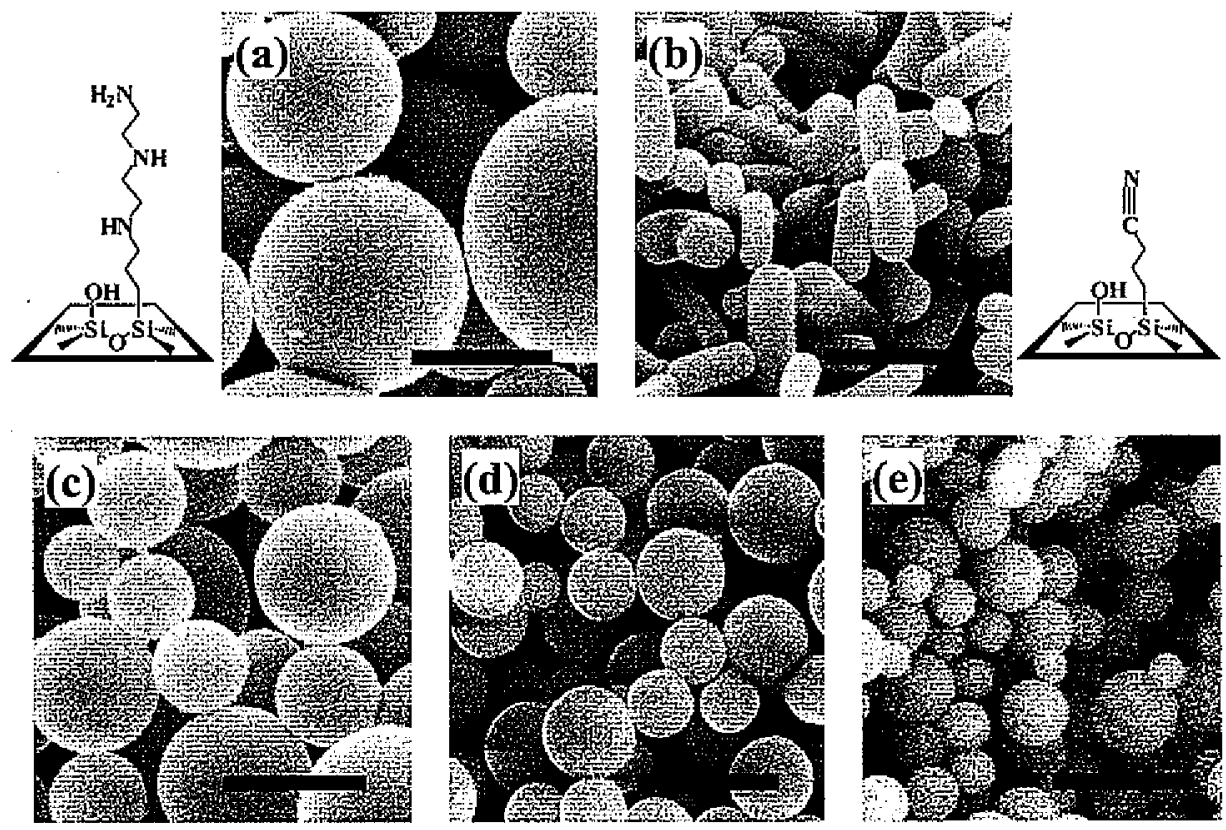
Figure 2. (a) Powder XRD diffraction patterns of bifunctional AEP/CP-MP materials synthesized with different molar ratios of AEPTMS/CPTES. (b) ${ }^{13} \mathrm{C}$ solid-state CPMAS NMR measurements of the AEP-MP (above) and CP-MP (below) materials.
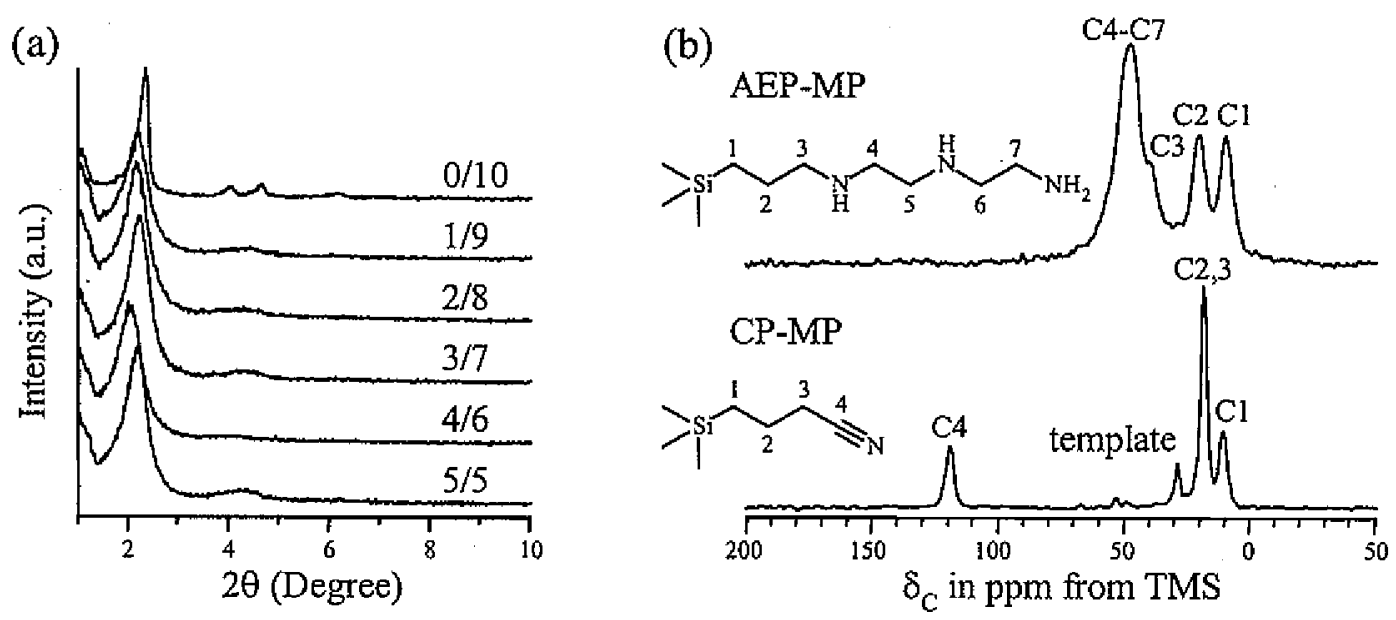
Figure $3 .{ }^{13} \mathrm{C}$ CPMAS spectra of monofunctionalized (top and bottom traces) and bifunctionalized (middle traces) AEP/CP-MP's. Arrows highlight the resonances that are unique for each species and thus were used for quantitative analysis. The numbers represent the molar ratio between two components used for preparation (left column) and obtained form analysis of NMR spectra (right column).

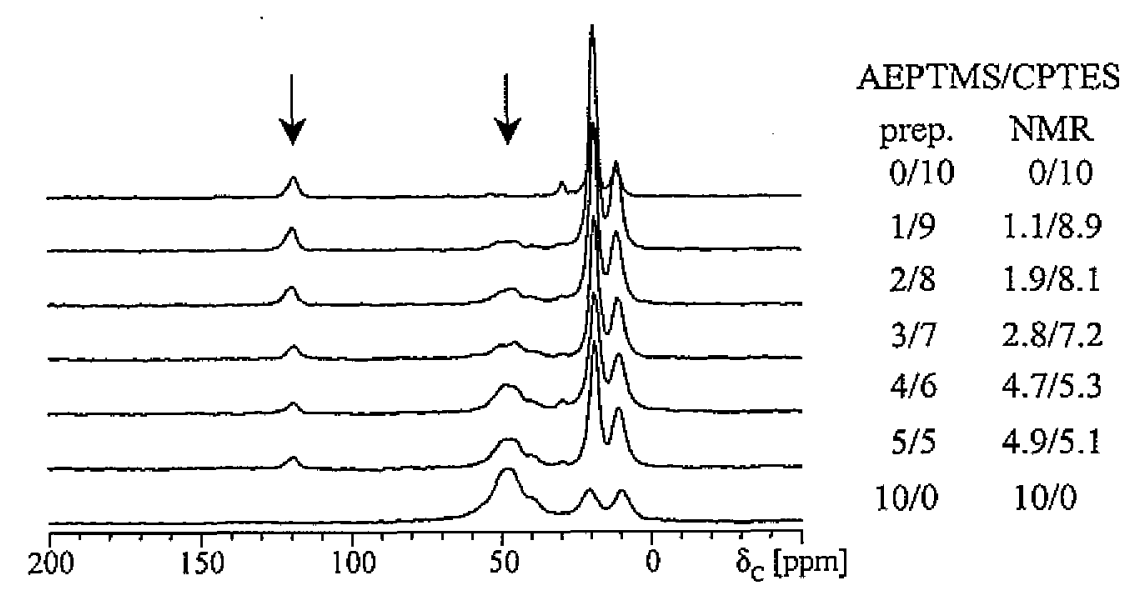


Figure 4. Diagram of $\mathrm{Cu}(\mathrm{II})$ adsorption capacity for selected samples.

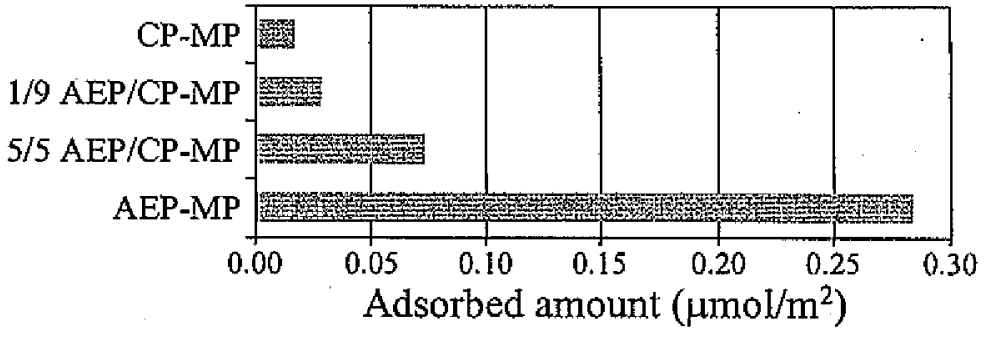




\section{References}

1. (a) M.H. Lim, C.F. Blanford and A. Stein, J. Am. Chem. Soc., 1997, 119, 4090; (b) A. Stein, B.J. Melde and R.C. Schroden, Adv. Mater., 2000, 12, 1403; (c) C.E. Fowler, S.L. Burkett and S. Mann, Chem. Commun., 1997, 1769; (d) S.R. Hall, C.E. Fowler, S. Mann and B. Lebeau, Chem. Commun., 1999, 201; (e) C.E. Fowler, S. Mann and B..Lebeau, Chem. Commun., 1998, 1825; (f) Q. Yang, M.P. Kapoor and S. Inagaki, J. Am. Chem. Soc., 2002, 124, 9694; (g) S. Inagaki, S. Guan, T. Ohsuna and O.

Terasaki, Nature, 2002, 416, 304; (h) H. Fan, Y. Lu, A. Stump, S.T. Reed, T. Baer, R. Schunk, V. Perez-Luna, G.P. Lopez and C.J. Brinker, Nature, 2000, 405, 56.

2. (a) V. S.-Y. Lin, D.R. Radu, M.-K. Han, W. Deng, S. Kuroki, B.H. Shanks and M. Pruski, J. Am. Chem. Soc., 2002, 124, 9040; (b) J.Y. Ying, C.P. Mehnert and M.S. Wong, Angew. Chem., Int. Ed., 1999, 38, 56; (c) A. Sayari, Chem. Mater., 1996, 8, 1840; (d) K. Moller and T. Bein, Chem. Mater., 1998, 10, 2950; (e) X. He and D. Antonelli, Angew. Chem., Int. Ed., 2002, 41, 214; (f) K. Kageyama, J.-I. Tamazawa and T. Aida, Science, 1999, 285, 2113; (g) M.E. Davis, Nature, 2002, 417, 813.

3. (a) S. Dai, M.C. Burleigh, Y. Shin, C.C. Morrow, C.E. Barnes and Z. Xue, Angew. Chem., Int. Ed., 1999, 38, 1235; (b) J. Brown, L. Mercier and T.J. Pinnavaia, Chem. Commun., 1999, 69; (c) X. Feng, G.E. Fryxell, L.Q. Wang, A.Y. Kim, J. Liu, K.M. Kemner, Science, 1997, 276, 923.

4. (a) V.S.-Y. Lin, C.-Y. Lai, J. Huang, S.-A. Song and S. Xu, J. Am. Chem. Soc., 2001, 123, 11510; (b) G. Wirnsberger, B.J. Scott and G.D. Stucky, Chem. Commun., 2001, 119; (c) A.B. Descalzo, D. Jimenez, M.D. Marcos, R. Martinez-Manez, J. Soto, J. El 
Haskouri, C. Guillem, D. Beltran, P. Amoros and M.V. Borrachero, Adv. Mater, $2002,14,966$.

5. (a) H.-P. Lin and C.-Y. Mou, Acc. Chem. Res., 2002, 35, 927; (b) Q. Huo, D. Zhao, J. Feng, K. Weston, S.K. Buratto, G.D. Stucky, S. Schacht and F. Schuth, Adv. Mater., 1997, 9, 974; (c) G.A. Ozin, Chem. Commun., $2000,419$.

6. (a) M.T. Anderson, J.E. Martin, J.G. Odinek and P.P. Newcomer, Chem. Mater., 1998, 10, 1490; (b) D. Zhao, J. Sun, Q. Li and G.D. Stucky, Chem. Mater, 2000, 12, 275; (c) M. Etienne, B. Lebeau and A. Walcarius, New J. Chem., 2002, 26, 384; (d) K. Schumacher, C. Du Fresne von Hohenesche, K.K. Unger, R. Ulrich, A. Du Chesne, U. Wiesner and H.W.Spiess, Adv. Mater., 1999, 11, 1194, and the references therein.

7. Q. Cai, Z.-S. Luo, W.-Q. Pang, Y.-W. Fan, X.-H. Chen and F.-Z. Cui, Chem. Mater., $2001,13,258$.

8. See the Supporting Information for experimental details, SEM images, $\mathrm{N}_{2}$ adsorption isotherms, pore size distributions, TEM images, and details of solid state ${ }^{13} \mathrm{C}$ and ${ }^{29} \mathrm{Si}$ NMR experiments (PDF).

9. A. Pines, M.G. Gibby and J.S. Waugh, J. Chem. Phys., 1973, 59, 569.

10. M.C. Burleigh, M.A. Markowitz, M.S. Spector and B.P. Gaber, Chem. Mater, 2001, 13,4760 . 


\section{Supporting Information of Chem. Commun. 2003, 2364-2365}

\section{Preparation of the materials}

For example, 5/5 AEP/CP-MP was prepared by the following method: The mixture of CTAB (2.0 g, $5.49 \mathrm{mmol}), 2.0 \mathrm{M}$ of $\mathrm{NaOH}(\mathrm{aq})(7.0 \mathrm{~mL}, 14.0 \mathrm{mmol})$ and $\mathrm{H}_{2} \mathrm{O}(480 \mathrm{~g}, 26.67$ mol) was heated at $80^{\circ} \mathrm{C}$ for $30 \mathrm{~min}$. To this clear solution, TEOS $(9.34 \mathrm{~g}, 44.8 \mathrm{mmol}$ ), AEPTMS $(0.76 \mathrm{~g}, 2.88 \mathrm{mmol})$ and CPTES $(0.67 \mathrm{~g}, 2.88 \mathrm{mmol})$ were added sequentially and rapidly via injection. The reaction mixture was allowed to be vigorously stirred (rpm ca. 550). White solids were observed within 2 min upon the mixing of the initial opaque emulsion. The reaction was further heated at $80^{\circ} \mathrm{C}$ for $2 \mathrm{~h}$ then white solids were separated by hot filtration of the mixture giving rise to the as-made solid products. The products were washed with copious amount of water and methanol and then dried under vacuum. An acid extraction was performed in methanol $(100 \mathrm{~mL})$ mixture of concentrated hydrochloric acid $(0.3 \sim 1.0 \mathrm{~mL})$ and as-made materials $(1.0 \mathrm{~g})$ at $50^{\circ} \mathrm{C}$ for $1.5 \sim 2 \mathrm{~h}$. Resulting surfactantremoved solid products were filtered and washed with water and methanol and then dried under vacuum. The materials were dried under vacuum at $90^{\circ} \mathrm{C}$ for $3 \mathrm{~h}$ before $\mathrm{Cu}$ (II) adsorption tests and solid state NMR study.

\section{2. $\mathrm{Cu}$ (II) adsorption capacity test}

The $\mathrm{Cu}(\mathrm{II})$ adsorption capacity tests were performed according to the literature method. ${ }^{2}$ We used $0.01 \mathrm{M} \mathrm{Cu}\left(\mathrm{NO}_{3}\right)_{2} \cdot 2.5 \mathrm{H}_{2} \mathrm{O}$ in $0.1 \mathrm{M}$ tris(hydroxymethyl)aminomethane (= Trizma, Aldrich) solution and the contact time was $1 \mathrm{~h}$. The remaining amount of $\mathrm{Cu}$ (II) ions

${ }^{2}$ Burleigh, M. C. et al. Chem. Mater. 2001, 13, 4760-4766. 
in the filtrate was measured using HP 8453 diode array UV/VIS spectrophotometer at $\lambda_{\max }=$ $601 \mathrm{~nm}$ after a centrifuge.

\section{Summary of NMR measurements}

\subsection{Experimental}

${ }^{13} \mathrm{C}$ solid-state nuclear magnetic resonance (NMR) was used to (i) obtain spectroscopic evidence for the presence of various organic functional moieties in the mesopores, (ii) confirm their structure, and (iii) measure the relative concentration of both moieties in bifunctionalized samples, whereas ${ }^{29} \mathrm{Si}$ NMR data (i) confirmed finctionalizaton of mesoporous materials with AEP and CP organic groups, (ii) provided relative concentration of $\mathrm{T}^{\mathrm{n}}$ and $\mathrm{Q}^{\mathrm{n}}$ groups, and (iii) imparted molecular formula of AEPMP and CP. MP samples as well as molar concentration of organic functionalities (AEP or CP) in the mesopores.

The spectra were obtained at $9.4 \mathrm{~T}$ on a Varian/Chemagnetics Infinity spectrometer, resonating at $100.59\left({ }^{13} \mathrm{C}\right)$, and $79.47 \mathrm{MHz}\left({ }^{29} \mathrm{Si}\right)$, equipped with a doubly tuned, $5 \mathrm{~mm}$ magic angle spinning (MAS) probe. ${ }^{1} \mathrm{H} \rightarrow{ }^{13} \mathrm{C}$ variable amplitude cross polarization (CP) pulse sequence (Fig. S1) was used to enhance the carbon signal and the repetition rate of data acquisitions. ${ }^{3}$ During each cross polarization period, the ${ }^{1} \mathrm{H}$ rf field was ramped between 16 and $40 \mathrm{kHz}$ using $2.4 \mathrm{kHz}$ increments, whereas the ${ }^{13} \mathrm{C}$ rf field was maintained at a constant level of $36 \mathrm{kHz}$. The ${ }^{1} \mathrm{H}$ rf magnetic fields of $83 \mathrm{kHz}$ and $60 \mathrm{kHz}$ were used for initial

\footnotetext{
${ }^{3}$ Pines, A.; Gibby, M. G.; Waugh, J. S. J. Chem. Phys. 1973, 59, 569-590; Peersen, O. B; Wu, X.; Kustanovich, I.; Smith, S. O. J. Magn. Reson., Ser. A, 1993, 104, 334-339.
} 
excitation and decoupling, respectively. The values of ${ }^{1} \mathrm{H}$ longitudinal relaxation time $T_{j}{ }^{H}$ encountered in all mesoporous samples examined in this study did not exceed $1 \mathrm{~s}$, which allowed for repetition time of $1.2 \mathrm{~s}$ to be used in the CPMAS experiments. Typically, 5 to $10 \mathrm{~K}$ scans were accumulated using a sample rotation rate of $9 \mathrm{kHz}$.

Fig. $\mathbf{S 2}$ presents the ${ }^{13} \mathrm{C}$ CPMAS spectra acquired for the mesoporous materials functionalized with AEPTMS (spectrum a, AEP-MP) and CPTES (spectrum b, CP-MP). The NMR results demonstrate that the mesopores are indeed functionalized as intended. The specific resonances are assigned based on the chemical shifts found in the liquid state spectra of the analogous compounds. Carbons $\mathrm{C} 1$ and $\mathrm{C} 2$ in both samples are observed at around 10 and 20 ppm, respectively. In CP-MP, the C3 carbon resonates at 19 ppm, while in AEP-MP the corresponding line is shifted downfield to $39 \mathrm{ppm}$ due to the influence of an adjacent nitrogen atom. The remaining carbon sites can serve as suitable fingerprints of both functional groups. In AEP-MP, the resonances from carbons C4-C7 are superimposed at around $48 \mathrm{ppm}$, whereas $\mathrm{C} 4$ carbon in CP-MP is found at $120 \mathrm{ppm}$.

For silicon measurements (see Fig. S3), direct polarization (DP) of ${ }^{29}$ Si nuclei experiment at $10 \mathrm{kHz}$ MAS was chosen, which involved single excitation $90^{\circ}$ pulse of $2.1 \mu \mathrm{s}$ followed by acquisition of ${ }^{29} \mathrm{Si}$ data accompanied by continuous wave (CW) decoupling of ${ }^{1} \mathrm{H}$ nuclei at $65 \mathrm{kHz}$ rf power. Typically 270 repetitions were completed using pulse delay of $300 \mathrm{~s}$. For additional evidence of presence of $\mathrm{T}^{\mathrm{n}}$ groups, ${ }^{1} \mathrm{H} \rightarrow{ }^{29} \mathrm{Si}$ CPMAS spectra were recorded under similar experimental conditions as ${ }^{1} \mathrm{H} \rightarrow{ }^{13} \mathrm{C}$ CPMAS data, but contact time of $10 \mathrm{~ms}$ and $2 \mathrm{~K}$ accumulations. Specifically the silicone groups were found at positions: -56 $\left(\mathrm{T}^{2}\right),-67\left(\mathrm{~T}^{3}\right),-92\left(\mathrm{Q}^{2}\right),-101\left(\mathrm{Q}^{3}\right)$, and $-110 \mathrm{ppm}\left(\mathrm{Q}^{4}\right)$. 


\subsection{Quantification of silicon groups}

Quantitative measurements of various $\mathrm{T}^{\mathrm{n}}$ and $\mathrm{Q}^{\mathrm{n}}$ silicon groups could be achieved only by ${ }^{29} \mathrm{Si}$ DPMAS experiment. Although $T_{I}$ of ${ }^{29} \mathrm{Si}$ is typically in order of minutes, pulse delay of $300 \mathrm{~s}$ was chosen to assure restoration up to $99 \%$ of initial magnetization. Indeed saturation recovery experiment, completed for allyl- and 3-isocyanatopropyl- functionalized MCM-41 samples, revealed that values of $T_{l}$ relaxation time are in the order of 50 to $65 \mathrm{~s}$ for $\mathrm{T}^{\mathrm{n}}$ groups and of 30 to $45 \mathrm{~s}$ for $\mathrm{Q}^{\mathrm{n}}$ groups. Hence integrals of those groups, obtained from ${ }^{29}$ Si DPMAS spectra, were achieved with $3 \%$ accuracy. Following are relative concentrations, molecular formulas and molar concentration of organic moieties $( \pm 0.05$ mmol/g accuracy) in AEP-MP and CP-MP attained from ${ }^{29} \mathrm{Si}$ DPMAS experiment.

\begin{tabular}{|c|c|c|c|c|c|c|c|}
\hline & \multicolumn{5}{|c|}{$\begin{array}{l}\text { Relative concentration of } \\
\text { silicon groups [\%] }\end{array}$} & \multirow[t]{2}{*}{ Molecular Formula } & \multirow[t]{2}{*}{$\begin{array}{l}\text { Molat concentration of } \\
\text { organic group }[\mathrm{mmol} / \mathrm{g}]\end{array}$} \\
\hline & $\mathrm{T}^{2}$ & $T^{3}$ & $\mathrm{Q}^{2}$ & $Q^{3}$ & $Q^{4}$ & & \\
\hline AEP-MP & 1 & 6 & 3 & 35 & 55 & $\left(\mathrm{SiO}_{2}\right)_{100}\left(\mathrm{H}_{2} \mathrm{O}\right)_{17.5}\left(\mathrm{C}_{7} \mathrm{H}_{19} \mathrm{~N}_{3}\right)_{7}$ & 0.95 \\
\hline CP-MP & 2 & 8 & 2 & 29 & 59 & $\left(\mathrm{SiO}_{2}\right)_{100}\left(\mathrm{H}_{2} \mathrm{O}\right)_{12.5}\left(\mathrm{C}_{4} \mathrm{H}_{7} \mathrm{~N}\right)_{10}$ & 1.44 \\
\hline
\end{tabular}

\subsection{Quantification of functional groups in bifunctionalized samples}

It is noted that direct (single pulse) ${ }^{13} \mathrm{C}$ polarization is often the preferred method in applications involving quantitative measurements. We initially tried to use this method, but chose the cross-polarization (CPMAS) experiment for three reasons. First, the relaxation delays required for direct excitation were prohibitively long, on the order of several minutes. In addition, the delays would have to be measured in several samples to assure quantitative accuracy. Second, all NMR probes used in our laboratory have some level of ${ }^{13} \mathrm{C}$ 
background, which interfered with the signals of interest to this study. Since most of the background originated from parts of the probe made of teflon, these unwanted signals were completely 'invisible' under the ${ }^{1} \mathrm{H} \rightarrow{ }^{13} \mathrm{C}$ cross polarization. Another important benefit of using the CPMAS method was the observation of very different dynamic properties of AEP and $\mathrm{CP}$, as described below. This discovery would not have been possible without the measurements of CPMAS dynamics.

The time evolution of each carbon magnetization during the CPMAS experiment is a result of complicated interplay between the spin-lattice relaxation processes in the rotating frame, described by relaxation time $T_{l \rho}{ }^{H}$, and cross polarization kinetics. ${ }^{4}$ The CP kinetics, in turn, is further influenced by sample spinning, molecular motions and sample heterogeneity. In the simplest case, for each resonance the time dependence of the ${ }^{13} \mathrm{C}$ magnetization $M_{x y}(\tau)$ during the cross-polarization contact is given by

$$
M_{x y}(\tau)=M_{0} \lambda^{-1}\left(1-\exp \left[-\lambda \frac{\tau}{\tau_{C H}}\right]\right) \times \exp \left(-\frac{\tau}{T_{J \rho}^{H}}\right)
$$

where $M_{0}$ is the carbon equilibrium magnetization, $\tau$ is the CP contact time, $\tau_{C H}$ is the time $\mathrm{CP}$ constant for a given species and of $\lambda=1-\tau_{C H} / T_{l \rho}{ }^{H}$. In general, a wide range of $\tau_{C H}$ and $T_{l p}{ }^{H}$ times can exist in molecular systems with different ${ }^{13} \mathrm{C}-{ }^{1} \mathrm{H}$ distances and/or in the presence of internal motion. MAS introduces additional time dependencies to homo- and heteronuclear dipolar Hamiltonians and further complicates the polarization transfer.

\footnotetext{
${ }^{4}$ M. Mehring, 'Principles of High Resolution NMR in Solids', 2nd edn., Springer, Berlin, 1983, Chapter 4.
} 
In this study, we measured separately the 'build-up' of a carbon magnetization during spin-lock for the mesoporous materials mono-functionalized with AEPTMS and CPTES. By fitting the experimental data using equation (1), we obtained the values of $M_{0}$, as well as the $T_{I \rho}^{H}$ and $\tau_{C H}$ times for all carbons in these samples. The results of Table S1 show that the values of $\tau_{C H}$ found for $\mathrm{CH}_{2}$ groups in AEP-MP are on the order of $60 \mu \mathrm{s}$, which is consistent with the literature data for such groups in rigid molecules. A similar time constant has been found for the $\mathrm{Cl}$ carbon in CP-MP. However, the evolution of resonance at $19 \mathrm{ppm}$ in this sample involved two time constants of approximately 100 and $700 \mu$ s. This result shows that the $\mathrm{C} 2-\mathrm{H}_{2}$ and $\mathrm{C} 3-\mathrm{H}_{2}$ groups in CP-MP experience increasing mobility, which weakens the dipolar coupling between ${ }^{1} \mathrm{H}$ and ${ }^{13} \mathrm{C}$ nuclei and inhibits the $\mathrm{CP}$ process. The $\tau_{C H}$ value of 5 ms observed for carbon $\mathrm{C} 4$ is consistent with the nitrile end of CPTES being the most mobile.

The standard strategy for measuring the relative concentrations using CPMAS involves fitting the build-up curves to obtain the values of $M_{0}$ for different ${ }^{13} \mathrm{C}$ resonance lines. However, our measurements showed that in the bifunctionalized AEP/CP-MP samples studied in this work the relaxation parameters were the same, within the experimental error, as for the corresponding carbon species in the samples containing only one type of moieties. This allowed us to avoid measuring the build-up curves. Instead, we prepared the physical mixture of AEP-MP with CP-MP in a known molar ratio of 6.9:3.1, and used it as intensity standard for the bifunctionalized samples, which were measured under identical conditions. The studies were performed using resonances at 48 and 120 ppm for AEP-MP and CP-MP, because they were easily distinguishable in the corresponding spectra. Due to significant 
differences in the polarization dynamics between these two resonances (see Fig. S4), the spectra were collected using two different contact times of 0.4 and $2 \mathrm{~ms}$, which favored one of the species involved at a time, and added before the final analysis. The resonances of our interest were then integrated and referred to the known standard in order to obtain the relative concentration of each species (see Table S2).

Fig. S1. Pulse scheme used in the ${ }^{1} \mathrm{H} \rightarrow{ }^{13} \mathrm{C}$ variable amplitude cross polarization (CP) experiment.

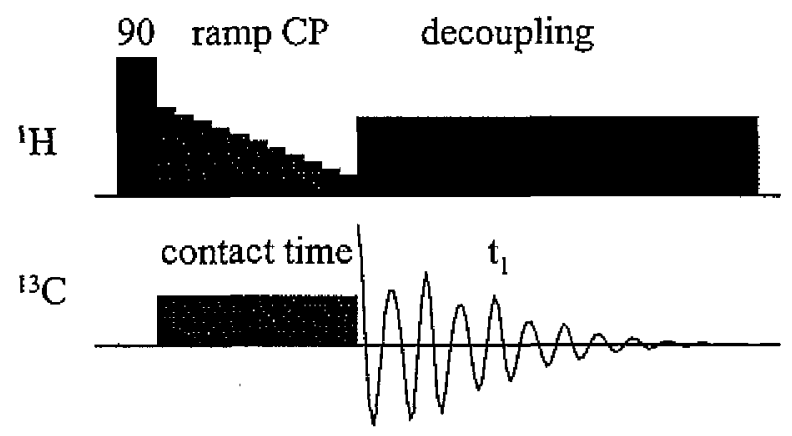

Fig. S2. ${ }^{1} \mathrm{H} \rightarrow{ }^{13} \mathrm{C}$ CPMAS spectra obtained for functionalized mesoporous materials with AEPTMS (a) and CPTES (b) using CP contact times 0.2 and $5 \mathrm{~ms}$, respectively.

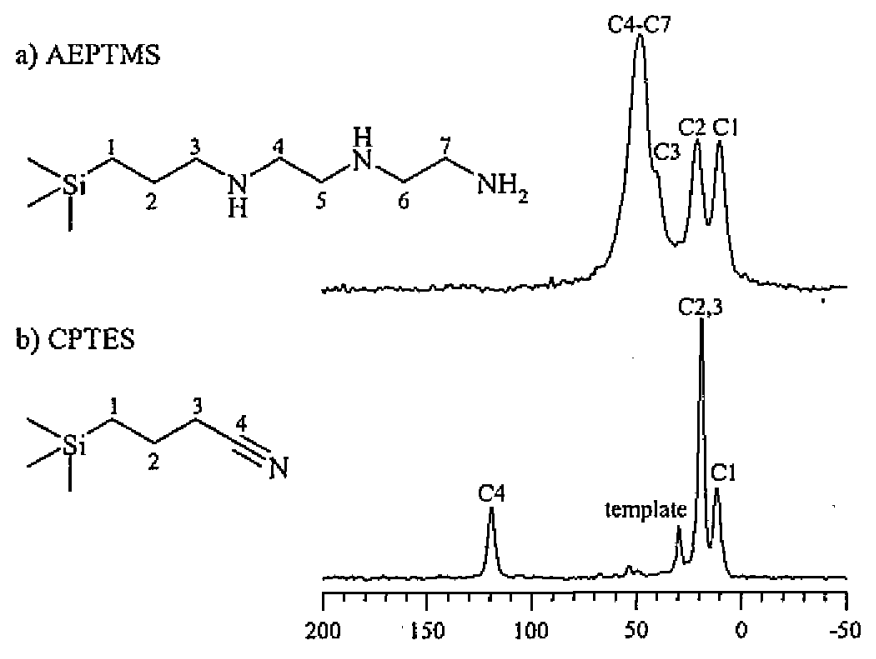


Fig. S3. ${ }^{29}$ Si DPMAS (left column) and ${ }^{1} \mathrm{H} \rightarrow{ }^{29}$ Si CPMAS (right column) spectra obtained for functionalized mesoporous materials with AEPTMS (a) and CPTES (b).

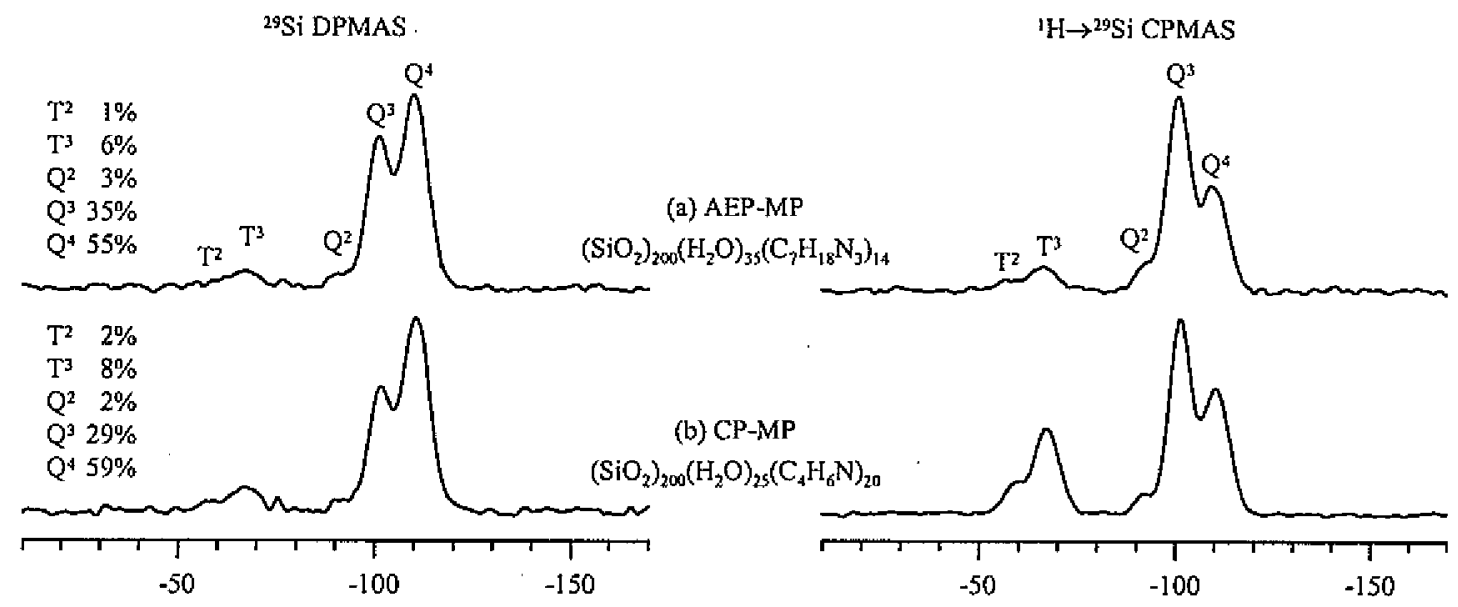

Table S1. Values of $T_{C P}$ and $T_{I \rho}{ }^{H}$ obtained for functionalized mesoporous samples from the analysis of ${ }^{13} \mathrm{C}$ cross polarization 'build-up' curves.

\begin{tabular}{lcccccccc}
\hline & \multicolumn{3}{c}{ AEPTMS } & \multicolumn{5}{c}{ CPTES } \\
\hline Peak [ppm $]$ & 48 & 39 & 20 & 9 & 119 & 19 & 19 & 11 \\
$\tau_{C H}[\mu \mathrm{s}]$ & 50 & 110 & 60 & 45 & 5000 & 700 & 100 & 60 \\
$T_{l \rho}{ }^{H}[\mathrm{~ms}]$ & 0.9 & 0.4 & 0.9 & 1.1 & 5.8 & 4 & 48 & 20
\end{tabular}


Fig. S4. 'Build-up' of carbon magnetization during spin-locking for the resonance lines at 48 ppm in AEP-MP ( () and 119 ppm in CP-MP (O) fitted using equation 1 (solid lines). Dashed lines reveal contact times selected for the quantitative measurements (see text).

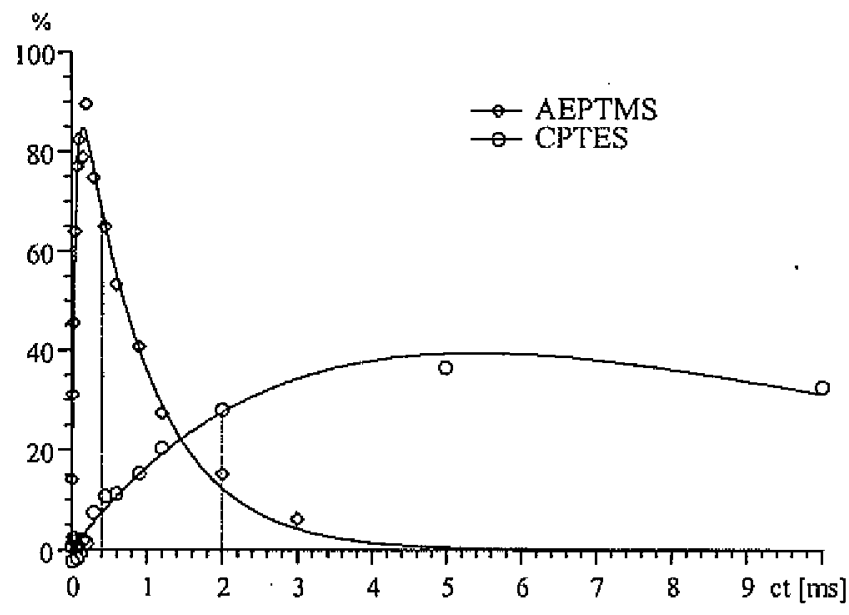

Table S2. Molar ratios of two components used for preparation of AEP/CP-MP materials and the relative concentrations of both moieties obtained from ${ }^{13} \mathrm{C}$ CPMAS spectra.

\begin{tabular}{cc}
\hline \multicolumn{2}{l}{ AEPTMS:CPTES } \\
\hline prep. & NMR \\
$1: 9$ & $1.1: 8.9$ \\
$2: 8$ & $2.0: 8.0$ \\
$3: 7$ & $2.9: 7.1$ \\
$4: 6$ & $4.7: 5.3$ \\
$5: 5$ & $5.0: 5.0$ \\
\hline
\end{tabular}


Fig. S5. FE-SEM images of monofunctional materials (Hitachi S4700).

(a) AEP-MP

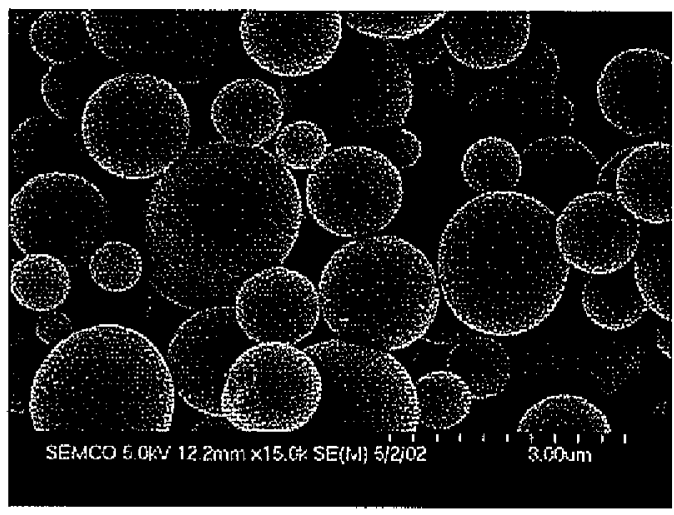

(b) CP-MP

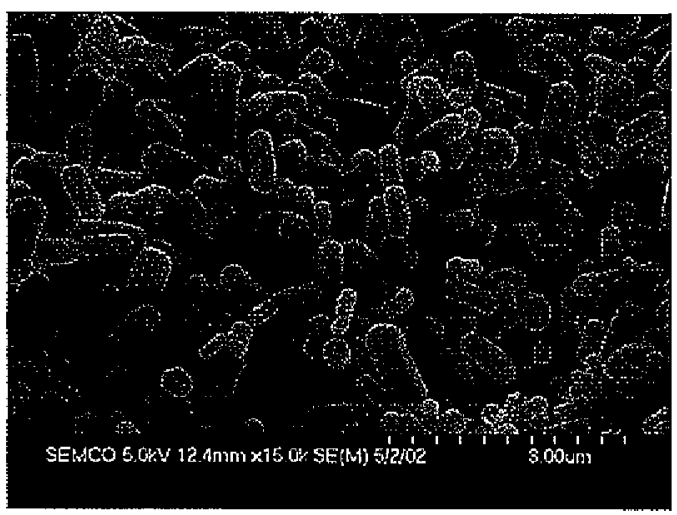

Fig. S6. FE-SEM images of bifunctional materials (Hitachi S4700).

(a) $5 / 5$ AEP/CP-MP

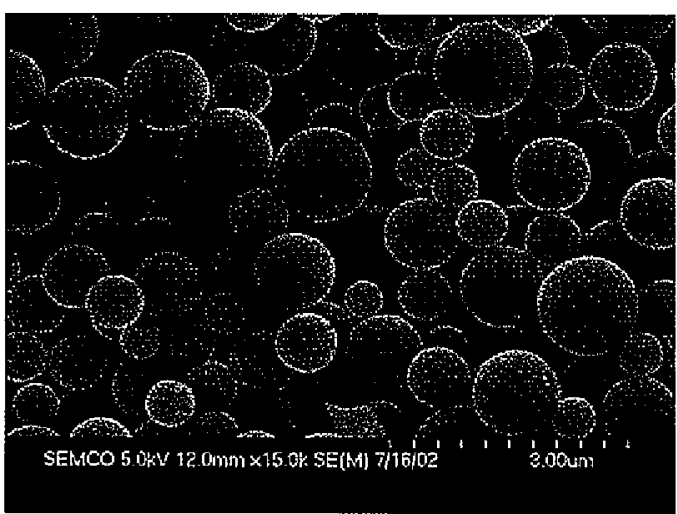

(b) $4 / 6 \mathrm{AEP} / \mathrm{CP}-\mathrm{MP}$

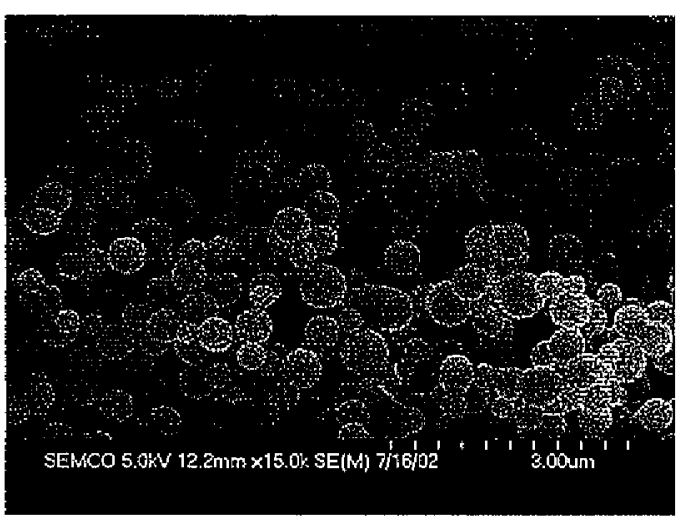


(c) 3/7 AEP/CP-MP

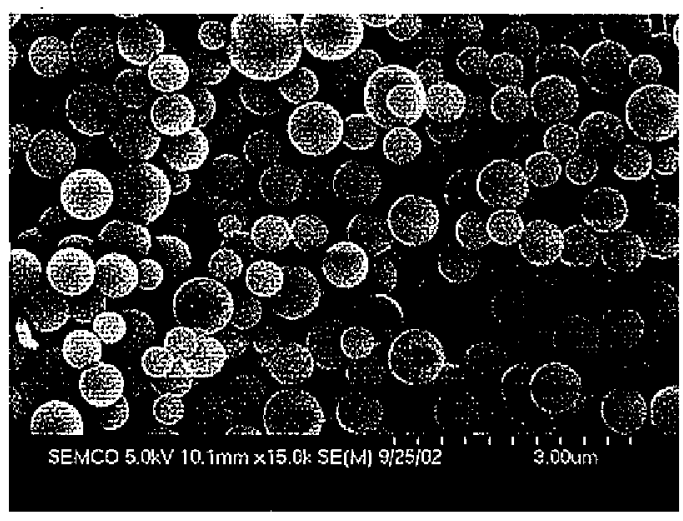

(e) $1 / 9 \mathrm{AEP} / \mathrm{CP}-\mathrm{MP}$

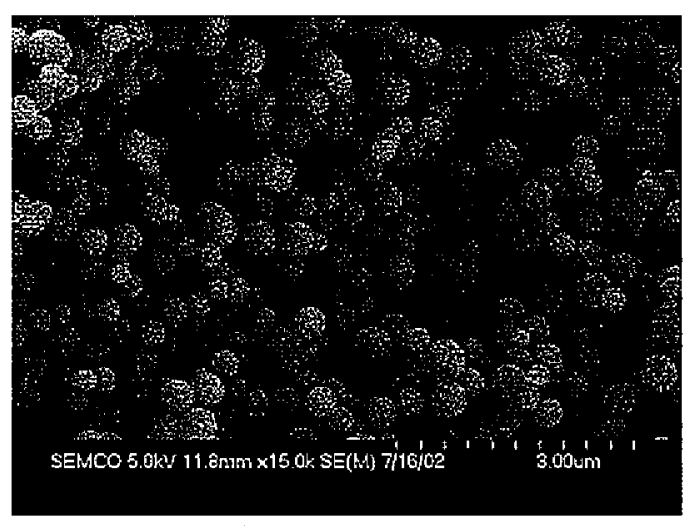

(d) 2/8 AEP/CP-MP

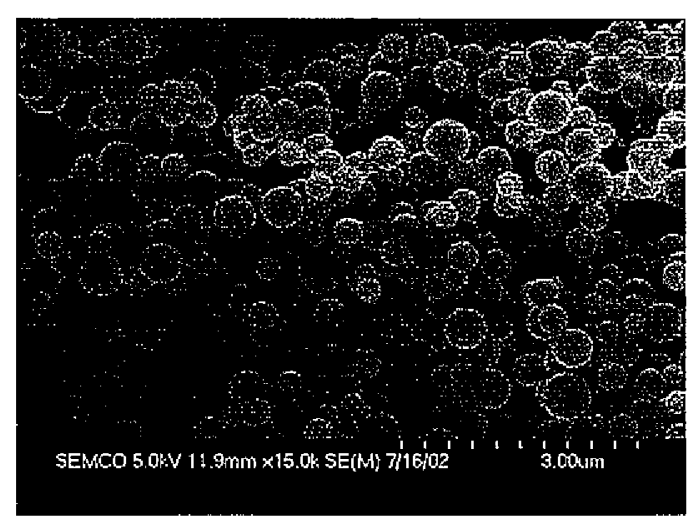

(f) Pure MCM-41

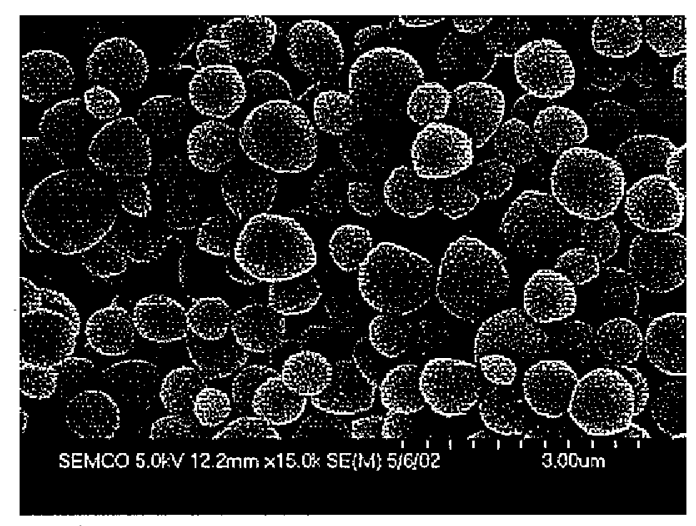


Fig. S7. TEM images of the selected materials.

(a) AEP-MP (Ultramicrotomed)

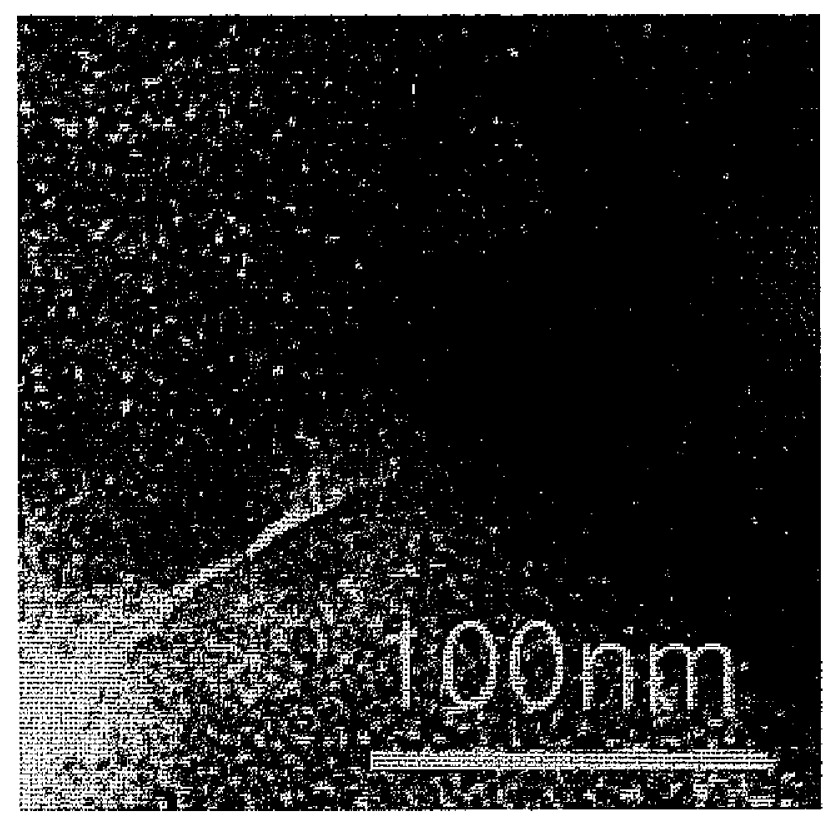

(b) CP-MP

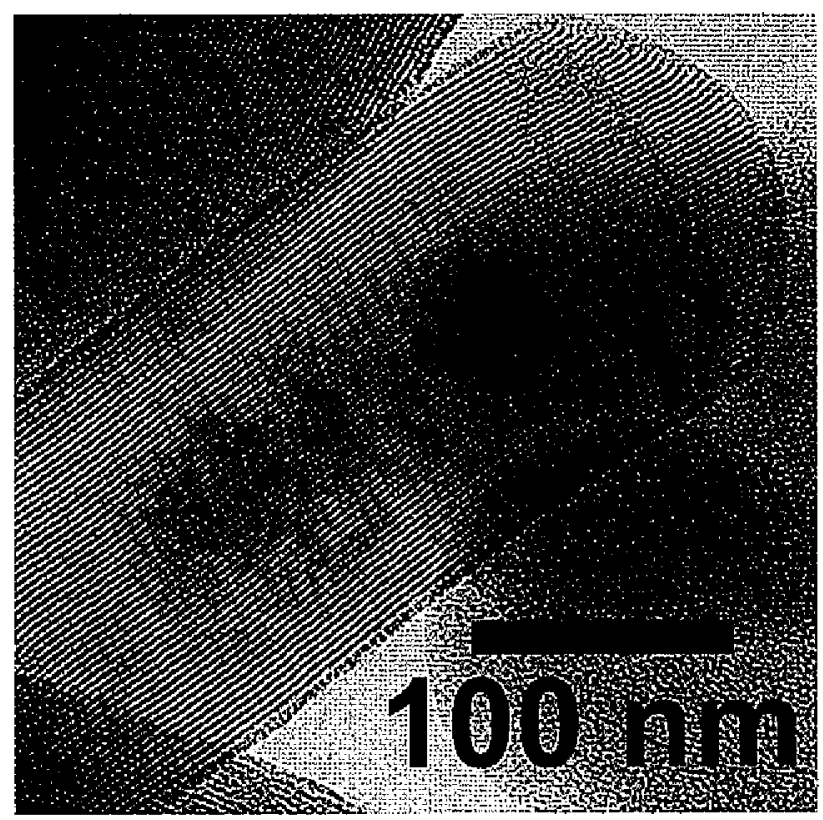


(c) 5/5 AEP/CP-MP (Ultramicrotomed)

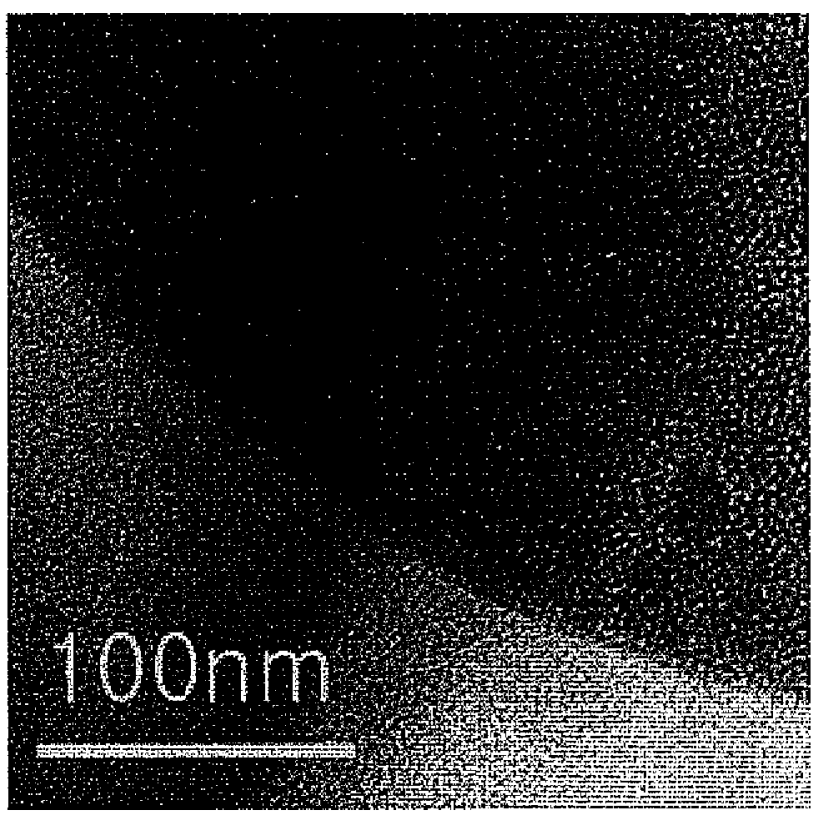

(d) 1/9 AEP/CP-MP (Ultramicrotomed)

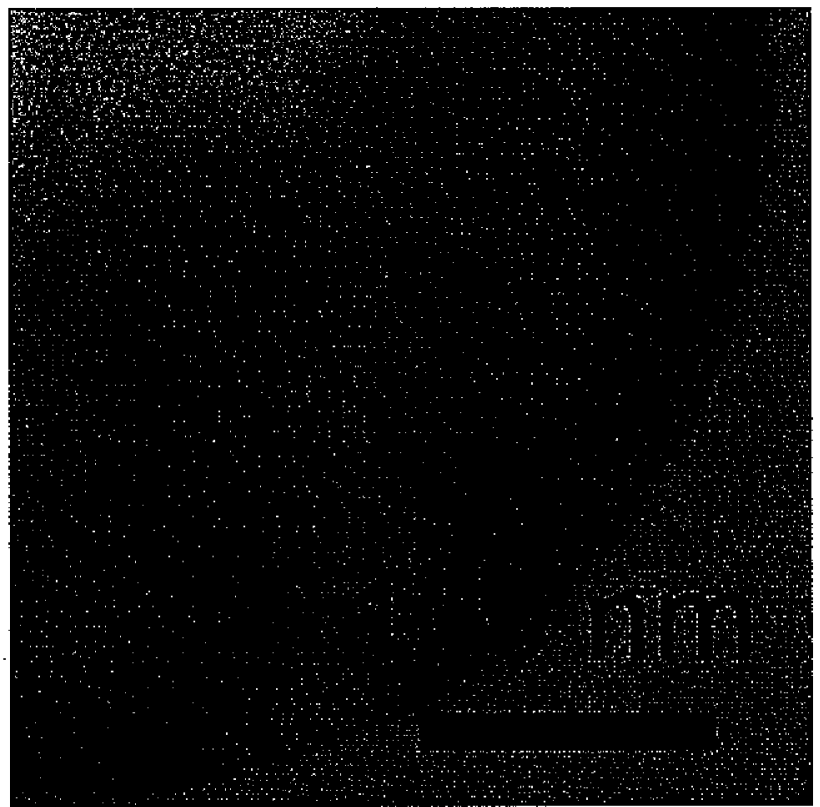


Table S3. Textural properties of the surfactant-free materials.

\begin{tabular}{|c|c|c|c|c|c|c|}
\hline Sample & $d_{100}(\AA)$ & $a_{0}(\AA)$ & $\begin{array}{c}S_{\mathrm{BET}} \\
\left(\mathrm{m}^{2} / \mathrm{g}\right)\end{array}$ & $\begin{array}{c}V_{\mathrm{p}} \\
\left(\mathrm{cm}^{3} / \mathrm{g}\right)\end{array}$ & $W_{\mathrm{BJH}}(\AA)$ & $\begin{array}{c}d_{\text {pore wall }} \\
(\AA)\end{array}$ \\
\hline 5/5 AEP/CP-MP & 37.1 & 42.9 & 722.2 & 0.38 & - & - \\
\hline 4/6 AEP/CP-MP & 42.1 & 48.6 & 822.6 & 0.51 & 26.4 & 22.2 \\
\hline 3/7 AEP/CP-MP & 38.1 & 44.0 & 980.8 & 0.56 & 26.4 & 17.6 \\
\hline 2/8 AEP/CP-MP & 37.4 & 43.2 & 801.4 & 0.43 & 20.5 & 22.7 \\
\hline 1/9 AEP/CP-MP & 36.5 & 42.2 & 966.6 & 0.51 & 20.7 & 21.5 \\
\hline
\end{tabular}


Fig. S8. PXRD data of as-made materials.

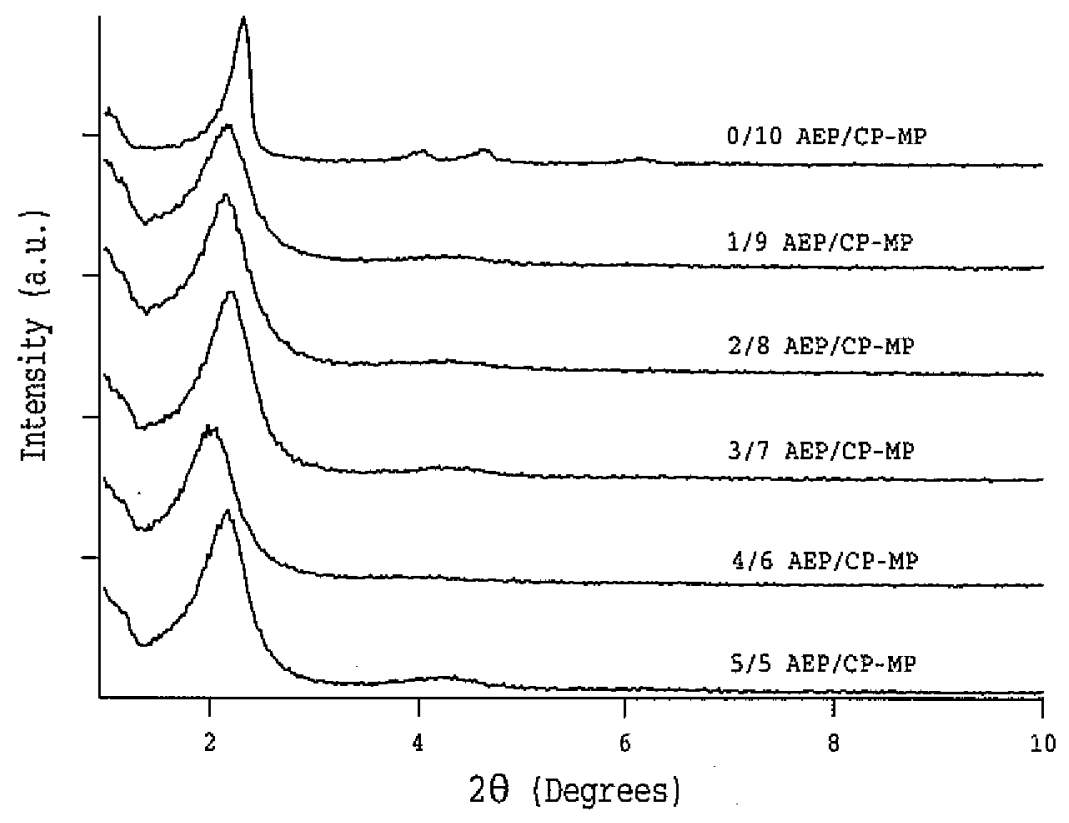

Fig. S9. BET isotherms and pore size distribution curves.

(a) $5 / 5 \mathrm{AEP} / \mathrm{CP}-\mathrm{MP}$
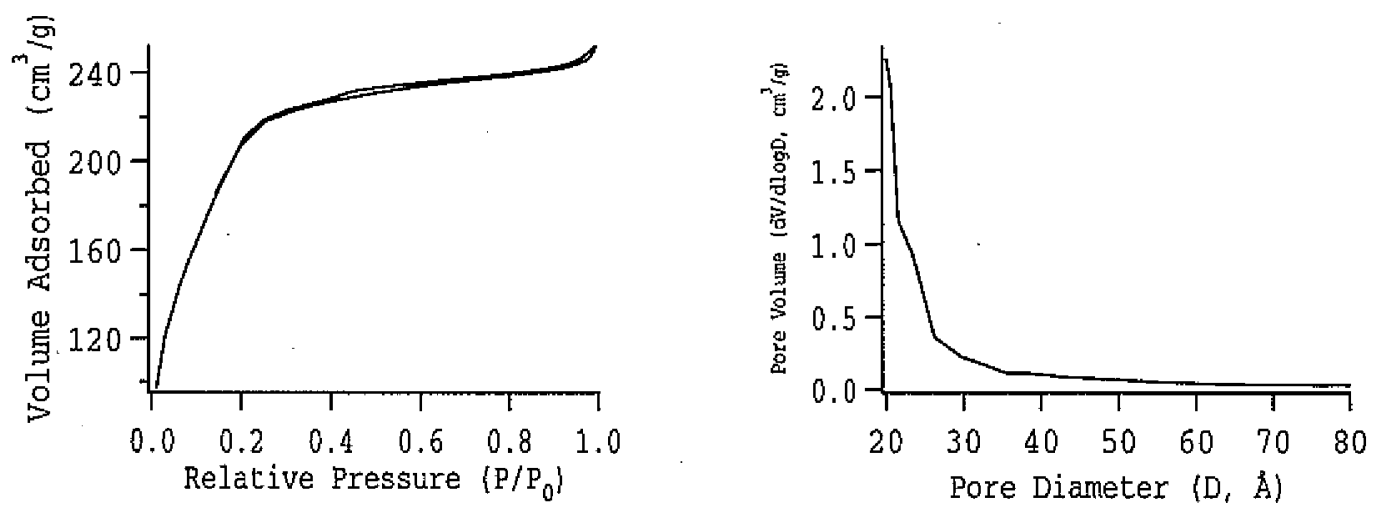
(b) 4/6 AEP/CP-MP

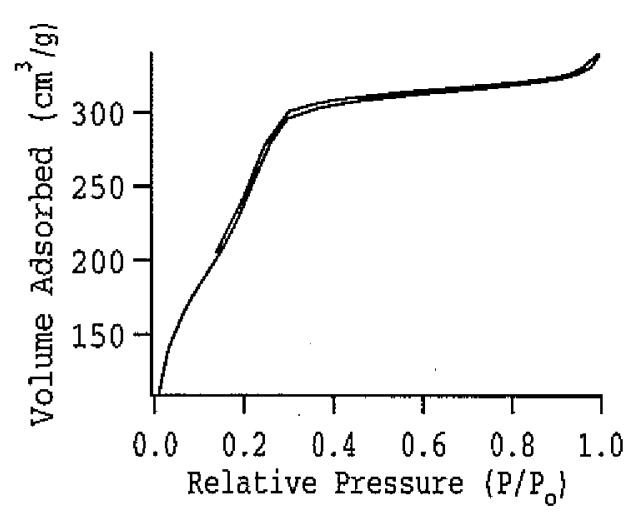

(c) $3 / 7$ AEP/CP-MP

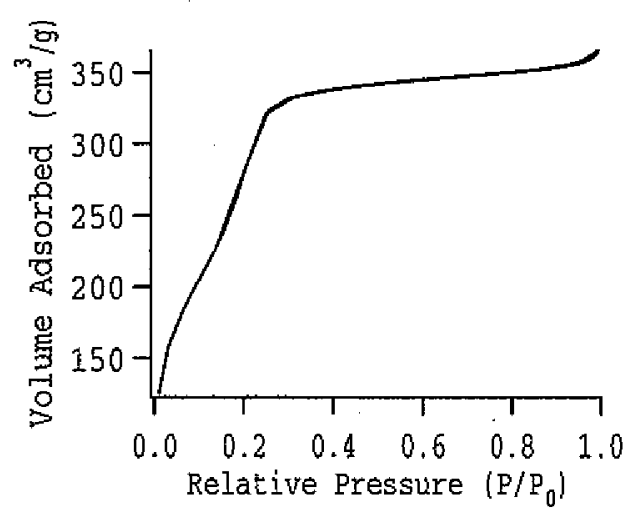

(d) 2/8 AEP/CP-MP

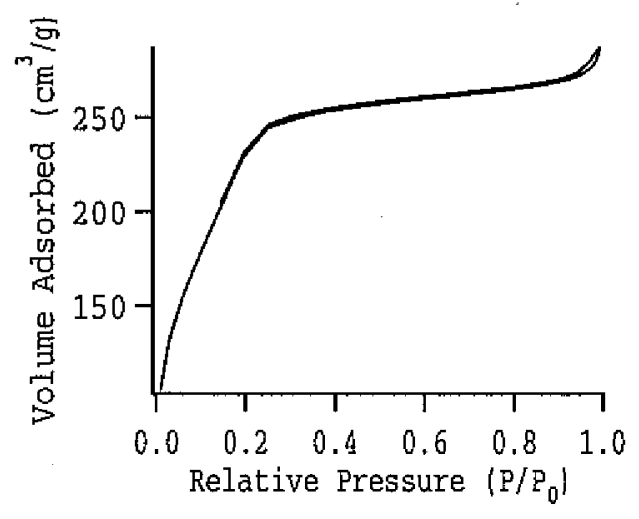

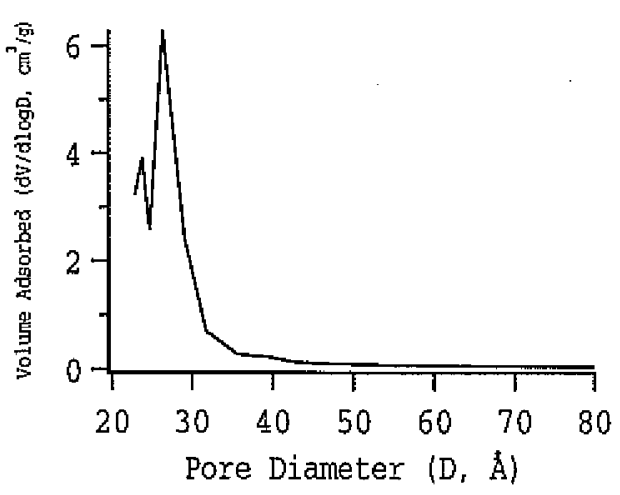
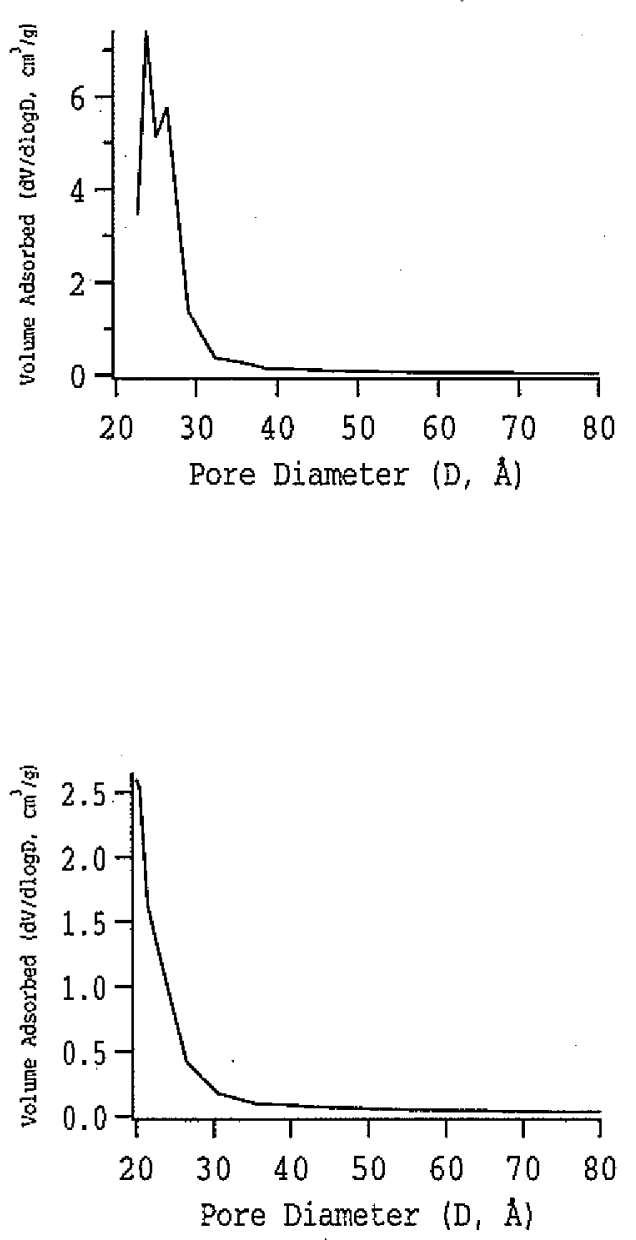
(e) 1/9 AEP/CP-MP
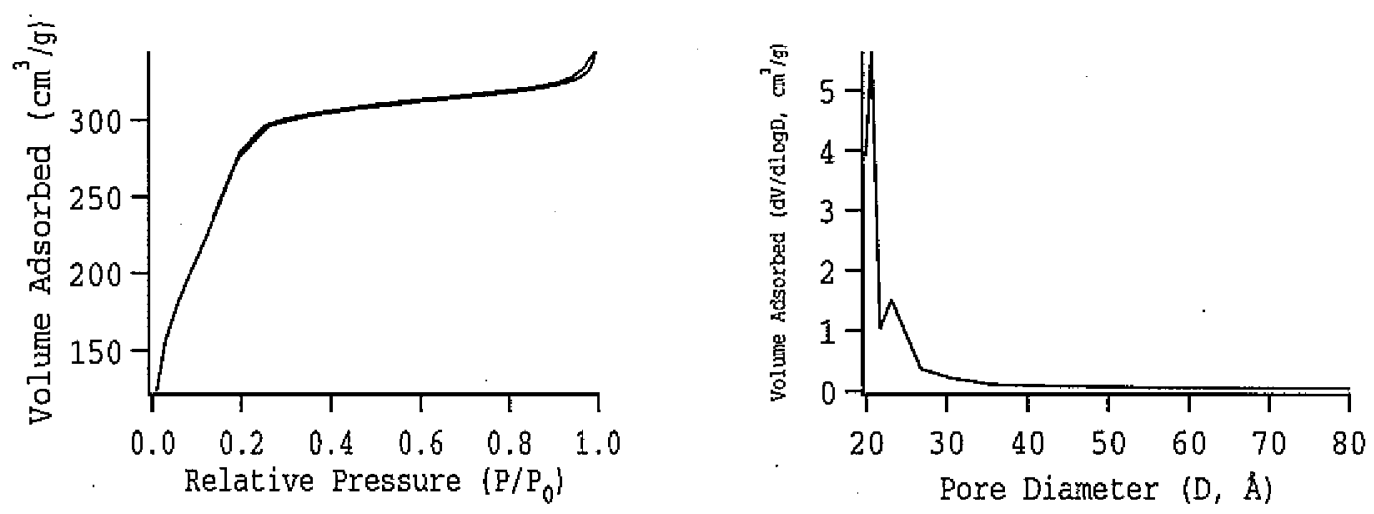


\title{
. CHAPTER 4. CONTROLLING THE SELECTIVITY OF COMPETITIVE NITROALDOL CONDENSATION BY USING A BIFUNCTIONALIZED MESOPOROUS SILICA NANOSPHERE-BASED CATALYTIC SYSTEM
}

\author{
A paper published in Journal of the American Chemical Society ${ }^{I}$ \\ Seong Huh, Hung-Ting Chen, Jerzy W. Wiench, Marek Pruski and Victor S. - Y. Lin
}

\begin{abstract}
A series of bifunctionalized mesoporous silica nanosphere-based (MSN) heterogeneouscatalysts for the nitroaldol (Henry) reaction have been synthesized. A common 3-[2-(2-aminoethylamino)ethylamino]propyl (AEP) primary group and three different secondary groups, ureidopropyl (UDP), mercaptopropyl (MP), and allyl (AL) functionalities, were incorporated to these mesoporous silica materials by introducing equal amts. of AEPtrimethoxysilane with UDP-; MP-, or AL-trialkoxysilane precursors to our previously reported co-condensation reaction. Nanospheres were prepd. by mixing the corresponding reactants in the presence of $\mathrm{CTAB}, \mathrm{NaOH}$, and $\mathrm{H}_{2} \mathrm{O}$ and heating to $80^{\circ}$ for $30 \mathrm{~min}$; an example compound thus prepared was $\mathrm{N}$-(2-aminoethyl)- $\mathrm{N}^{\prime}-[3-($ trimethoxysilyl)propyl]-1,2ethanediamine polymer with silicic acid $\left(\mathrm{H}_{4} \mathrm{SiO}_{4}\right)$ tetraethyl ester and [3(trimethoxysilyl)propyl]urea. Structures and relative concentrations of the functional groups were detailed by solid-state NMR and other spectroscopic techniques. The AEP group served as a catalyst, and the other secondary groups provided different noncovalent interactions to

\footnotetext{
${ }^{1}$ Reproduced with permission from J. Am. Chem. Soc. 2004, 126, 1010-1011. Copyright 2004, American Chemical Society.
} 
reactants and thereby controlled the reaction selectivity. By varying the secondary group in these bifunctionalized MSN catalysts, the selectivity of a nitroaldol reaction of two competing benzaldehydes reacting with nitromethane was investigated by measuring the molar ratio of the nitroalkene products. The selectivity of the bifunctionalized MSN catalysts could be systematically tuned simply by varying the physicochemical properties of the pore surface-bound secondary groups, i.e., polarity and hydrophobicity.

\section{Introduction}

Recent progress in functionalization of MCM and SBA types of mesoporous silicas with catalytically active groups has highlighted the potential of utilizing these structurally uniform materials as a new generation of heterogeneous catalysts with high selectivity. Several previous studies ${ }^{1}$ involved immobilization of single-site catalysts, such as transition metal complexes and Lewis or Brönsted acids and bases, onto the mesopore surfaces.

However, in contrast to zeolite-based catalysts, which utilize the "shape/size selective cavity effect", 2 the selectivity of mesoporous silica-based systems was mainly controlled by the intrinsic coordination environment of the heterogenized catalytic group. The mesoporous silica itself served only as an inert supporting matrix with large surface area, whose chemical and geometric properties were often not utilized. ${ }^{\text {la,c,g,3 } 3}$

We recently reported a new synthetic method based on co-condensation, which allowed us to functionalize mesoporous silica materials with multiple organic groups. ${ }^{4}$ By using this method, not only the loading of functional groups, but also the particle size and shape of the resulting mesoporous silicas could be controlled. ${ }^{4}$ Herein we apply the same principle to synthesize a class of bifunctionalized mesoporous silica nanosphere (MSN) 
materials, where one common functional group (primary group) served as a catalyst and the other functionality (secondary group) provided different non-covalent interactions to reactants and thereby controlled the reaction selectivity. By varying the secondary group in these bifunctionalized MSN catalysts, we investigated the selectivity of a nitroaldol (Henry) reaction of two competing benzaldehydes reacting with nitromethane by measuring the molar ratio of the nitroalkene products as depicted in Figure 1. To the best of our knowledge, this is the first demonstration of utilizing multi-functionalized mesoporous silicas as heterogeneous catalysts to control the selectivity of a competitive organic reaction.

\section{Experimental Section}

The bifunctionalized MSN materials with a common 3-[2-(2aminoethylamino)ethylamino]propyl (AEP) group and three different secondary groups, ureidopropyl (UDP), mercaptopropyl (MP), and allyl (AL) functionalities, were synthesized by introducing equal amounts of AEP-trimethoxysilane with UDP-, MP- or ALtrialkoxysilane precursors to our co-condensation reaction. ${ }^{4 a, b}$ A monofunctionalized MSN with only AEP group incorporated inside the mesoporous silica framework was also synthesized via the same method. ${ }^{4 a}$

\section{Results and Discussion}

Despite of a variation in the particle sizes, all of the organically functionalized MSNs

exhibited the same spherical particle shape (Figure 2). The XRD measurements showed large (100) peaks and broad higher diffraction patterns in all samples, typical of disordered porous structure. ${ }^{5}$ The observed $d_{100}$ values ranged between $38.4 \AA$ for sample AEP/AL-MSN and 
$41.7 \AA$ for sample AEP/UDP-MSN. The TEM study of these materials further confirmed their disordered channel structure (Figure $2 \mathrm{e}$ ). ${ }^{5}$

The $\mathrm{N}_{2}$ surface sorption analyses of these mono- and bi-functionalized MSNs showed typical type IV BET isotherms. ${ }^{5}$ The measured BET surface areas of AEP-MSN, AEP/UDPMSN, AEP/MP-MSN, and AEP/AL-MSN are $805.8,759.6,778.7$ and $703.5 \mathrm{~m}^{2} / \mathrm{g}$, respectively. Interestingly, the $\mathrm{BJH}$ pore distributions of the MSNs functionalized with hydrophilic organic groups, i.e., AEP-MSN and AEP/UDP-MSN, displayed average pore diameters of 26.0 and $22.9 \AA$, respectively, whereas functionalization with the hydrophobic functional groups (AEP/MP-MSN and AEP/AL-MSN) resulted in smaller mean pore diameters of ca. $15 \AA$, as evidenced by the TEM images. ${ }^{5}$

The structures of organic functional groups in the mesopores, their relative concentrations, and the overall surface coverages were scrutinized by ${ }^{29} \mathrm{Si} \mathrm{MAS},{ }^{29} \mathrm{Si}$ CPMAS and ${ }^{13} \mathrm{C}$ CPMAS solid-state NMR spectroscopy. ${ }^{5}$ The ${ }^{29} \mathrm{Si}$ and ${ }^{13} \mathrm{C}$ NMR spectra confirmed the successful functionalization of MSNs. The resulting materials were surfactantfree. The ${ }^{29}$ Si resonances were observed at positions typical of silicon groups $Q^{n}$ $\left((\equiv \mathrm{SiO})_{n} \mathrm{Si}(\mathrm{OH})_{4-n}\right.$, where $n$ is 2,3 , or 4$)$ and $T^{n}\left((\equiv \mathrm{SiO})_{n} \mathrm{Si}(\mathrm{OH})_{4-n} \mathrm{R}\right.$, where $n$ is 2 or 3$) .{ }^{5,6}$ The ${ }^{13} \mathrm{C}$ peaks (Figure 3) were assigned based on the solution spectra of the corresponding precursors and on our earlier study of AEP-, AL- and UDP-MSN's. ${ }^{4 a}$ Also detailed in the Supporting Information are the quantitative ${ }^{13} \mathrm{C}$ and ${ }^{29} \mathrm{Si}$ measurements, which showed that all MSNs contained approximately equal total amounts of organic functional groups (1.0 $\mathrm{mmol} / \mathrm{g}$ in AEP/UDP-MSN, $1.4 \mathrm{mmol} / \mathrm{g}$ in AEP/MP-MSN and $1.3 \mathrm{mmol} / \mathrm{g}$ in AEP/ALMSN). This corresponded to $15 \%, 25 \%$ and $23 \%$, respectively, of surface silicon atoms being involved in Si-C bonds. Furthermore, the relative molar concentrations between AEP and the 
secondary groups were very similar $(1.17,1.04$ and 1.13 for AEP/UDP-MSN, AEP/MP-MSN and AEP/AL-MSN). ${ }^{5}$

As demonstrated in recent literature reports, ${ }^{7} \mathrm{MCM}-41$ silicas grafted with amines or polyamines could effectively catalyze nitroaldol reactions to produce nitroalkenes in high yields, whereas the pure inorganic MCM-41 silica gave rise to only small amounts of $\beta$ nitroalcohol intermediates. To investigate how the secondary functional groups of our bifunctionalized MSN catalysts could influence the reaction selectivity, three series of competitive nitroaldol reactions were performed by introducing equal molars of 4hydroxybenzaldehyde (1) and one of the three different alkoxybenzaldehydes $(2,3$ and 4$)$ to nitromethane solutions of a chosen bifunctional MSN. By analyzing the molar ratios between products $(10 / 9,11 / 9$, and $12 / 9)$, we observed that the mono-functionalized AEP-MSN and the bydrophilic bi-functionalized AEP/UDP-MSN catalysts did not show any reaction selectivity for all three combinations of the reactants as shown in Figure 4 and the Supporting Information. However, an increase of reaction selectivity towards the nonpolar and more hydrophobic alkoxybenzaldehyde reactants $(2,3$, and 4$)$ was clearly observed in the cases of AEP/MP-MSN and AEP/AL-MSN catalysts, where the catalytic AEP groups are situated in mesopores decorated with hydrophobic groups. The hydrophobic nature of MP and AL is corroborated by the low dielectric constants of propanethiol (5.94) and propene (2.14) around room temperature. ${ }^{5}$ The AEP/AL-MSN displayed the highest reactant selectivity toward alkoxybenzaldehydes. For example, a molar product ratio (12/9) of 2.58 (Figure 4) was reached when 4-n-octyloxybenzaldehyde (4) was used in competition with 4hydroxybenzaldehyde (1) indicating the high selectivity of AEP/AL-MSN catalyst toward the nonpolar reactant. The results suggested that the hydrophobic secondary groups (MP and 
AL) played a significant role in preferentially allowing the more hydrophobic reactants to penetrate into the mesopores and react with the AEP functionality. To demonstrate this hydrophobic solvation effect, $1 \mathrm{mmol}$ of reactants 1 and 4 were introduced to $1 \mathrm{~mL}$ of propanethiol to simulate the penetration/dissolution of these substituted benzaldehydes with different polarities ${ }^{5}$ into the mercaptopropyl-functionalized mesopores. The fact that the more polar reactant 1 was insoluble in propanethiol, whereas compound 4 was completely miscible with propanethiol, indicated that the selectivity of our catalysts most likely originated from the variation of the physicochemical properties of the bifunctionalized mesopores, i.e. polarity and hydrophobicity.

\section{Acknowledgement}

This research was supported at Ames Laboratory by the U.S. DOE, office of BES, under contract W-7405-Eng-82 and by the NSF (CHE-0239570). 
Figure 1. Competitive nitroaldol reaction. Reaction condition: $50 \mathrm{mg}$ MSN catalyst, $10 \mathrm{~mL}$ $\mathrm{CH}_{3} \mathrm{NO}_{2}, 5.0 \mathrm{mmol}$ aldehydes, $263 \mathrm{~K}$ for $24 \mathrm{~h}$.

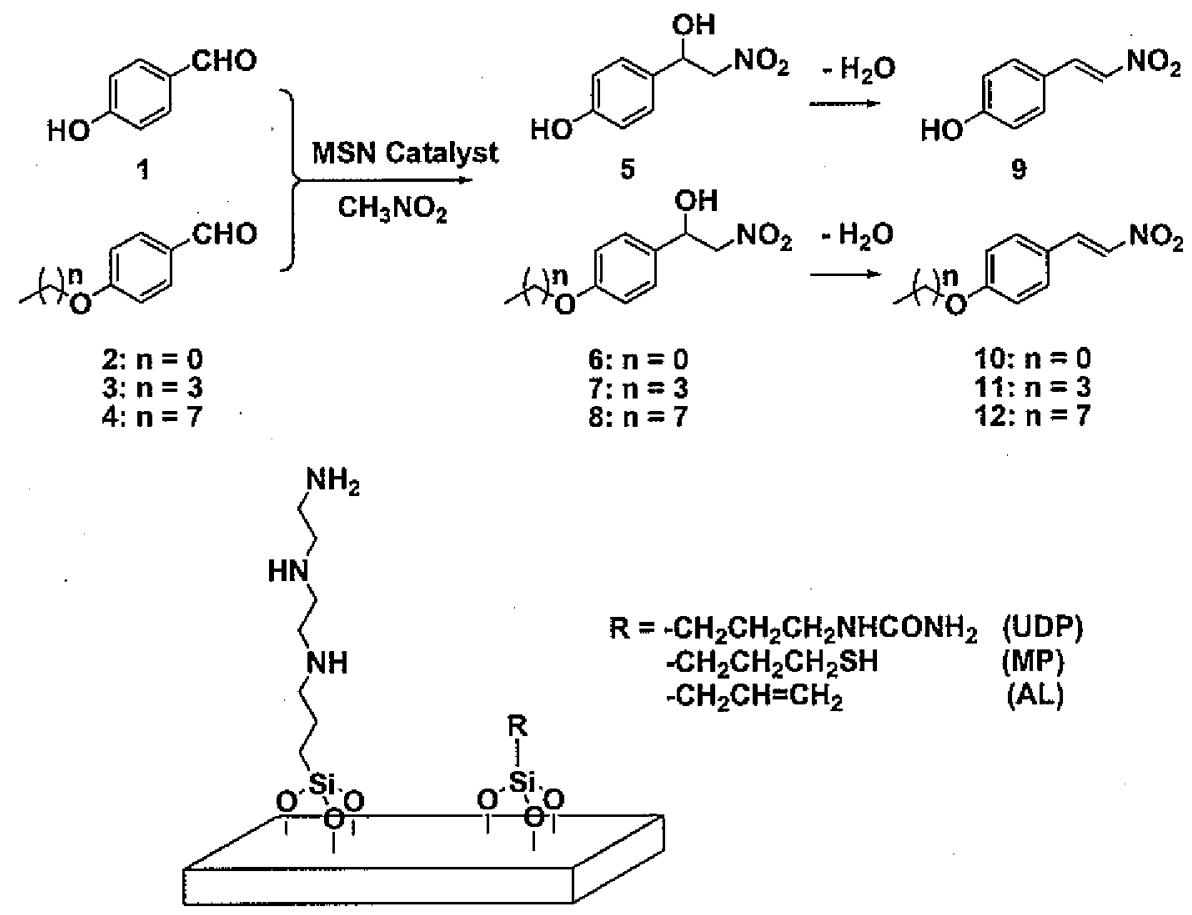


Figure 2. FE-SEM images of (a) AEP/UDP-MSN (0.7 1.3 $\mu \mathrm{m}$ ), (b) AEP/MP-MSN (0.7 1.6 $\mu \mathrm{m})$, (c) AEP/AL-MSN $(0.2 \sim 0.7 \mu \mathrm{m})$, and (d) AEP-MSN $(0.8 \sim 2.1 \mu \mathrm{m})$. TEM micrograph of the ultramicrotomed sample (60 to $90 \mathrm{~nm}$ thickness) of AEP/AL-MSN (e). Scale bar is $3 \mu \mathrm{m}$ for the (a-d) micrographs and $100 \mathrm{~nm}$ for the (e) micrograph.
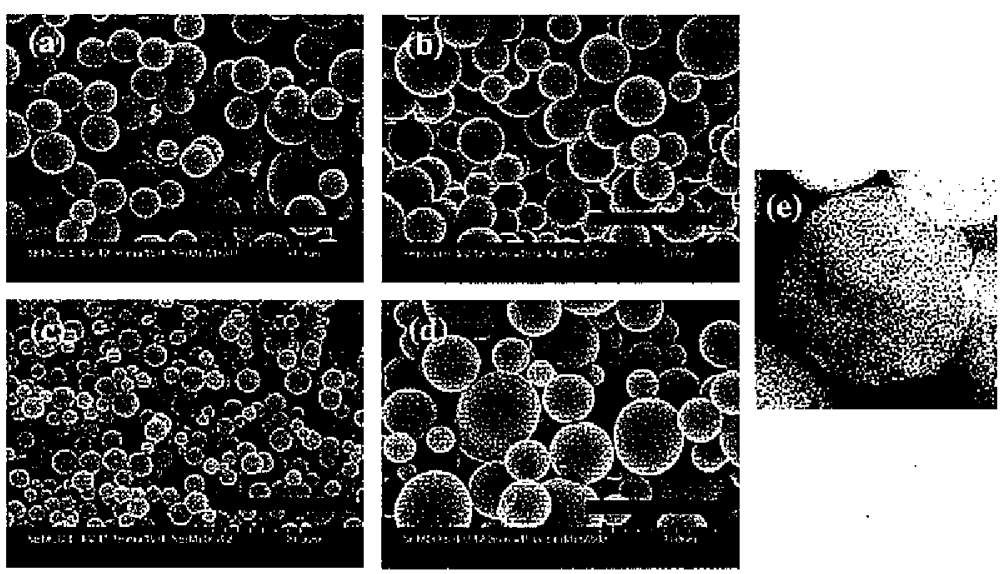
Figure 3. ${ }^{13} \mathrm{C}$ CPMAS spectra of (a) AEP, (b) AEP/UDP, (c) AEP/MP, (d) AEP/AL-MSN. Only the resonances due to secondary groups are marked in spectra (b)-(d).

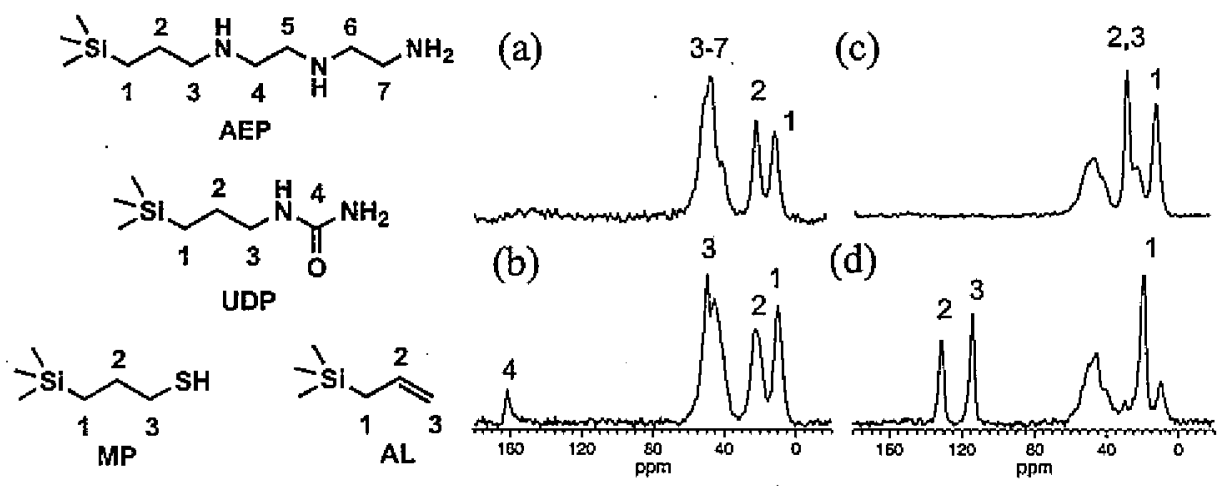


Figure 4. Histogram of the competitive nitroaldol reactions. Blue bars: Yield of 9 (mmol); Red bars: Yield of 10,11 , or 12 (mmol); White bars: Molar ratio of products $(10 / 9,11 / 9$, or 12/9). Series 1,2 , and 3 are experiments conducted with reactants $1 \& 2,1 \& 3$, and $1 \& 4$, respectively.

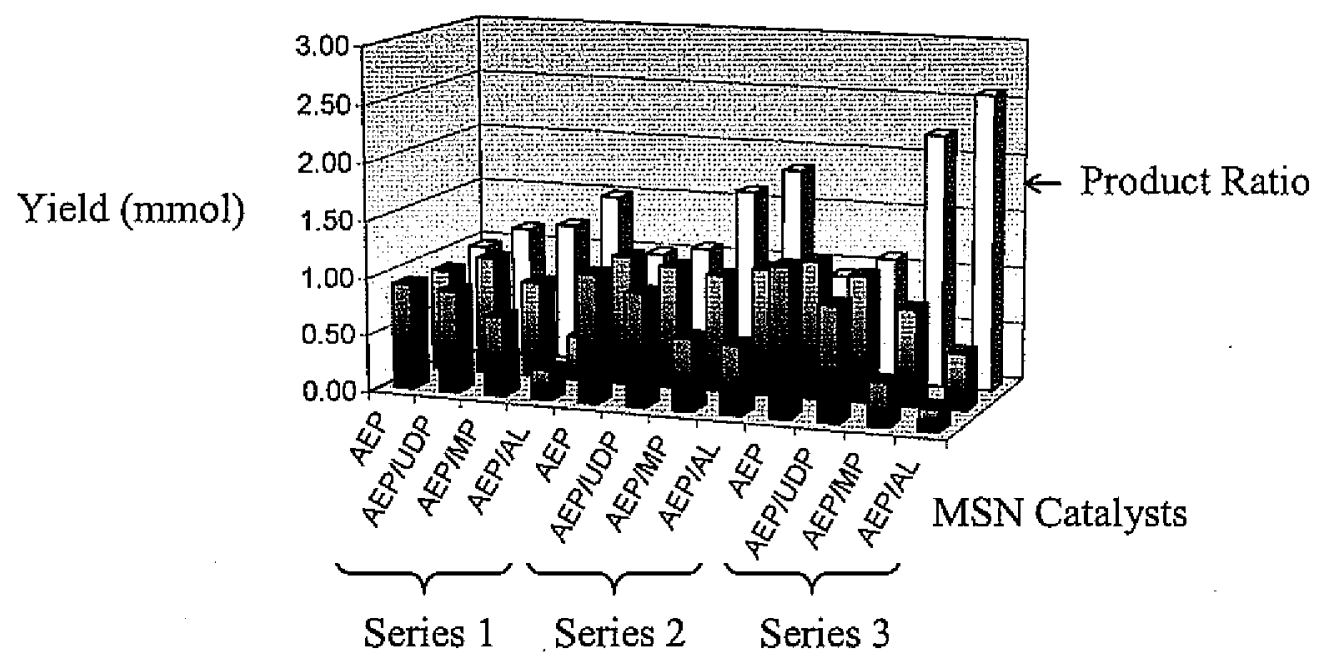




\section{References}

1. (a) Clark, J. H. Acc. Chem. Res. 2002, 35, 791-797. (b) Davis, M. E. Nature (London) 2002, 417, 813-821. (c) Corma, A.; Garcia, H. Chem. Rev. 2003, 103, 4307-4365. (d) Ying, J. Y.; Mehnert, C. P.; Wong, M. S. Angew. Chem., Int. Ed. Engl. 1999, 38, 56-77. (e) Mehnert, C. P.; Weaver, D. W.; Ying, J. Y. J. Am. Chem. Soc. 1998, 120, 1228912296. (f) Liu, Y.; Pinnavaia, T. J. J. Am. Chem. Soc. 2003, 125, 2376-2377, and the references therein.

2. (a) Flanigen, E. M.; Bennett, J. M.; Grose, R. W.; Cohen, J. P.; Patton, R. L.; Kirchner, R. M.; Smith, J. V. Nature (London) 1978, 271, 512-516. (b) Dubbeldam, D.; Calero, S.; Maesen, T. L. M.; Smit, B. Angew. Chem., Int. Ed. Engl. 2003, 42, 3624-3626.

3. (a) Jones, M. D.; Raja, R.; Thomas, J. M.; Johnson, B. F. G.; Lewis, D. W.; Rouzaud, J.; Harris, K. D. M. Angew. Chem., Int. Ed. Engl. 2003, 42, 4326-4331. (b) Kageyama, K.; Tamazawa, J.-I.; Aida, T. Science (Washington, D. C.) 1999, 285, 2113-2115.

4. (a) Huh, S.; Wiench, J. W.; Yoo, J.-C.; Pruski, M.; Lin, V. S. Y. Chem. Mater. 2003, 15, 4247-4256. (b) Huh, S.; Wiench, J. W.; Trewyn, B. G.; Song, S.; Pruski, M.; Lin, V. S. Y. Chem. Commun. 2003, 2364-2365. (c) Lai, C.-Y.; Trewyn, B. G.; Jeftinija, D. M.; Jeftinija, K.; Xu, S.; Jeftinija, S.; Lin, V. S. Y. J. Am. Chem. Soc. 2003, 125, 4451-4459. (d) Lin, V. S. Y.; Radu, D. R.; Han, M.-K.; Deng, W.; Kuroki, S.; Shanks, B. H.; Pruski, M. J. Am. Chem. Soc. 2002, 124, 9040-9041. (e) Lin, V. S. Y.; Lai, C.-Y.; Huang, J.; Song, S.-A.; Xu, S. J. Am. Chem. Soc. 2001, 123, 11510-11511.

5. See Supporting Information for details.

6. Maciel, G. E. In Encyclopedia of Nuclear Magnetic Resonance; Grant, D. M., Harris, R. K., Eds.; John Wiley \& Sons Ltd: Chichester, 1996; Vol. 7, pp 4370-4386. 
7. (a) Kantam, M. L; Sreekanth, P. Catal. Lett. 1999, 57, 227-231. (b) Demicheli, G.; Maggi, R.; Mazzacani, A.; Righi, P.; Sartori, G.; Bigi, F. Tetrahedron Lett. 2001, 42, 2401-2403. 
Supporting Information of $J$. Am. Chem. Soc. 2004, 126, 1010-1011

\section{Synthesis of mono- and bi-functionalized MSN materials}

The functionalized materials were synthesized via the previously described cocondensation reaction. ${ }^{1,2}$ An example of the specific procedure, used for preparation of bifunctionalized MSN materials, such as AEP/UDP-MSN material which has equimolar ratio of 3-[2-(2-aminoethylamino)ethylamino]propyl (AEP) and 3-ureidopropyl (UDP) groups, is given below. A mixture of CTAB $(2.0 \mathrm{~g}, 5.49 \mathrm{mmol}), 2.0 \mathrm{M}$ of $\mathrm{NaOH}(\mathrm{aq})(7.0 \mathrm{~mL}, 14.0$ mmol) and $\mathrm{H}_{2} \mathrm{O}(480 \mathrm{~g}, 26.67 \mathrm{~mol})$ was heated at $80^{\circ} \mathrm{C}$ for $30 \mathrm{~min}$. To this clear solution, TEOS (9.34 g, $44.8 \mathrm{mmol})$, AEPTMS (0.76 g, $2.88 \mathrm{mmol}$ ), and UDPTMS (0.64 g, 2.88 mmol) were added rapidly and sequentially via injection, yielding an opaque reaction mixture. The white solid products of synthesis were observed after vigorous (550 rpm) stirring of the mixture for $\sim 2 \mathrm{~min}$. The as-synthesized bifunctionalized mesoporous materials were obtained after additional 2 hours of heating at $80^{\circ} \mathrm{C}$, followed by hot filtration, washing with copious amount of water and methanol, and drying under vacuum. An acid extraction of the $\mathrm{CTAB}$ surfactant was performed at $50^{\circ} \mathrm{C}$, by placing $1.0 \mathrm{~g}$ of the as-synthesized material in a mixture of methanol $(100 \mathrm{~mL})$ and bydrochloric acid $(0.3 \sim 0.5 \mathrm{~mL})$ for $1.5 \sim 2 \mathrm{~h}$. The resulting surfactant-removed solid products were filtered and washed with water and methanol and then dried under vacuum for $3 \mathrm{~h}$ at $90^{\circ} \mathrm{C}$.

\section{Competitive catalytic nitroaldol reactions}

All the chemicals were purchased from Aldrich and used without further purification. The reaction was performed in the presence of equimolar ratio amounts of two different 
aldehydes in a capped vial. Reagent grade nitromethane was used without any purification. For example, the reaction mixture consisting of $50 \mathrm{mg}$ of the mesoporous silica catalyst, $0.300 \mathrm{~g}(2.5 \mathrm{mmol})$ of $p$-tolualdehyde and $0.305 \mathrm{~g}(2.5 \mathrm{mmol})$ of $p$-hydroxybenzaldehyde in $10 \mathrm{~mL}$ of nitromethane, was heated at $90^{\circ} \mathrm{C}$ with a constant stirring for $24 \mathrm{~h}$. The reaction mixture was filtered on a glass frit and the solids were washed with chloroform. The resultant filtrate was evaporated on a rotary evaporator. The residue was completely dissolved in a sufficient amount of acetone- $d_{6}$. An internal standard, THF (ca. $10 \mathrm{mmol}$ ), was added into the acetone- $d_{6}$ solution. Analysis of the product was performed by measuring ${ }^{1} \mathrm{H}$ NMR spectra on a Bruker DRX400 NMR spectrometer. All combinations of two different sets of products gave distinctive vinylic proton chemical shifts for the integrations. Assignments of the peaks were performed by comparing the chemical shifts of the products with the authentic samples, which were independently prepared using AEP/UDP-MSN material under the similar reaction condition and purified by silica gel column chromatography. 
Table S1. Results of competitive nitroaldol reactions by mono- and bi-functionalized MSN catalysts.

\begin{tabular}{|c|c|c|c|c|c|}
\hline \multirow{2}{*}{ Catalyst } & \multicolumn{2}{|c|}{ Product A } & \multicolumn{2}{|c|}{ Product B } & \multirow{2}{*}{ Product Ratio $\mathrm{B} / \mathrm{A}$} \\
\hline & Yield, mmol & Turnover $^{[\mathrm{a}]}$ & Yield, mmol & Turnover $^{[\mathrm{a}]}$ & \\
\hline \multicolumn{6}{|l|}{ Series 1} \\
\hline AEP & 0.92 & 18.4 & 0.89 & 17.8 & 0.97 \\
\hline AEP/UDP & 0.89 & 33.0 & 1.03 & 38.1 & 1.16 \\
\hline AEP/MP & 0.69 & 18.9 & 0.84 & 23.0 & 1.22 \\
\hline $\mathrm{AEP} / \mathrm{AL}$ & 0.26 & 7.5 & 0.39 & 11.3 & 1.50 \\
\hline \multicolumn{6}{|l|}{ Series 2} \\
\hline AEP & 1.12 & 22.4 & 1.13 & 22.6 & 1.01 \\
\hline $\mathrm{AEP} / \mathrm{UDP}$ & 0.99 & 36.7 & 1.07 & 39.6 & 1.08 \\
\hline AEP/MP & 0.63 & 17.3 & 1.02 & 27.9 & 1.62 \\
\hline AEP/AL & 0.60 & 17.4 & 1.10 & 31.9 & 1.83 \\
\hline \multicolumn{6}{|l|}{ Series 3} \\
\hline AEP & 1.30 & 26.0 & 1.20 & 24.0 & 0.92 \\
\hline AEP/UDP & 1.00 & 37.0 & 1.10 & 40.7 & 1.10 \\
\hline AEP/MP & 0.38 & 10.4 & 0.84 & 23.0 & 2.21 \\
\hline AEP/AL & 0.19 & 5.5 & 0.49 & 14.2 & 2.58 \\
\hline \multicolumn{6}{|l|}{ Series 4} \\
\hline AEP & 1.37 & 27.4 & 1.08 & 21.6 & 0.79 \\
\hline AEP/UDP & 1.11 & 41.1 & 1.03 & 38.1 & 0.93 \\
\hline $\mathrm{AEP} / \mathrm{MP}$ & 0.89 & 24.4 & 0.89 & 24.4 & 1.00 \\
\hline $\mathrm{AEP} / \mathrm{AL}$ & 0.32 & 9.3 & 0.37 & 10.7 & 1.16 \\
\hline \multicolumn{6}{|l|}{ Series 5} \\
\hline AEP & 1.05 & 21.0 & 0.92 & 18.4 & 0.88 \\
\hline AEP/UDP & 0.97 & 35.9 & 0.89 & 33.0 & 0.91 \\
\hline AEP/MP & 0.65 & 17.8 & 0.69 & 18.9 & 1.06 \\
\hline $\mathrm{AEP} / \mathrm{AL}$ & 0.57 & 16.5 & 0.88 & 25.5 & 1.54 \\
\hline
\end{tabular}

[a] Turnover $=\mathrm{mmol}$ product $/ \mathrm{mmol}$ catalyst during $24 \mathrm{~h}$ of reaction time. 


\section{Summary of solid-state NMR measurements}

\section{1. Experimental}

Solid-state NMR spectra were obtained at $100.59\left({ }^{13} \mathrm{C}\right)$ and $79.47 \mathrm{MHz}\left({ }^{29} \mathrm{Si}\right)$ on a Varian/Chemagnetics Infinity spectrometer, equipped with a doubly tuned, $5 \mathrm{~mm}$ magic angle spinning (MAS) probe. Direct polarization (DP) and variable amplitude cross polarization (CP) methods were used under the conditions described earlier. ${ }^{1,2}$ These measurements provided quantitative evidence for functionalization of the mesopores with the organic moieties and confirmed their structure. For AEP-, UDP-, AL-, AEP/UDP- and AEP/AL-MSN's, the assignments of ${ }^{29} \mathrm{Si}$ and ${ }^{13} \mathrm{C}$ NMR spectra were made following our earlier study (see Figures S1 and S2). ${ }^{2}$ The interpretation of ${ }^{13} \mathrm{C}$ spectra of samples containing mercaptopropyl (MP-MSN and AEP/MP-MSN) was also straightforward (see Figure S1 c). We note the presence of small concentration of methoxy groups in the MPMSN sample. Similar spectrum of MP-functionalized silica was earlier reported by Maciel et al. ${ }^{3}$ The methods used for quantitative measurements of ${ }^{29} \mathrm{Si}$ and ${ }^{13} \mathrm{C}$ intensities are detailed in Sections 3.2 and 3.3 below. All NMR results are summarized in Table 1, which contains the relative concentrations of $T^{n}$ and $Q^{n}$ groups, the molar concentrations of organic functional groups and the corresponding average molecular formulae.

\subsection{Quantification of silicon groups}

Relative concentrations of $T^{n}$ and $Q^{n}$ silicon groups ${ }^{4}$ were obtained from the analysis of ${ }^{29} \mathrm{Si}$ DPMAS spectra. In agreement with our earlier results, the measurements of $T_{1}$ relaxation in AL-MSN and 3-cyanopropyl-MSN (CP-MSN) systems, yielded $T_{\mathrm{I}}$ values on 
the order of 50 to $65 \mathrm{~s}$ for $T^{n}$ groups and 30 to $45 \mathrm{~s}$ for $Q^{n}$ groups. $^{2}$ Therefore, a delay of 300 $s$ between scans has been used during the acquisition of ${ }^{29} \mathrm{Si} \mathrm{NMR} \mathrm{spectra.} \mathrm{The} \mathrm{accumulation}$ of 270 scans yielded intensities that were accurate within $\pm 5 \%$.

\subsection{Quantification of functional groups in bifunctionalized samples using ${ }^{13} \mathrm{C}$ NMR}

Although direct polarization is the preferred method for quantitative measurements,

${ }^{13} \mathrm{C}$ intensities were compared using a CPMAS-based method. The following strategy, which proved reliable in our earlier study, ${ }^{1}$ was developed in order to speed up the measurements and eliminate the probe background. In short, the time evolution of each carbon magnetization during the CPMAS experiment is a result of complicated interplay between the spin-lattice relaxation processes in the rotating frame, described by relaxation time $T_{1 \rho}{ }^{H}$, and cross polarization kinetics described by cross polarization time $\tau_{C H}$. For example, the cross polarization kinetics for AEP-MSN and CP-MSN revealed different values of $T_{\mathrm{l} \rho}{ }^{H}$ and $\tau_{C H}$ times. ${ }^{1}$ The AEP moieties were rigidly bound with $\tau_{C H}$ values on the order of $60 \mu \mathrm{s}$ for all carbons. For the $\mathrm{CP}$ groups, $\tau_{C H}$ values increased from $60 \mu \mathrm{s}$ at the point of attachment to the surface (carbon $\mathrm{C} 1$ ) to $5 \mathrm{~ms}$ for the nitrile carbon (C4), which reflected increasing mobility toward the end of the chain. Other samples, AL-MSN, UDP-MSN, and MP-MSN, exhibited $\tau_{C H}$ time constants between $60 \mu \mathrm{s}$ and $2 \mathrm{~ms}$. Our measurements also showed that in the bifunctionalized samples the relaxation parameters were the same, within the experimental error, as for the corresponding carbon species in the samples containing only one type of moieties. Thus, by properly measuring the spectra of known physical mixtures of mono-functionalized samples as intensity standards, the bifunctionalized samples could be 
quantitatively characterized without the tedious measurements of the ${ }^{13} \mathrm{C}$ build-up curves. ${ }^{1}$ In case of AEP/CP-MSN, the studies were performed using resonances at $48 \mathrm{ppm}$ (AEP) and $120 \mathrm{ppm}(\mathrm{CP})$, because they were easily distinguishable in the corresponding spectra. Similar method was used in current report for AEP/UDP-, AEP/MP-, and AEP/AL-MSN systems.

Table S2. Relative concentrations of $T^{n}$ and $Q^{n}$ silicon groups (in \%), surface coverage (SC, in \%), molecular concentrations of organic functionalities $(M C$, in mmol $/ \mathrm{g}$ ), molecular formulae $(M F)$, molar ratios in bifunctional samples, and amounts (in mmol/g) of each organic functionality derived from solid state ${ }^{13} \mathrm{C} \mathrm{CPMAS}$ and ${ }^{29} \mathrm{Si}$ DPMAS NMR data.

\begin{tabular}{|c|c|c|c|c|c|c|c|c|c|c|}
\hline Functionality & $T^{2}$ & $T^{3}$ & $Q^{2}$ & $Q^{3}$ & $Q^{4}$ & $S C$ & $M C$ & $M F$ & Ratios & Amounts \\
\hline $\mathrm{AEP}^{(\mathrm{a})}$ & 1 & 6 & 3 & 35 & 55 & 16 & 1.0 & $\left(\mathrm{SiO}_{2}\right)_{100}\left(\mathrm{H}_{2} \mathrm{O}\right)_{17.5}(\mathrm{ORG})_{7}{ }^{(\mathrm{b})}$ & & \\
\hline $\mathrm{AL}^{(\mathrm{a})}$ & 3 & 8 & 1 & 24 & 64 & 31 & $1: 7$ & $\left(\mathrm{SiO}_{2}\right)_{100}\left(\mathrm{H}_{2} \mathrm{O}\right)_{9}(\mathrm{ORG})_{\mathrm{t}}$ & & \\
\hline MP & 3 & 9 & 3 & 28 & 57 & 26 & 1.6 & $\left(\mathrm{SiO}_{2}\right)_{100}\left(\mathrm{H}_{2} \mathrm{O}\right)_{12.5}(\mathrm{ORG})_{12}$ & & \\
\hline $\mathrm{UDP}^{(\mathrm{a})}$ & 2 & 4 & 4 & 38 & 52 & 13 & 0.9 & $\left(\mathrm{SiO}_{2}\right)_{100}\left(\mathrm{H}_{2} \mathrm{O}\right)_{21}(\mathrm{ORG})_{6}$ & & \\
\hline \multirow[t]{2}{*}{ AEP/UDP } & 2 & 5 & 3 & 36 & 54 & 15 & 1.0 & $\left(\mathrm{SiO}_{2}\right)_{100}\left(\mathrm{H}_{2} \mathrm{O}\right)_{18.5}(\mathrm{ORG})_{7}$ & $5.4: 4.6$ & AEP: 0.54 \\
\hline & & & & & & & & & & UDP: 0.46 \\
\hline \multirow[t]{2}{*}{ AEP/MP } & 2 & 8 & 2 & 28 & 60 & 25 & 1.4 & $\left(\mathrm{SiO}_{2}\right)_{100}\left(\mathrm{H}_{2} \mathrm{O}\right)_{12}(\mathrm{ORG})_{10}$ & $5.1: 4.9$ & AEP: 0.71 \\
\hline & & & & & & & & & & MP: 0.69 \\
\hline \multirow[t]{2}{*}{$\mathrm{AEP} / \mathrm{AL}$} & 2 & 7 & 2 & 28 & 61 & 23 & 1.3 & $\left(\mathrm{SiO}_{2}\right)_{100}\left(\mathrm{H}_{2} \mathrm{O}\right)_{12.5}(\mathrm{ORG})_{9}$ & $5.3: 4.7$ & AEP: 0.69 \\
\hline & & & & & & & & & & AL: 0.61 \\
\hline
\end{tabular}

(a) Data taken from ref 2. (b) 'ORG' denotes the concentration of the corresponding organic moieties in each sample. 
Figure $\mathrm{S} 1 .{ }^{29} \mathrm{Si}$ DPMAS (left column), ${ }^{1} \mathrm{H} \rightarrow{ }^{29} \mathrm{Si}$ CPMAS (middle column), and ${ }^{1} \mathrm{H} \rightarrow{ }^{13} \mathrm{C}$ CPMAS (right column) spectra obtained for monofunctionalized mesoporous materials: AEP-MSN (a), AL-MSN (b), MP-MSN (c), and UDP-MSN (d).
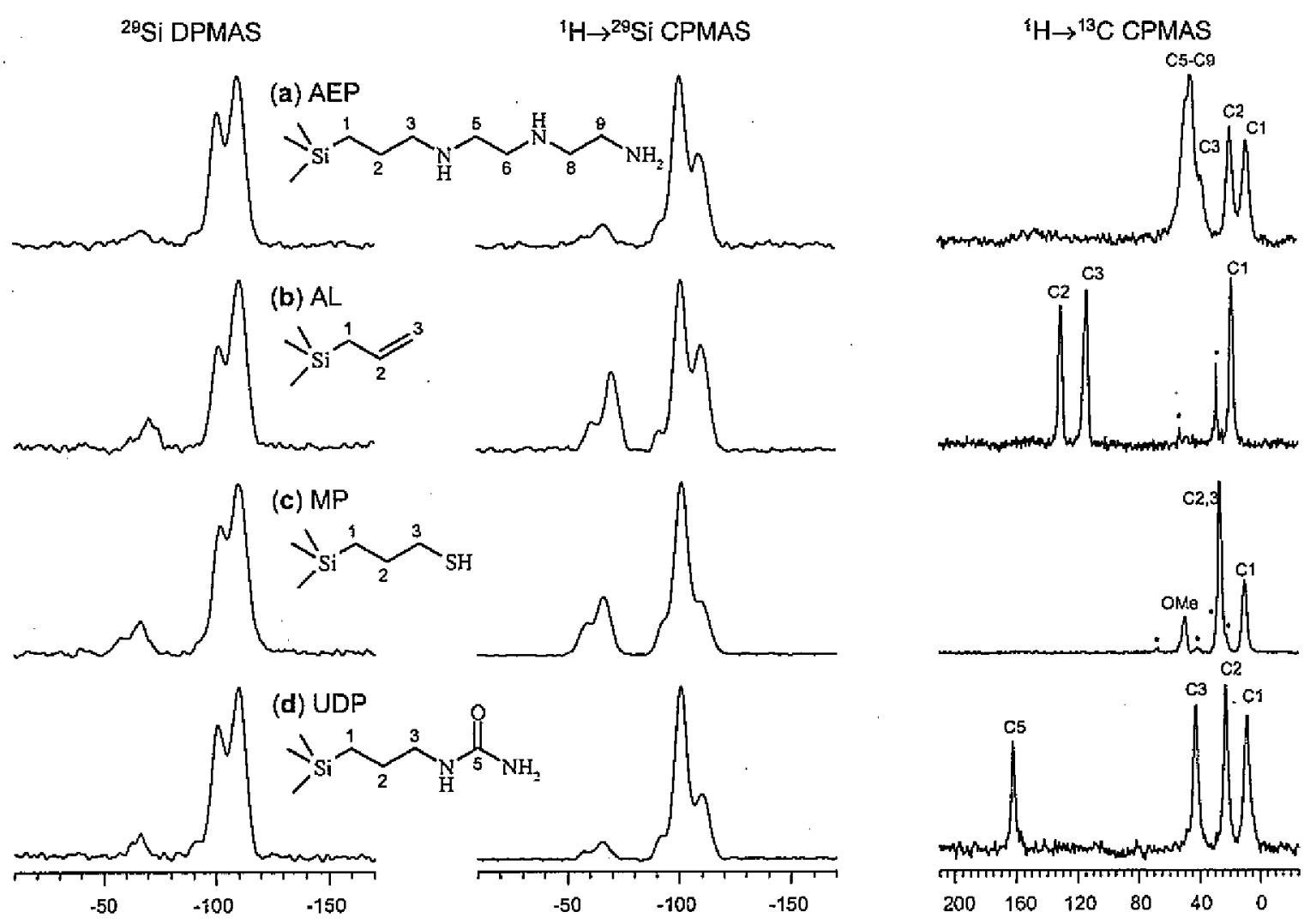
Figure S2. ${ }^{29} \mathrm{Si}$ DPMAS (left column), ${ }^{1} \mathrm{H} \rightarrow{ }^{29} \mathrm{Si}$ CPMAS (middle column), and ${ }^{1} \mathrm{H} \rightarrow{ }^{13} \mathrm{C}$ CPMAS (right column) spectra obtained for bifunctionalized mesoporous silica materials: AEP/AL-MSN (a), AEP/MP-MSN (b), and AEP/UDP-MSN (c).
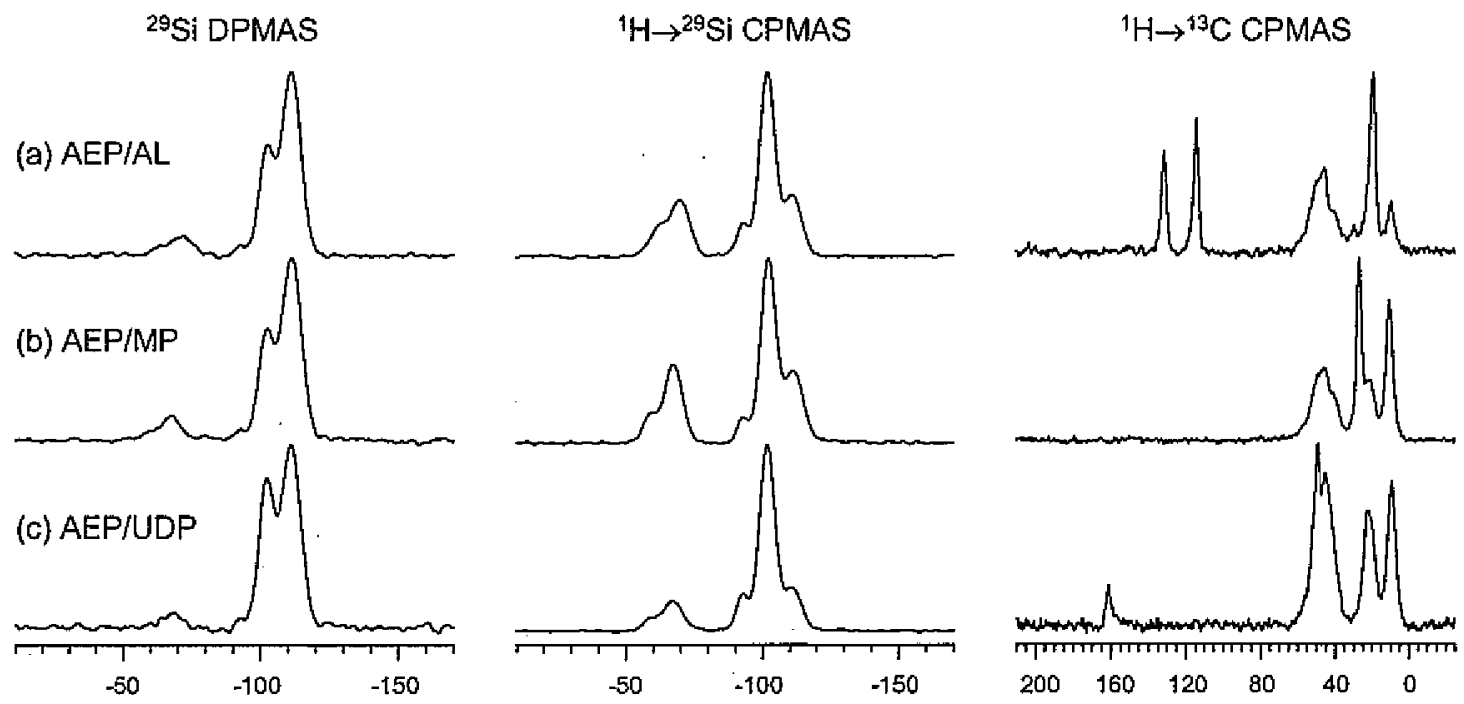
Figure S3. FE-SEM images of MSN materials (Hitachi S4700).

(a) AEP-MSN

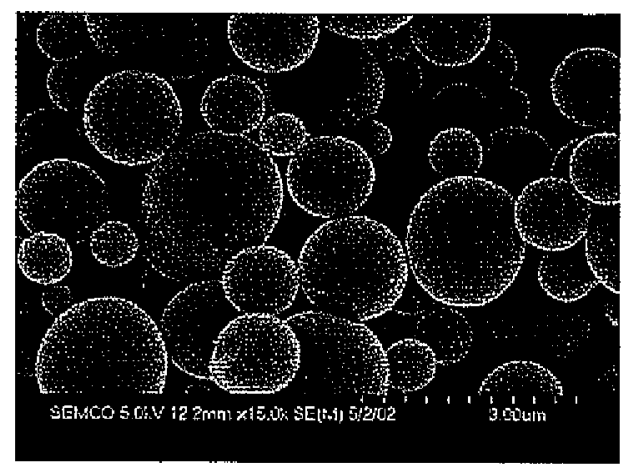

(c) AEP/MP-MSN

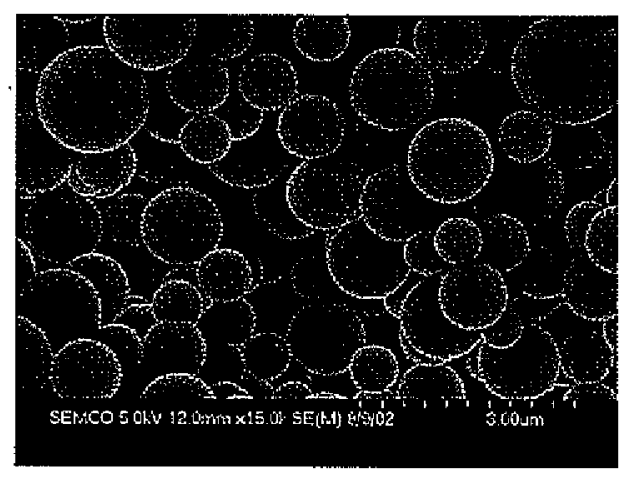

(b) AEP/UDP-MSN

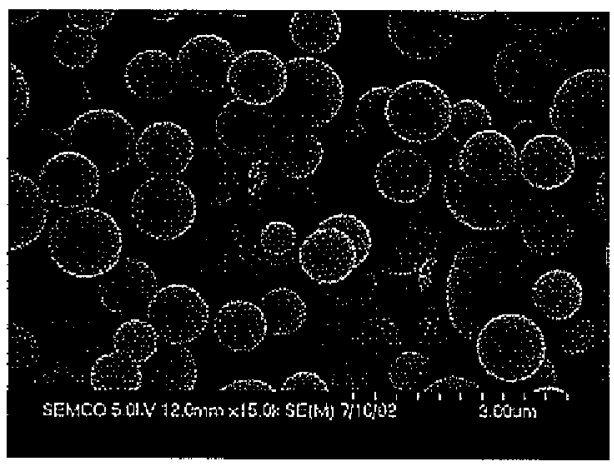

(d) AEP/AL-MSN

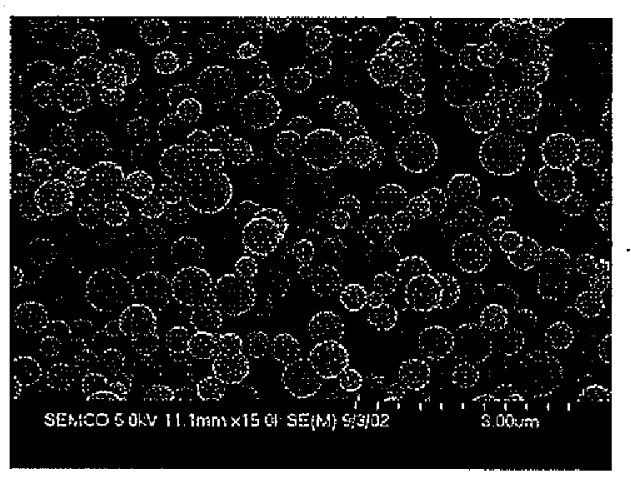


Figure S4. TEM micrographs of ultramicrotomed MSN materials (300 kV).

(a) AEP-MSN

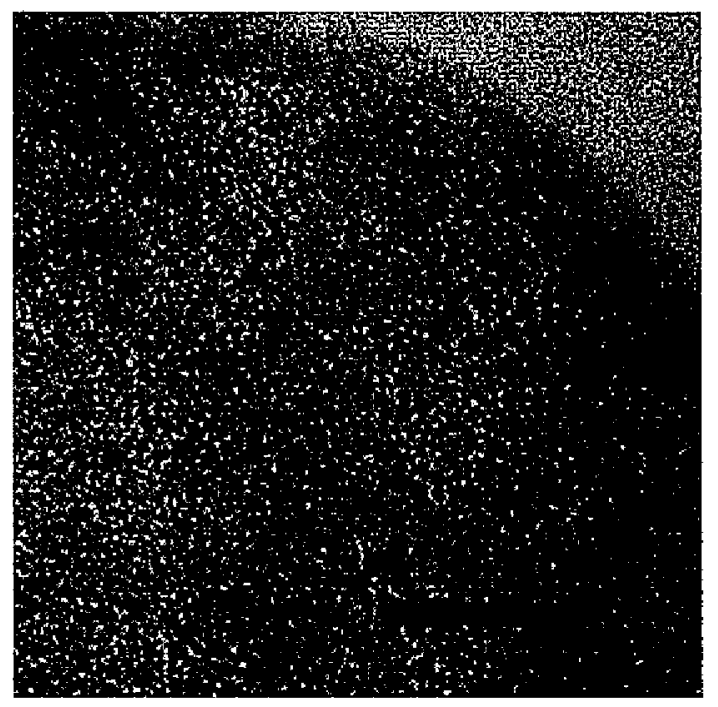

(b) AEP/AL-MSN

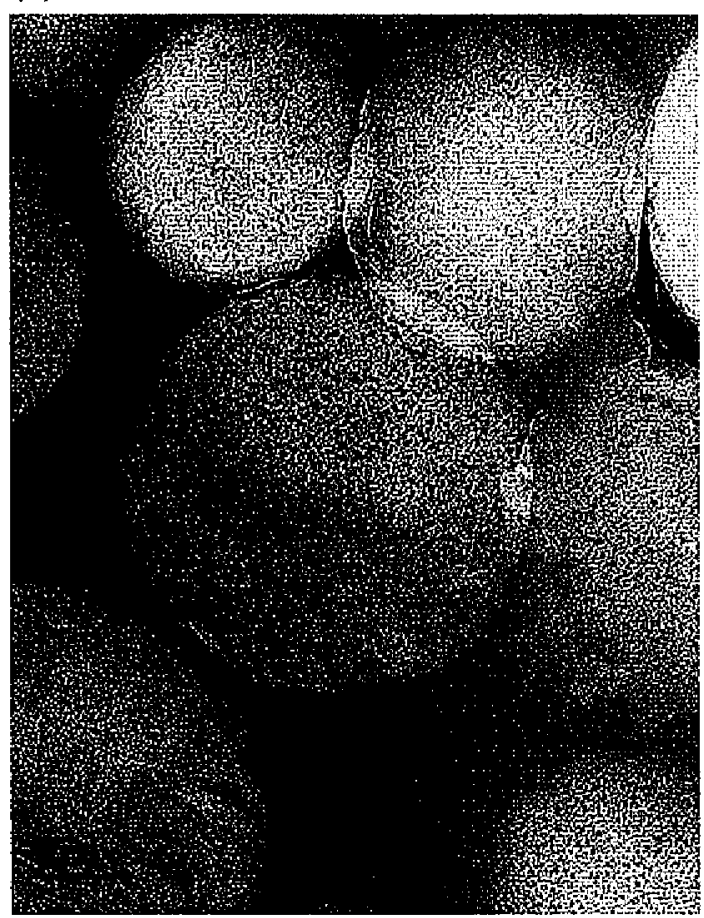

Table S3. Structural properties of the surfactant-free MSN materials. ${ }^{[a]}$

\begin{tabular}{ccccccc}
\hline Samples & $d_{100}(\AA)$ & $a_{0}(\AA)$ & $S_{\mathrm{BET}}\left(\mathrm{m}^{2} / \mathrm{g}\right)$ & $V_{\mathrm{p}}\left(\mathrm{cm}^{3} / \mathrm{g}\right)$ & $W_{\mathrm{BJH}}(\AA)$ & $\begin{array}{c}d_{\text {pore wall }} \\
(\AA)\end{array}$ \\
\hline AEP-MSN & 38.4 & 44.4 & 805.8 & 0.57 & 26.0 & 18.4 \\
AEP/UDP-MSN & 41.7 & 48.2 & 759.6 & 0.47 & 22.9 & 25.3 \\
AEP/MP-MSN & 39.1 & 45.1 & 778.7 & 0.39 & - & - \\
AEP/AL-MSN & 38.4 & 44.4 & 703.5 & 0.40 & - & - \\
\hline
\end{tabular}

[a] The BET surface area $\left(S_{\mathrm{BET}}\right)$, the mesopore volume $\left(V_{\mathrm{p}}\right)$, and the mean mesopore size $\left(W_{\mathrm{BJH}}\right)$ were obtained from the nitrogen adsorption/desorption data. The $d_{100}$ numbers represent the $d$-spacing corresponding to the main (100) XRD peak. The unit cell size $\left(a_{0}\right)$ is calculated from the $d_{100}$ data using $a_{0}=2 d_{100} / 3^{1 / 2}$. The pore wall thickness $\left(d_{\text {pore wall }}=a_{0}-\right.$ $\left.W_{\mathrm{BJH}}\right)$. 
Figure S5. Powder XRD data of the MSN materials: (a) AEP-, (b) AEP/UDP-, (c) AEP/MP-, (d) AEP/AL-MSN.

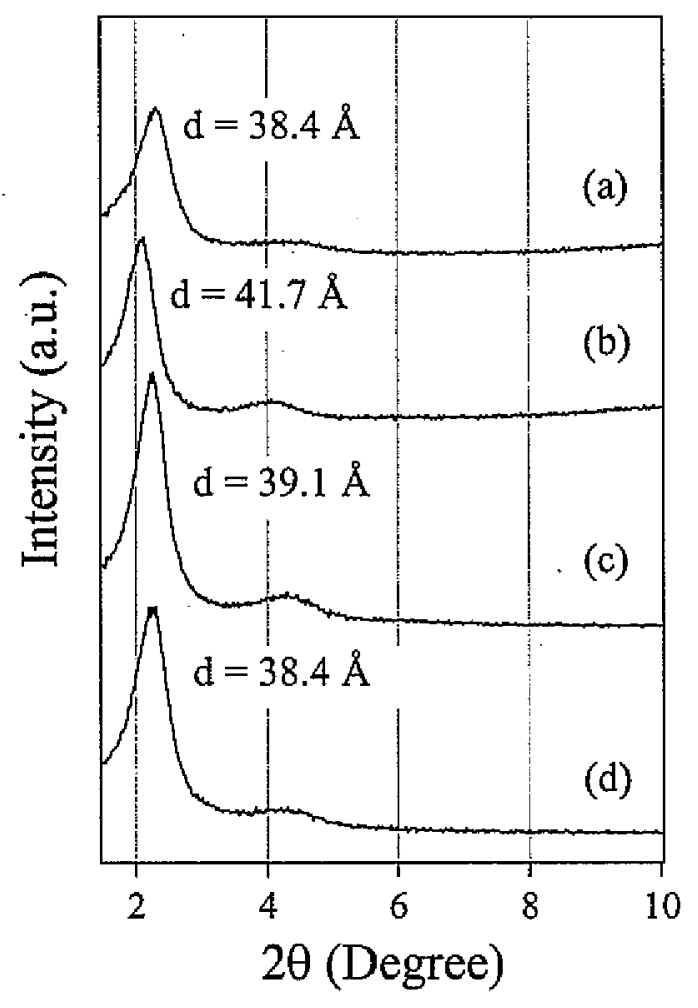


Figure S6. BET isotherms and BJH pore size distribution curves of the MSN materials.

(a) AEP/UDP-MSN
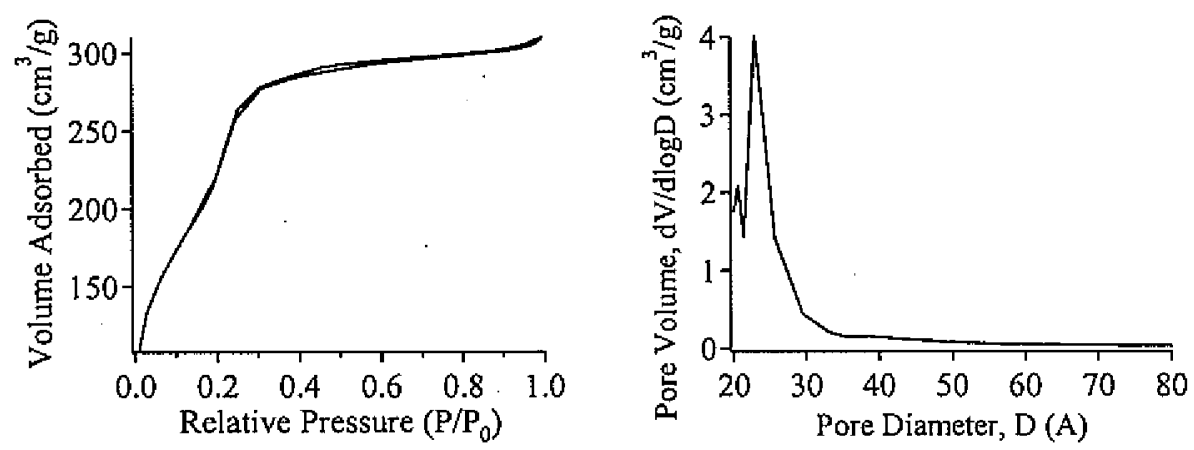

(b) AEP/MP-MSN
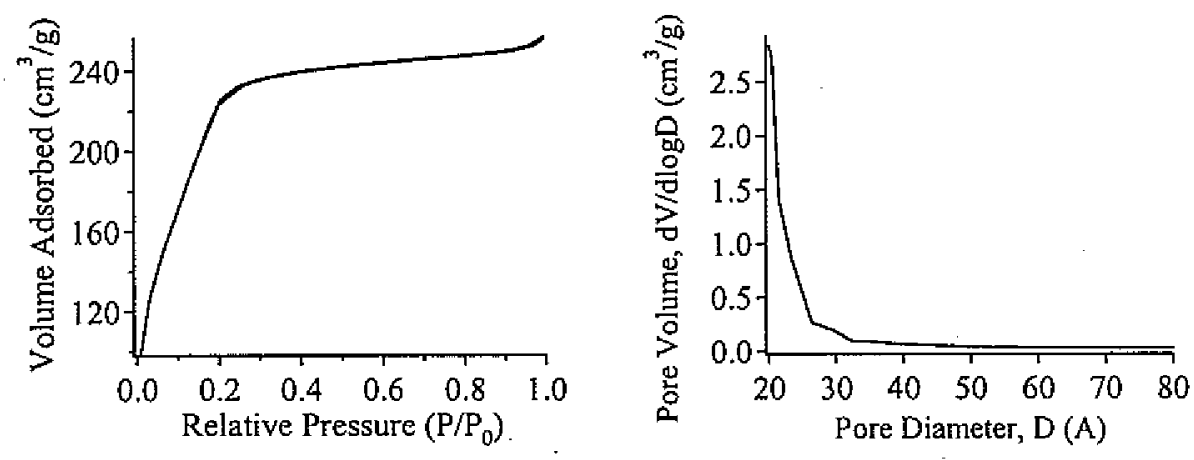

(c) AEP/AL-MSN
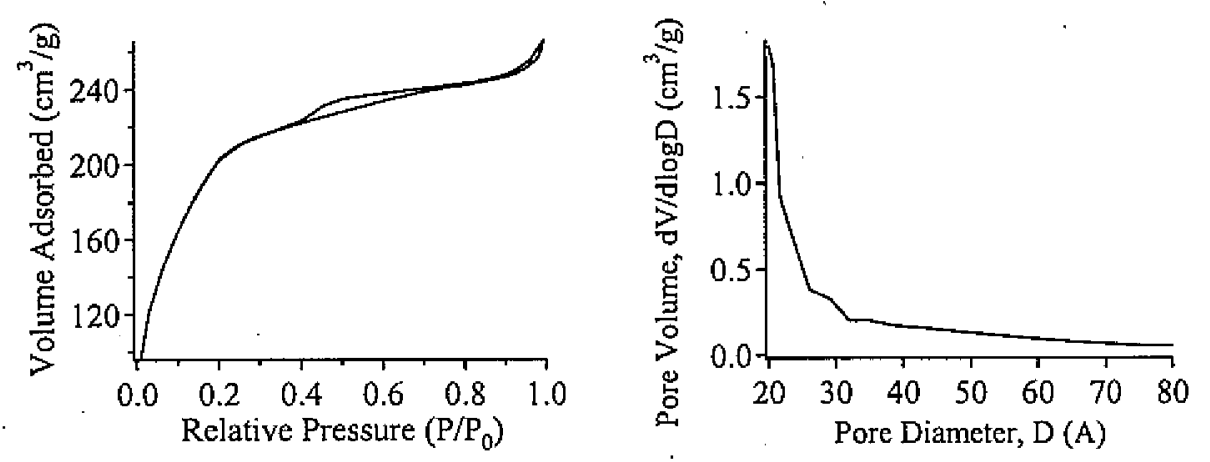
Table S4. Dielectric constants of various organic compounds [a].

\begin{tabular}{|c|c|c|}
\hline Compound & Dielectric Constant & Temp. (K) \\
\hline $\mathrm{H}_{2} \mathrm{O}$ & 80.10 & 293.2 \\
\hline & 67.60 & 363.7 \\
\hline & 38.25 & 293.2 \\
\hline $\mathrm{CH}_{3} \mathrm{NO}_{2}$ & 37.27 & 293.2 \\
\hline $\mathrm{SH}$ & 5.94 & 288.2 \\
\hline 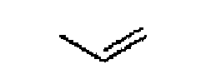 & 2.14 & 220.0 \\
\hline
\end{tabular}

[a] Data taken from "CRC Handbook of Chemistry and Physics" $84^{\text {th }}$ ed., CRC Press. The dipole moment of 4-methoxybenzaldehyde is $3.85 \times 10^{-18}$ esu (J.Phys. Chem., 1935, 39, 1005).

Table S5. Solubility tests of two different aldehydes in 1-propanethiol.

Colubility in $1 \mathrm{~mL}$ of 1-propanethiol




\section{References}

1. Huh, S.; Wiench, J. W.; Trewyn, B. G.; Song, S.; Pruski, M.; Lin, V. S. Y. Chem. Commun. 2003, 2364.

2. Huh, S.; Wiench, J. W.; Yoo, J. C.; Pruski, M.; Lin, V. S. Y. Chem. Mater. 2003, 15, 4247.

3. Maciel, G. E.; Sindorf, D. W.; Bartuska, V. J. J. Chromatogr. 1981, 205, 438.

4. Maciel, G. E. In Encyclopedia of Nuclear Magnetic Resonance; Grant, D. M., Harris, R. K., Eds.; John Wiley \& Sons Ltd: Chichester, 1996; Vol. 7, pp 4370. 


\title{
CHAPTER 5. COOPERATIVE CATALYSIS BY GENERAL ACID AND BASE BIFUNCTIONALIZED MESOPOROUS SILICA NANOSPHERE CATALYSTS
}

\author{
A paper submitted to Angew. Chem. Int. Ed. \\ Seong Huh, Hung-Ting Chen, Jerzy W. Wiench, Marek Pruski and Victor S. -.Y. Lin
}

\begin{abstract}
We synthesized and characterized a new cooperative catalytic system comprised of a series of bifunctionalized mesoporous silica nanosphere (MSN) materials with various relative concentrations of a general acid, ureidopropyl (UDP) group, and a base, 3-[2-(2aminoethylamino)ethylamino]propyl (AEP) group. Three bifunctional AEP/UDP-MSN materials with different relative ratios (AEP/UDP $=2 / 8,5 / 5$, and $8 / 2$ ) were employed as catalysts for aldol, Henry and cyanosilylation reactions. A common electrophile, 4nitrobenzaldehyde, and different nucleophiles, acetone, nitromethane and trimethylsilyl cyanide (TMSCN), were used as reactants. The turnover numbers (TONs) of these reactions indicated that the UDP groups could cooperatively activate substrates with the AEP groups in catalyzing reactions that involve carbonyl activation. By fine-tuning the relative concentrations and proper spatial arrangements of different cooperative functional groups, we envision that our multifunctionalized MSNs could serve as new selective catalysts for many important reactions.
\end{abstract}




\section{Introduction}

Enzymes engaged in carbonyl chemistry often employ both general acid and base catalytic residues in the active sites to cooperatively activate specific subtrates. ${ }^{1}$ Recently, several synthetic catalytic systems have utilized the double hydrogen bonding capability of urea or thiourea functionality as a general acid catalyst to activate carbonyl compounds in homogeneous reactions. ${ }^{2}$ However, to our knowledge, the cooperativity between general acid and base groups is yet to be demonstrated in any synthetic heterogeneous catalyst. Clearly, an important prerequisite for the construction of such a cooperative catalytic system would be to multifunctionalize a solid support with control of the relative concentrations and proper spatial arrangements between these functional groups. In contrast to many recently reported monofunctionalized mesoporous silica catalysts, ${ }^{3}$ we and others focused on multifunctionalized mesoporous catalysts. ${ }^{4}$ Herein, we report a new cooperative catalytic system comprised of a series of bifunctionalized mesoporous silica nanosphere (MSN) materials with various relative concentrations of a general acid, ureidopropyl (UDP) group, and a base, 3-[2-(2-aminoethylamino)ethylamino]propyl (AEP) group (Figure 1).

\section{Results and Discussion}

Three bifunctional AEP/UDP-MSN catalysts with the initial molar ratio of the organosilane precursors, $\mathrm{AEP} / \mathrm{UDP}=2 / 8,5 / 5$, and $8 / 2$, were synthesized via our previously reported cocondensation method. ${ }^{5,6}$ The syntheses and characterizations of the monofunctionalized MSNs with either AEP or UDP functionality were reported previously. ${ }^{\text {5a }}$ All of the mono- and bi-functionalized MSNs exhibited spherical particle shapes with similar particle sizes $(1 \mu \mathrm{m}) .{ }^{5 a, 6}$ The actual concentrations of the two functional groups (AEP and 
UDP) were measured using the previously described solid state ${ }^{13} \mathrm{C}$ CPMAS and ${ }^{29}$ Si MAS NMR methods. ${ }^{5 b, 6}$ The total surface concentrations of the organic functional groups (AEP + UDP) in the $2 / 8,5 / 5$, and $8 / 2$ AEP/UDP-MSNs were determined to be $1.3,1.0$, and 1.5 $\mathrm{mmol} / \mathrm{g}$, and the concentration ratios of AEP/UDP were 2.5/7.5, 5.4/4.6, and 6.7/3.3, respectively. ${ }^{6}$ The XRD measurements of these materials showed large (100) peaks and broad higher diffraction patterns, typical of disordered pore structure. ${ }^{5}$ The observed $d_{100}$ values ranged between $37.8,41.7$, and $38.1 \AA$ for sample $2 / 8,5 / 5$, and $8 / 2$ AEP/UDP-MSNs. The TEM micrographs of these materials also confirmed their disordered pore structure. ${ }^{6}$ The $\mathrm{N}_{2}$ surface sorption analyses of these bifunctionalized MSNs revealed typical type IV BET isotherms. The measured BET surface areas of 2/8, 5/5, and 8/2 AEP/UDP-MSNs are 938.7, 759.6 , and $830.4 \mathrm{~m}^{2} / \mathrm{g}$, respectively. The corresponding $\mathrm{BJH}$ average pore diameters of these MSNs are $27.8,22.9$, and $25.9 \AA$.

To investigate how UDP and AEP could cooperatively catalyze different reactions involving carbonyl activation, the aforementioned AEP/UDP-MSN materials were employed as catalysts for aldol, Henry and cyanosilylation reactions. As shown in Figure 2, a common electrophile, 4-nitrobenzaldehyde, and different nucleophiles, acetone, nitromethane and trimethylsilyl cyanide (TMSCN), were used as reactants. In these reactions, the secondary amines of the AEP group were demonstrated in the literature to be responsible for the enamine formation with acetone (aldol reaction), ${ }_{2}^{7}$ the deprotonation of $\mathrm{CH}_{3} \mathrm{NO}_{2}$ (Henry reaction), ${ }_{2}^{4}$ and the generation of a potential nucleophile of TMSCN through a hypervalent silicate formation (cyanosilylation). ${ }^{8}$ On the other hand, a general acid group (UDP) could activate (through double hydrogen bonding) the carbonyl group of 4-nitrobenzaldehyde for nucleophilic attacks. ${ }^{2}$ Therefore, the presence of both AEP and UDP groups in a close 
proximity could cooperatively activate the electrophile and nucleophile to enhance the reaction rates of the desired catalytic reactions (Scheme 1). Indeed, the observed turnover numbers (TONs) of these reactions (Table 1) are consistent with this hypothesis. In the case of aldol reaction, the monofunctionalized AEP-MSN catalyzed the conversion of 4nitrobenzaldehyde $(0.5 \mathrm{mmol})$ to compound $1(0.091 \mathrm{mmol})$ and a small amount of the dehydrated product, compound $2(0.018 \mathrm{mmol})$, in the presence of acetone $(10 \mathrm{~mL})$. In contrast, the UDP-MSN did not show any catalytic activity under the same reaction condition. The result suggested that the presence of AEP functionality is crucial for converting acetone solvent molecules to the active enamine species. ${ }^{7}$ However, a synergistic effect between AEP and UDP groups was observed in the case of the bifunctionalized AEP/UDP-MSN catalysts. As shown in Table 1 and Figure 3, the TONs of all three AEP/UDP-MSNs are higher than that of AEP-MSN. It is noteworthy that the TON (6.4) of a 1:1 mixture of the monofunctionalized AEP-MSN and UDP-MSN was clearly lower than that of the $5 / 5$ AEP/UDP-MSN (11.9). Furthermore, the TONs of the bifunctionalized MSNs significantly increased as the actual ratio of surface concentrations between AEP and UDP groups decreased from 2.5/7.5 to 5.4/4.6, and 6.7/3.3. According to our solid state NMR data, the total numbers of organic functional groups (AEP + UDP) in these bifunctionalized MSNs are similar, only the relative concentrations between the AEP and UDP groups were varied. To examine whether this activity enhancement was due to the "surface dilution effect" of the AEP group, we investigated the catalytic performance of two bifunctional MSN materials (2/8 and 5/5 AEP/CP-MSNs) that have the AEP group and a cyanopropyl (CP) functionality, which cannot activate the electrophiles through the double hydrogen bonding interaction. The synthesis and characterizations of these two materials have been previously reported. ${ }^{5 b}$ As 
shown in Table 1, the TONs of the $2 / 8$ and 5/5 AEP/CP-MSNs are 12.4 and 9.3, respectively. Indeed, the TON increased slightly as the AEP/CP ratio decreased. However, the large difference in TONs between the AEP/CP-MSNs and the AEP/UDP-MSN catalysts that have the similar surface concentrations of the AEP group cannot be explained by the surface dilution effect. These results strongly indicated that the rate of aldol reaction was accelerated as the surface concentration of UDP groups increased. Given that the UDP group can only activate the electrophile, the observed rate acceleration in the UDP abundant MSN catalysts suggested that the activation of the carbonyl group of 4-nitrobenzaldehyde might be the ratedetermining step in our cooperative catalysts. Such a "cooperative dual catalysis" effect in homogeneous system where one catalyst activates the nucleophile and the other catalyst is responsible for the activation of the electrophile has been reported recently by Jacobsen and co-workers. ${ }^{9}$ In their study, the best mol ratio between the two catalysts was 0.67 and not 1 , which indicated that the best ratio between the cooperative catalytic groups greatly depends on the kinetic nature of the reaction of interest. Similar trend of catalytic reactivity was also observed in the cases of Henry and cyanosilylation reactions. A pronounced cooperativity effect was manifested by a two-fold increase of TONs between 8/2 and 2/8 AEP/UDP-MSNs in both reactions (Table 1). Since the surface concentration of the primary catalytic group (AEP) in the $2 / 8$ AEP/UDP-MSN (AEP $=0.32 \mathrm{mmol} / \mathrm{g}$ ) is only $1 / 3$ of that of $8 / 2 \mathrm{AEP} / \mathrm{NDP}-$ $\operatorname{MSN}(\operatorname{AEP}=1.00 \mathrm{mmol} / \mathrm{g})$, these unusual catalytic enhancements are strong indications of the existence of cooperativity between the general acid (UDP) and base (AEP) groups in our system. 


\section{Conclusions}

In conclusion, we have demonstrated that a general acid group, UDP, could cooperatively activate substrates with a base group, AEP, in catalyzing various reactions that involve carbonyl activation. By fine-tuning the relative concentrations and proper spatial arrangements of different cooperative functional groups, we envision that our multifunctionalized MSNs could serve as new selective catalysts for many important reactions.

\section{Acknowledgement}

This research was supported at Ames Laboratory by the U.S. DOE, office of BES, under contract W-7405-Eng-82 and by the NSF (CHE-0239570). 
Figure 1. Scanning electron micrographs (SEM, above) and schematic drawings (below) of the bifunctional MSNs: (a) 2/8 AEP/UDP-MSN, (b) 5/5 AEP/UDP-MSN and (c) $8 / 2$ AEP/UDP-MSN. Scale bar $=2.0 \mu \mathrm{m}$.
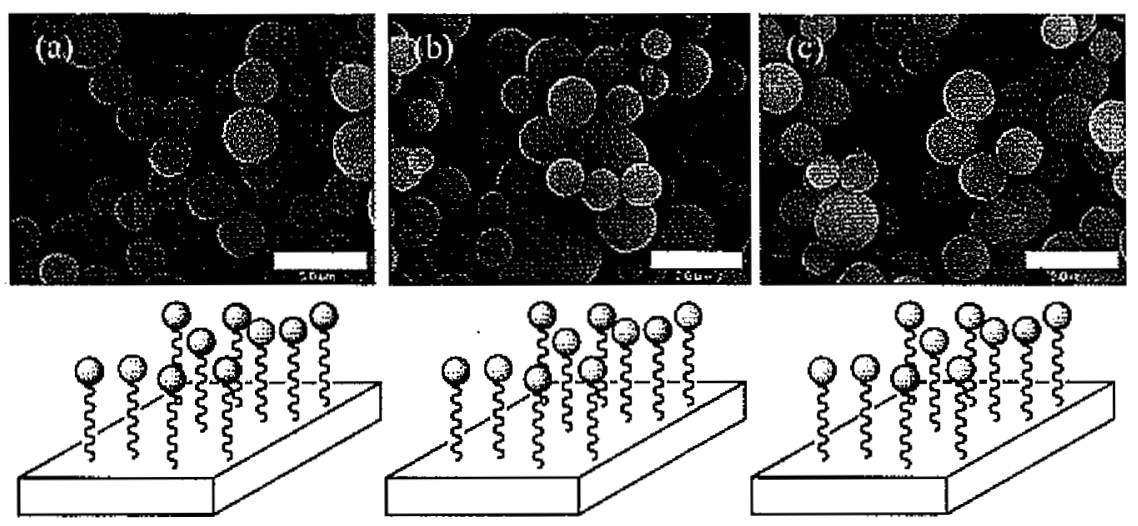

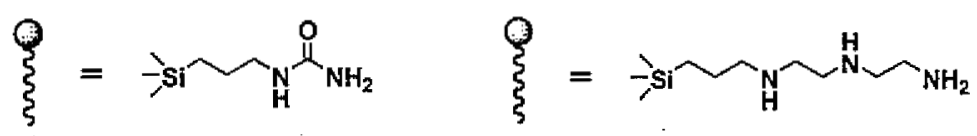


Figure 2. Three model reactions catalyzed by the MSN catalysts: aldol reaction (a), Henry reaction (b) and cyanosilylation (c).

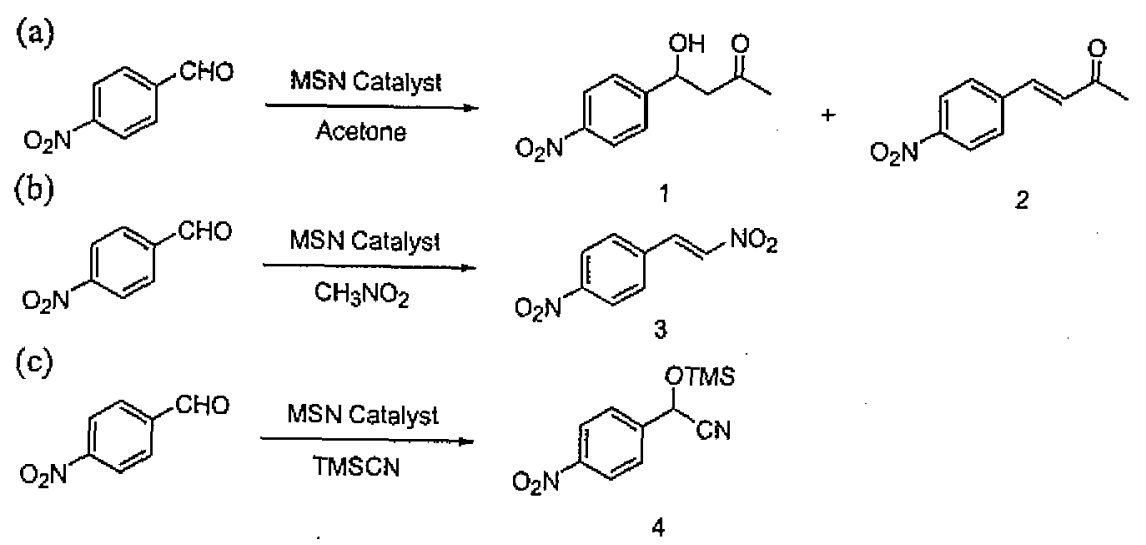


Figure 3. Diagram showing the TONs for the aldol reaction: $2 / 8$ AEP/UDP-MSN (1), 5/5 AEP/UDP-MSN (2), 8/2 AEP/UDP-MSN (3), AEP-MSN (4), physical mixture of AEP-MSN and UDP-MSN (5) and UDP-MSN (6). Product alcohol is 1 and alkene is 2.

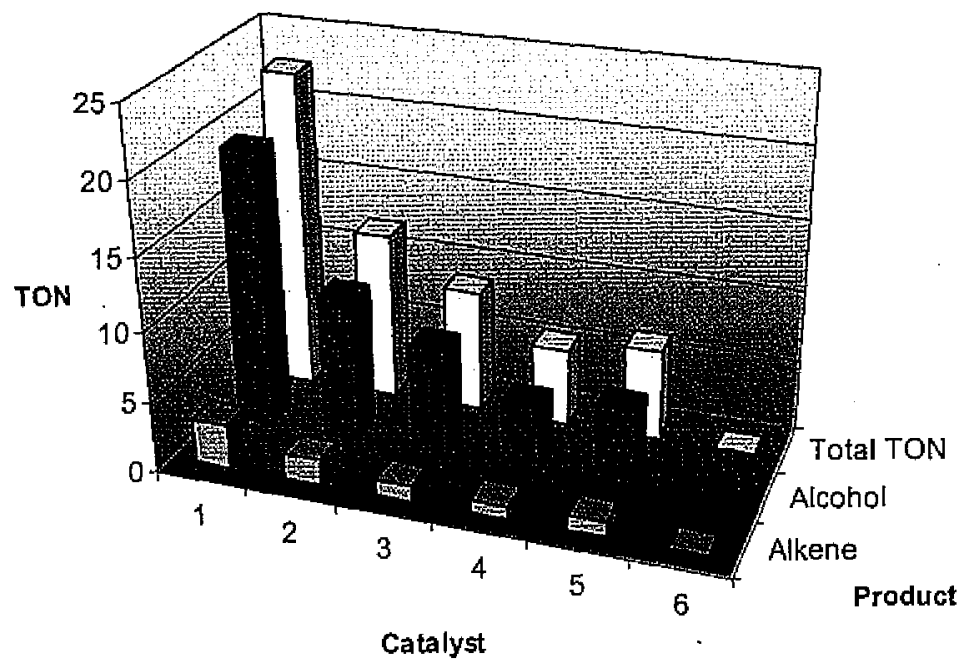


Table 1. TONs of the MSN-catalyzed Reactions ${ }^{\mathrm{a}}$

\begin{tabular}{|c|c|c|c|c|}
\hline Reaction & MSN Catalyst & Temp ${ }^{\circ} \mathrm{C}$ & Product & TON \\
\hline \multirow[t]{8}{*}{ Aldol } & 2/8 AEP/UDP & 50 & 1,2 & 22.6 \\
\hline & 5/5 AEP/UDP & 50 & 1,2 & 11.9 \\
\hline & 8/2 AEP/UDP & 50 & 1,2 & 8.6 \\
\hline & AEP & 50 & 1,2 & 5.4 \\
\hline & physical mixture $^{b}$ & 50 & 1,2 & 6.4 \\
\hline & UDP & 50 & 1,2 & 0.0 \\
\hline & $2 / 8 \mathrm{AEP} / \mathrm{CP}$ & 50 & 1,2 & 12.4 \\
\hline & $5 / 5 \mathrm{AEP} / \mathrm{CP}$ & 50 & 1,2 & 9.3 \\
\hline \multirow[t]{8}{*}{ Henry } & 2/8 AEP/UDP & 90 & 3 & 125.0 \\
\hline & 5/5 AEP/UDP & 90 & 3 & 91.1 \\
\hline & 8/2 AEP/UDP & 90 & 3 & 65.8 \\
\hline & $\mathrm{AEP}$ & 90 & 3 & 55.9 \\
\hline & physical mixture $^{b}$ & 90 & 3 & 79.2 \\
\hline & $\mathrm{UDP}$ & 90 & 3 & 5.8 \\
\hline & 2/8 AEP/CP & 90 & 3 & 78.0 \\
\hline & 5/5 AEP/CP & 90 & 3 & 71.0 \\
\hline \multirow[t]{6}{*}{ Cyanosilylation } & 2/8 AEP/UDP & 50 & 4 & 276.1 \\
\hline & 5/5 AEP/UDP & 50 & 4 & 170.5 \\
\hline & 8/2 AEP/UDP & 50 & 4 & 109.4 \\
\hline & AEP & 50 & 4 & 111.4 \\
\hline & physical mixture $^{\mathrm{b}}$ & 50 & 4 & 126.9 \\
\hline & UDP & 50 & 4 & 45.9 \\
\hline
\end{tabular}

${ }^{\mathrm{a}} \mathrm{TON}=\mathrm{mmol}$ product $/ \mathrm{mmol}$ catalyst during $20 \mathrm{~h}$ of reaction time for aldol and Henry reactions and $24 \mathrm{~h}$ for cyanosilylation reaction using $20 \mathrm{mg}$ of MSN. ${ }^{b}$ Physical mixture $=20$ $\mathrm{mg}$ of AEP-MSN + $20 \mathrm{mg}$ of UDP-MSN. 


\section{Scheme 1}

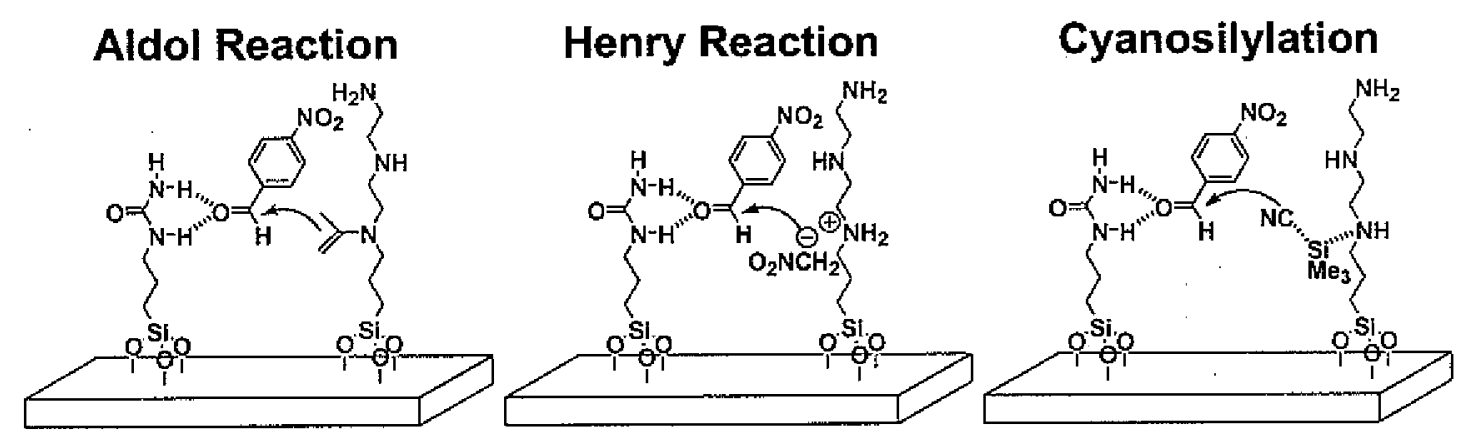




\section{References}

1. For review: Nakayama, T.; Suzuki, H.; Nishino, T. J. Mol. Catal. B 2003, 23, 117 132.

2. For review: Pihko, P. M. Angew. Chem, Int. Ed. 2004, 43, 2062-2064

3. (a) Wight, A. P.; Davis, M. E. Chem. Rev. 2002, 102, 3589-3613. (b) Lindner, E.;

Schneller, T.; Auer, F.; Mayer, H. A. Angew. Chem. Int. Ed. 1999, 38, 2155-2174.

(c) Corma, A. Chem. Rev. 1997, 97, 2373-2419.

4. (a) Huh, S.; Chen, H.-T.; Wiench, J. W.; Pruski, M.; Lin, V. S. Y. J. Am. Chem. Soc. 2004, 126, 1010-1011. (b) Liu, J.; Shin, Y.; Nie, Z.; Chang, J. H.; Wang, L.-Q.; Fryxel1, G. E.; Samuels, W. D.; Exarhos, G. J. J. Phys. Chem. A 2000, 104, 83288339.

5. (a) Huh, S.; Wiench, J. W.; Yoo, J.-C.; Pruski, M.; Lin, V. S. Y. Chem. Mater. 2003, 15, 4247-4256. (b) Huh, S.; Wiench, J. W.; Trewyn, B. G.; Song, S.; Pruski, M.; Lin, V. S. Y. Chem. Commun. 2003, 2364-2365.

6. See Supporting Information for details.

7. (a) Kubota, Y.; Goto, K.; Miyata, S.; Goto, Y.; Fukushima, Y.; Sugi, Y. Chem. Lett. 2003, 32, 234-235. (b) List, B. Acc. Chem. Res. 2004, 37, 548-557.

8. Kantam, M. L.; Sreekanth, P.; Santhi, P. L. Green Chem. 2000, 2, 47-48.

9. Sammis, G. M.; Danjo, H.; Jacobsen, E. N. J. Am. Chem. Soc. 2004, 126, 9928-9929. 


\section{Supporting Information}

\section{Synthesis of mono- and bi-functionalized MSN materials}

The functionalized materials were synthesized via the previously described co-

condensation reaction. ${ }^{5}$ For example, the preparation of 2/8 AEP/UDP-MSN is as follows. A mixture of cetyltrimethylammonium bromide, CTAB $(2.0 \mathrm{~g}, 5.49 \mathrm{mmol}), 2.0 \mathrm{M}$ of $\mathrm{NaOH}(\mathrm{aq})(7.0 \mathrm{~mL}, 14.00 \mathrm{mmol})$ and $\mathrm{H}_{2} \mathrm{O}(480 \mathrm{~g}, 26.67 \mathrm{~mol})$ was heated to $80^{\circ} \mathrm{C}$ for 30 min. To this solution, tetraethoxysilane, TEOS $(9.34 \mathrm{~g}, 44.8 \mathrm{mmol}), 3-[2-(2-$ aminoethylamino)ethylamino]propyltrimethoxysilane, AEPTMS (0.305 g, $1.15 \mathrm{mmol}$ ), and ureidopropyltrimethoxysilane, UDPTMS (1.023 $\mathrm{g}, 4.60 \mathrm{mmol})$ were rapidly and sequentially added via injection, yielding an opaque reaction mixture. White precipitates were observed after vigorous $(550 \mathrm{rpm}$ ) stirring of the reaction mixture for $\sim 2 \mathrm{~min}$. After additional $2 \mathrm{~h}$ of heating at $80^{\circ} \mathrm{C}$, the as-synthesized bifunctionalized 2/8 AEP/UDP-MSN material was isolated by hot filtration, washed with copious water and methanol, and dried under vacuum. An acid extraction of The CTAB surfactant molecules were extracted out of the mesopores of the MSN by placing $1.0 \mathrm{~g}$ of the as-synthesized material in a mixture of methanol $(100 \mathrm{~mL})$ and hydrochloric acid $(0.6 \mathrm{~mL})$ for $2.5 \mathrm{~h}$ at $60^{\circ} \mathrm{C}$. The resulting surfactant-removed solid product was filtered and washed with water and methanol and then dried under vacuum for 3 h at $90^{\circ} \mathrm{C}$.

5. (a) Huh, S.; Wiench, J. W.; Trewyn, B. G.; Song, S.; Pruski, M.; Lin, V. S. Y. Chem. Commun. 2003, 23642365. (b) Huh, S.; Wiench, J. W.; Yoo, J.-C.; Pruski, M.; Lin, V. S. Y. Chem. Mater. 2003, I5, 4247-4256. 


\section{Bifunctionalized MSN-catalyzed aldol reaction of 4-nitrobenzaldehyde with acetone}

All chemicals were purchased from Aldrich and used without further purification. Reagent grade acetone was used without any purification. For example, a reaction mixture consisted of $20 \mathrm{mg}$ of the MSN catalyst and $0.076 \mathrm{~g}(0.5 \mathrm{mmol})$ of 4-nitrobenzaldehyde in 10 $\mathrm{mL}$ of acetone, was heated at $50^{\circ} \mathrm{C}$ with a constant stirring for $20 \mathrm{~h}$. The reaction mixture was filtered on a glass frit and the solids were washed with chloroform and acetone. The resulting filtrate was evaporated on a rotary evaporator and dried under high vacuum. The residue was completely dissolved in a sufficient amount of $\mathrm{CDCl}_{3}$. Analysis of the product was performed by measuring ${ }^{\mathrm{l}} \mathrm{H}$ NMR spectra on a Bruker DRX 400 NMR spectrometer. The resulting two products gave distinctive proton chemical shifts for the integrations. Assignments of the peaks were performed by comparing the chemical shifts of the products with the literature values. ${ }^{6,7}$

\section{Bifunctionalized MSN-catalyzed Henry (Nitroaldol) reaction of 4-nitrobenzaldehyde} with nitromethane

Reagent grade nitromethane was used without any purification. For example, a reaction mixture consisted of $20 \mathrm{mg}$ of the MSN catalyst and $0.453 \mathrm{~g} \mathrm{(3.0} \mathrm{mmol)} \mathrm{of} \mathrm{4-}$ nitrobenzaldehyde in $10 \mathrm{~mL}$ of nitromethane, was heated at $90^{\circ} \mathrm{C}$ with a constant stirring for $20 \mathrm{~h}$. The reaction mixture was filtered on a glass frit and the solids were washed with chloroform and acetone. The resulting filtrate was evaporated on a rotary evaporator and dried under high vacuum. The residue was completely dissolved in $10 \mathrm{~mL}$ of acetone- $d_{6}$. Analysis of the product was performed by measuring ${ }^{1} H$ NMR spectra on a Bruker DRX400

6. Shokat, K.; Uno, T.; Schultz, P. G. J. Am. Chem. Soc. 1994, 116, 2261-2270.

7. Sakthivel, K.; Notz, W.; Bui, T.; Barbas, C. F. III. J. Am. Chem. Soc. 2001, 123, 5260-5267. 
NMR spectrometer. The resulting product gave distinctive vinylic proton chemical shifts for the integrations. Assignments of the peaks were performed by comparing the chemical shifts of the products with the literature values. ${ }^{8}$

\section{Bifunctionalized MSN-catalyzed cyanosilylation of 4-nitrobenzaldehyde with}

\section{TMSCN}

All chemicals were purchased from Aldrich and used without further purification. For example, a reaction mixture consisted of $20 \mathrm{mg}$ of the MSN catalyst, $0.453 \mathrm{~g} \mathrm{(3.0} \mathrm{mmol)} \mathrm{of}$ 4-nitrobenzaldehyde, and $0.298 \mathrm{~g}$ ( $3.0 \mathrm{mmol})$ of TMSCN in $10 \mathrm{~mL}$ of dry toluene was heated at $50^{\circ} \mathrm{C}$ with a constant stirring for $24 \mathrm{~h}$. The reaction mixture was filtered on a glass frit and the solids were washed with chloroform and acetone. The resulting filtrate was evaporated on a rotary evaporator and dried under high vacuum. The residue was completely dissolved in $\mathrm{CDCl}_{3}$. Analysis of the product was performed by measuring ${ }^{1} \mathrm{H}$ NMR spectra on a Bruker DRX400 NMR spectrometer. The resulting silylether product gave a distinctive proton chemical shift at $5.6 \mathrm{ppm}$ for the integrations. Assignments of the peaks were performed by comparing the chemical shifts of the products with the literature values. ${ }^{9}$

8. Huh, S.; Chen, H.-T.; Wiench, J. W.; Pruski, M.; Lin, V. S. Y. J. Am. Chem. Soc. 2004, 126, 1010-1011.

9. Deuchert, K.; Hertenstein, U.; Huenig, S.; Wehner, G. Chem. Ber. 1979, 112, 2045-2061. 
Table S1. Turnover numbers (TONs) of the MSN-catalyzed reactions.

\begin{tabular}{|c|c|c|c|}
\hline \multirow{2}{*}{ Catalyst } & \multicolumn{2}{|c|}{ Product } & \multirow{2}{*}{$\begin{array}{c}\text { Total TON } \\
\text { (Yield in mmol) }\end{array}$} \\
\hline & Turnover $^{[\mathrm{a}]}$ & Tumover ${ }^{[\mathrm{a}]}$ & \\
\hline \multicolumn{4}{|c|}{ Aldol Reaction } \\
\hline 2/8 AEP/UDP & 19 & 3 & $22(0.14)$ \\
\hline 5/5 AEP/UDP & 10 & 2 & $12(0.13)$ \\
\hline 8/2 AEP/UDP & 7 & 1 & $8(0.17)$ \\
\hline AEP & 5 & 1 & $6(0.11)$ \\
\hline Physical mixture & 5 & 1 & $6(0.13)$ \\
\hline UDP & 0 & 0 & $0(0.00)$ \\
\hline
\end{tabular}

Henry reaction<smiles>O=[N+]([O-])C/C=C/c1ccc([N+](=O)[O-])cc1</smiles>

\begin{tabular}{lrr}
\hline 2/8 AEP/UDP & 125 & $125(0.80)$ \\
$5 / 5$ AEP/UDP & 91 & $91(0.98)$ \\
$8 / 2$ AEP/UDP & 66 & $66(1.32)$ \\
AEP & 56 & $56(1.12)$ \\
Physical mixture & 79 & $79(1.58)$ \\
UDP & 6 & $6(0.12)$ \\
\hline
\end{tabular}

Cyanosilylation<smiles>COC(C#N)c1ccc([N+](=O)[O-])cc1</smiles>

\begin{tabular}{lcc}
\hline 2/8 AEP/UDP & 276 & $276(1.77)$ \\
$5 / 5$ AEP/UDP & 170 & $170(1.84)$ \\
$8 / 2$ AEP/UDP & 109 & $109(2.19)$ \\
AEP & 111 & $111(2.23)$ \\
Physical mixture & 127 & $127(2.54)$ \\
UDP & 46 & $46(0.92)$ \\
\hline
\end{tabular}

[a] Turnover $=\mathrm{mmol}$ product $/ \mathrm{mmol}$ catalyst during $20 \mathrm{~h}$ for aldol and Henry reactions and $24 \mathrm{~h}$ for cyanosilylation. 


\section{Summary of solid-state NMR measurements}

\subsection{Experimental}

Solid-state NMR spectra were obtained at $100.59\left({ }^{13} \mathrm{C}\right)$ and $79.47 \mathrm{MHz}\left({ }^{29} \mathrm{Si}\right)$ on a Varian/Chemagnetics Infinity spectrometer, equipped with a doubly tuned, $5 \mathrm{~mm}$ magic angle spinning (MAS) probe. Direct polarization (DP) and variable amplitude cross polarization (CP) methods were used under the conditions described earlier. ${ }^{1,4}$ These measurements provided quantitative evidence for functionalization of the mesopores with the organic moieties and confirmed their structure. For AEP-, UDP-, and AEP/UDP-MSN's, the assignments of ${ }^{29} \mathrm{Si}$ and ${ }^{13} \mathrm{C}$ NMR spectra were made following our earlier study (see Figure S1). ${ }^{\mathrm{Ib}, 4}$ The methods used for quantitative measurements of ${ }^{29} \mathrm{Si}$ and ${ }^{13} \mathrm{C}$ intensities are detailed in Sections 5.2 and 5.3 below. All NMR results are summarized in Table 1, which contains the relative concentrations of $T^{n}$ and $Q^{n}$ groups, the molar concentrations of organic functional groups and the corresponding average molecular formulae.

\subsection{Quantification of silicon groups}

Relative concentrations of $T^{n}$ and $Q^{n}$ silicon groups ${ }^{10}$ were obtained from the analysis of ${ }^{29} \mathrm{Si}$ DPMAS spectra. In agreement with our earlier results, ${ }^{1 \mathrm{~b}}$ the measurements of $T_{1}$ relaxation in functionalized MSN's yielded $T_{1}$ values on the order of 50 to $65 \mathrm{~s}$ for $T^{n}$ groups and 30 to $45 \mathrm{~s}$ for $Q^{n}$ groups. Therefore, a delay of $300 \mathrm{~s}$ between scans has been used during the acquisition of ${ }^{29} \mathrm{Si}$ NMR spectra. The accumulation of 270 scans yielded intensities that were accurate within $\pm 10 \%$.

10. Maciel, G. E. In Encyclopedia of Nuclear Magnetic Resonance; Grant, D. M., Harris, R. K., Eds.; John Wiley \& Sons Ltd: Chichester, 1996; Vol. 7, pp 4370-4386. 


\subsection{Quantification of functional groups in bifunctionalized samples using ${ }^{13} \mathrm{C} N M R$}

Although direct polarization is the preferred method for quantitative measurements, relative ${ }^{13} \mathrm{C}$ intensities were measured using a CPMAS-based method. The strategy, developed in our earlier study, ${ }^{1 a}$ was also successfully used for AEP/UDP-MSN system in our previous report. ${ }^{4}$ The procedure utilizes differences in values of $T_{1 p}{ }^{H}$ and $\tau_{C H}$ times between AEP and UDP. ${ }^{\text {la }}$ The bifunctionalized samples could be quantitatively characterized without the tedious measurements of the ${ }^{13} \mathrm{C}$ build-up curves ${ }^{12,4}$ by properly measuring and processing the CPMAS spectra with two different contact times (i.e. 0.4 and $1.5 \mathrm{~ms}$ ), using known physical mixtures of mono-functionalized samples as intensity standards. ${ }^{1,4}$

Table S2. Relative concentrations of $T^{t}$ and $Q^{n}$ silicon groups (in \%), surface coverage (SC, in \%), molecular concentrations of organic functionalities $(M C$, in $\mathrm{mmol} / \mathrm{g})$, molecular formulae $(M F)$, molar ratios in bifunctional samples, and concentrations (in $\mathrm{mmol} / \mathrm{g}$ ) of each organic functionality derived from solid state ${ }^{13} \mathrm{C}$ CPMAS and ${ }^{29} \mathrm{Si}$ DPMAS NMR data.

\begin{tabular}{|c|c|c|c|c|c|c|c|c|c|c|}
\hline Functionality & $r^{2}$ & $T^{\hat{a}}$ & $Q^{2}$ & $Q^{3}$ & $Q^{4}$ & $S C$ & $M C$ & $M F$ & Molar ratio & Concentr. \\
\hline $\mathrm{AEP}^{(\mathrm{a})}$ & 1 & 6 & 3 & 35 & 55 & 16 & 1.0 & $\left(\mathrm{SiO}_{2}\right)_{100}\left(\mathrm{H}_{2} \mathrm{O}\right)_{17.5}(\mathrm{ORG})_{7}{ }^{(\mathrm{c})}$ & & \\
\hline $\mathrm{UDP}^{(\mathrm{a})}$ & 2 & 4 & 4 & 38 & 52 & 13 & 0.9 & $\left(\mathrm{SiO}_{2}\right)_{100}\left(\mathrm{H}_{2} \mathrm{O}\right)_{21}(\mathrm{ORG})_{6}$ & & \\
\hline 2/8 AEP/UDP & 4 & 5 & 1 & 35 & 55 & & 1.3 & $\left(\mathrm{SiO}_{2}\right)_{100}\left(\mathrm{H}_{2} \mathrm{O}\right)_{16}(\mathrm{ORG})_{9}$ & $2.5: 7.5$ & $\begin{array}{l}\text { AEP: } 0.32 \\
\text { UDP: } 0.98\end{array}$ \\
\hline $\begin{array}{l}\text { 5/5 } \\
\text { (bEP/UDP }\end{array}$ & 2 & 5 & 3 & 36 & 54 & 15 & 1.0 & $\left(\mathrm{SiO}_{2}\right)_{100}\left(\mathrm{H}_{2} \mathrm{O}\right)_{18.5}(\mathrm{ORG})_{7}$ & $5.4: 4.6$ & $\begin{array}{l}\text { AEP: } 0.54 \\
\text { UDP: } 0.46\end{array}$ \\
\hline 8/2 AEP/UDP & 3 & 3 & 4 & 30 & 60 & & 1.5 & $\left(\mathrm{SiO}_{2}\right)_{100}\left(\mathrm{H}_{2} \mathrm{O}\right)_{12.5}(\mathrm{ORG})_{12}$ & $6.7: 3.3$ & $\begin{array}{l}\text { AEP: } 1.00 \\
\text { UDP: } 0.50\end{array}$ \\
\hline
\end{tabular}

(a), (b) Data taken from ref $1 \mathrm{~b}$ and ref, 4. (c) 'ORG' denotes the organic functional groups (AEP and UDP). 
Figure S1. ${ }^{1} \mathrm{H} \rightarrow{ }^{13} \mathrm{C}$ CPMAS (top) and ${ }^{29} \mathrm{Si}$ DPMAS (bottom) spectra obtained for $2 / 8$ AEP/UDP-MSN (left column) and 8/2 AEP/UDP-MSN (right column). Locations of carbon resonances in UDP and AEP are marked separately on the left top and the right top spectra.
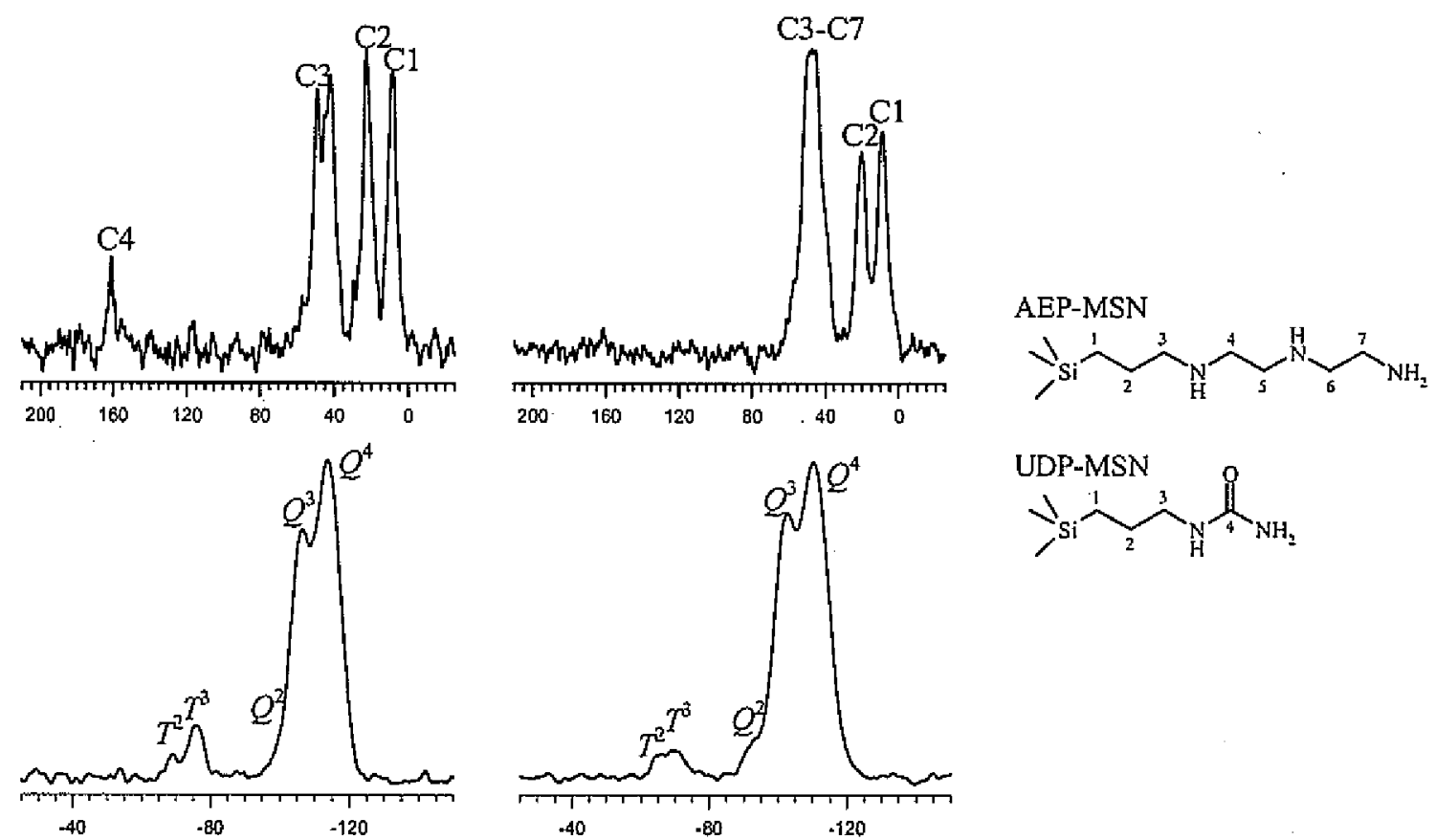<smiles>[Y15]C(C)(C)C(CC(C)NC(N)=O)[Si](C)(C)C</smiles> 
Figure S3. SEM images of MSN materials (JEOL 840A).

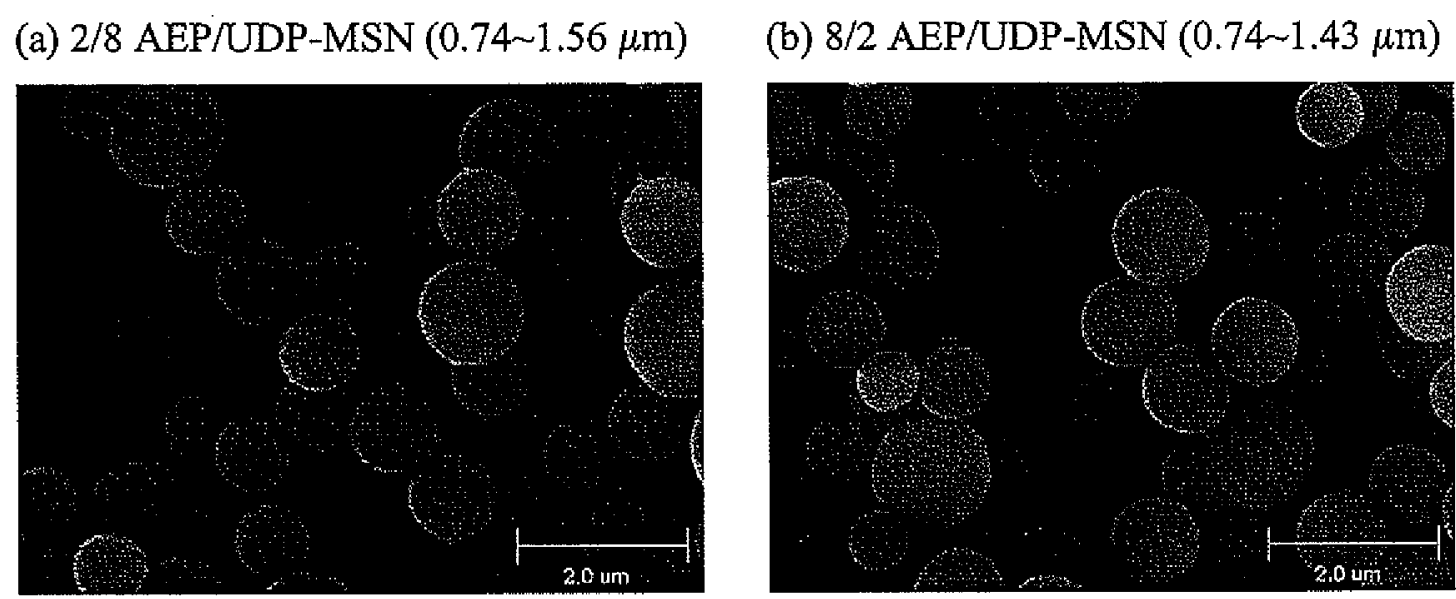


Figure S4. TEM micrographs of 2/8 AEP/UDP-MSN (top) and 8/2 AEP/UDP-MSN (bottom) materials (Philips CM-30 at $300 \mathrm{kV}$ ).
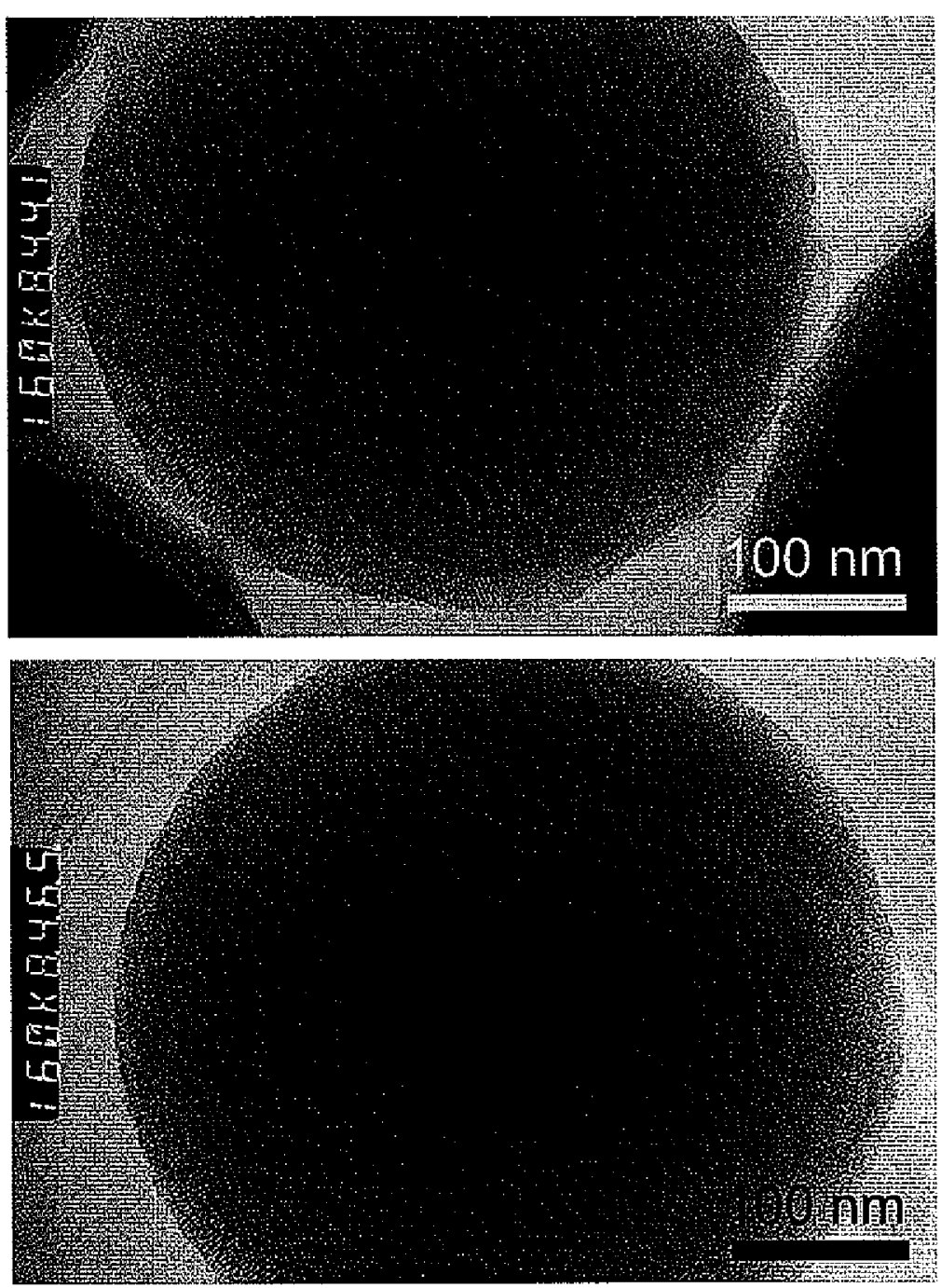
Figure S5. TEM micrograph of 2/8 AEP/UDP-MSN (top) after aldol reaction (Philips CM30 at $300 \mathrm{kV}$ ).

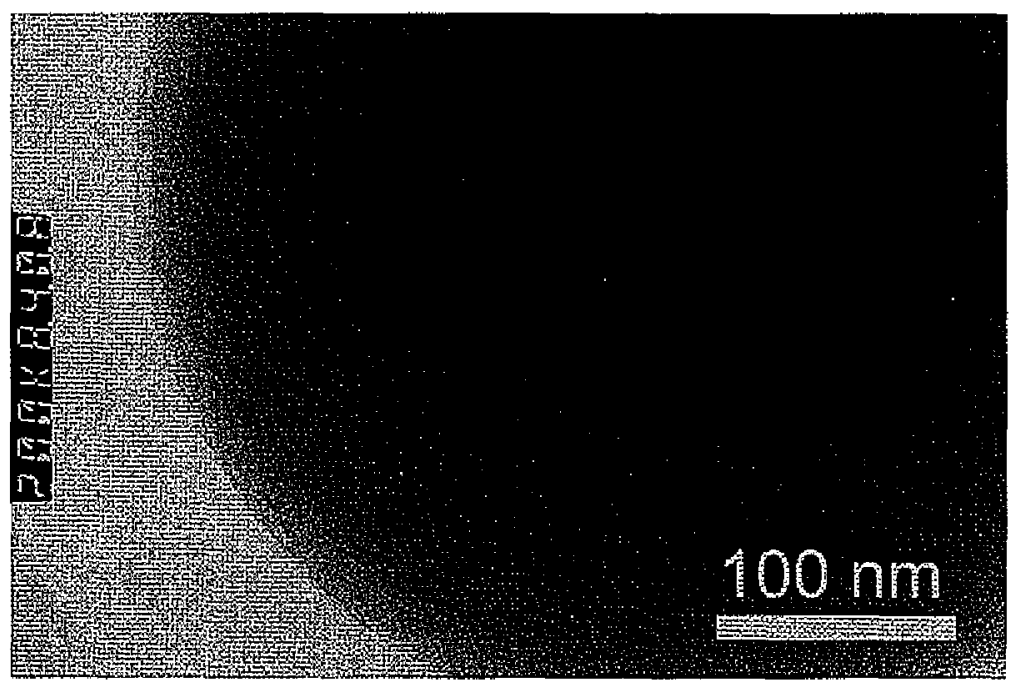

Table S3. Structural properties of the surfactant-free MSN materials. ${ }^{[a]}$

\begin{tabular}{ccccccc}
\hline Samples & $d_{100}(\AA)$ & $a_{0}(\AA)$ & $S_{\mathrm{BET}}\left(\mathrm{m}^{2} / \mathrm{g}\right)$ & $V_{\mathrm{p}}\left(\mathrm{cm}^{3} / \mathrm{g}\right)$ & $W_{\mathrm{BJH}}(\AA)$ & $\begin{array}{c}d_{\text {pore wall }} \\
(\AA)\end{array}$ \\
\hline 2/8 AEP/UDP-MSN & 37.8 & 43.6 & 938.7 & 0.77 & 27.8 & 15.8 \\
5/5 AEP/UDP-MSN & 41.7 & 48.2 & 759.6 & 0.47 & 22.9 & 25.3 \\
8/2 AEP/UDP-MSN & 38.1 & 44.0 & 830.4 & 0.60 & 25.9 & 18.1 \\
\hline
\end{tabular}

[a] The BET surface area $\left(S_{\mathrm{BET}}\right)$, the mesopore volume $\left(V_{\mathrm{p}}\right)$, and the mean mesopore size $\left(W_{\mathrm{BJH}}\right)$ were obtained from the nitrogen adsorption/desorption data. The $d_{100}$ numbers represent the $d$-spacing corresponding to the main (100) XRD peak. The unit cell size $\left(a_{0}\right)$ is calculated from the $d_{100}$ data using $a_{0}=2 d_{100} / 3^{1 / 2}$. The pore wall thickness $\left(d_{\text {pore wall }}=a_{0}-\right.$ $\left.W_{\mathrm{BJH}}\right)$. 
Figure S6. Powder XRD data of the MSN materials: 2/8 AEP/UDP-MSN (blue) and 8/2 AEP/UDP-MSN (red).

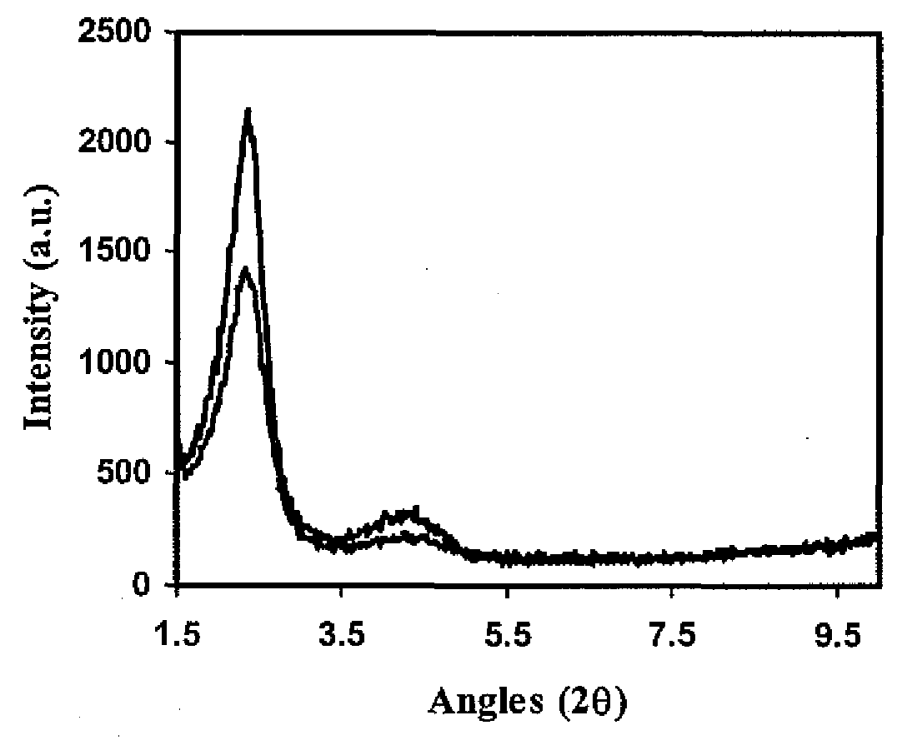


Figure S7. BET isotherms of the bifunctionalized MSN materials (ASAP 2000).

(a) 2/8 AEP/UDP-MSN

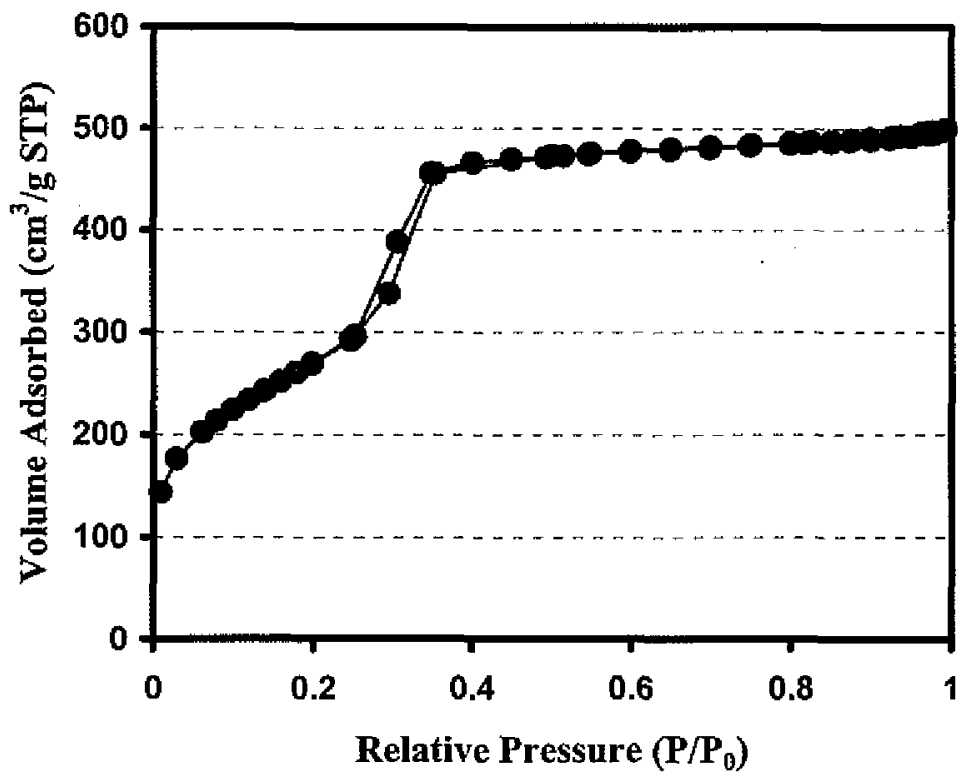

(b) $8 / 2$ AEP/UDP-MSN

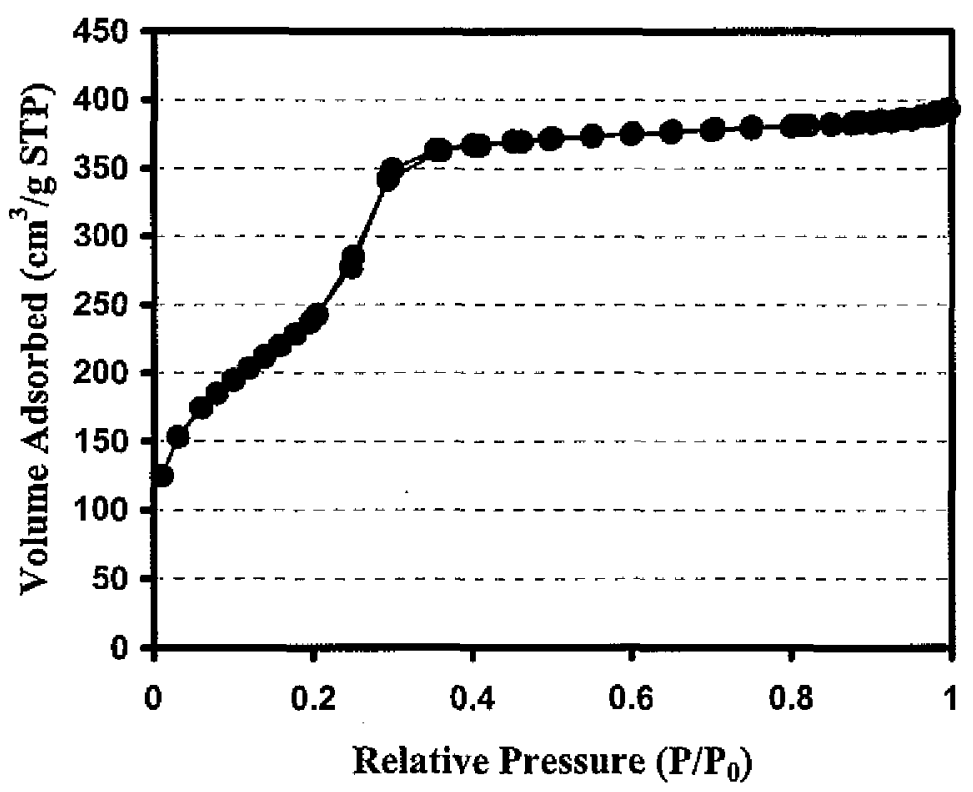




\section{CHAPTER 6. GENERAL CONCLUSIONS}

My original goal to prepare shape-controlled hybrid mesoporous silica nanoparticles has been successfully achieved. A series of new mesoporous silica materials with MCM-41 type of structure containing a homogeneous layer of organic functional groups inside the pores was prepared using a co-condensation method under low surfactant concentration condition. This reproducible synthetic approach resulted in high surface coverage with several functional groups such as a primary amine, secondary amine, urea, isocyanate, vinyl, and nitrile. In addition, I found that the presence of organoalkoxysilane precursors during the base catalyzed condensation greatly influenced the final particle shape. By simply changing the precursor or its concentration, the particle morphology was fine-tuned in a predictable way to various shapes, including spheres, tubes, and rods of various dimensions. The mechanism of this unprecedented synthetic procedure that gave rise to the specific particle morphologies was investigated. The structure and functionality of these novel materials were fully characterized by the field-emission scanning electron microscopy, transmission scanning microscopy, solid state NMR spectroscopy, thermogravimetric analysis, and nitrogen adsorption and desorption studies.

In addition, I have developed another important synthetic method has been developed for the first time that can control both multifunctionalization and morphology of the mesoporous organic/inorganic hybrid materials. The method involved the introduction of different molar ratios of organoalkoxysilane precursors to a base-catalyzed co-condensation of silicate. Bifunctional mesoporous silica nanosphere (MSN) materials containing various 
ratios of two different organic groups were obtained. They exhibited characteristic $\mathrm{Cu}^{2+}$ sorption behaviours depending of the physicochemical nature of the mesopore surface.

I also succeeded in preparing a series of bifunctionalized MSN-based heterogeneous catalysts for the nitroaldol (Henry) reaction. A common 3-[2-(2aminoethylamino)ethylamino]propyl (AEP) primary group and three different secondary groups, ureidopropyl (UDP), mercaptopropyl (MP), and allyl (AL) functionalities, were incorporated to these mesoporous silica materials by introducing equal amounts of AEPtrimethoxysilane with UDP-, MP-, or AL-trialkoxysilane precursors to our co-condensation reaction. The AEP group served as a catalyst, and the other secondary groups provided different noncovalent interactions to reactants and thereby controlled the reaction selectivity. By varying the secondary group in these bifunctionalized MSN catalysts, the selectivity of a nitroaldol reaction of two competing benzaldehydes reacting with nitromethane was controlled depending on the surface characteristics. The selectivity of the bifunctionalized MSN catalysts could be systematically tuned simply by varying the physicochemical nature of the pore surface-bound secondary groups, i.e., polarity and hydrophobicity unlike the well known size selection in zeolite catalysis.

Furthermore, I synthesized and characterized a new cooperative catalytic system comprised of a series of bifunctional MSN materials with various relative concentrations of a general acid, ureidopropyl (UDP) group, and a base, 3-[2-(2aminoethylamino)ethylamino]propyl (AEP) group. Three bifunctional AEP/UDP-MSN materials with different relative ratios ( $\mathrm{AEP} / \mathrm{UDP}=2 / 8,5 / 5$, and $8 / 2$ ) were employed as catalysts for aldol, Henry and cyanosilylation reactions. A common electrophile, 4- 
nitrobenzaldehyde, and different nucleophiles, acetone, nitromethane and trimethylsilyl cyanide (TMSCN), were used as reactants. The turnover numbers (TONs) of these reactions suggested that the UDP groups cooperatively activate substrates with the AEP groups in catalyzing reactions that involve carbonyl activation. By fine-tuning the relative concentrations and proper spatial arrangements of different cooperative functional groups, we envision that our multifunctionalized MSNs could serve as new selective catalysts for many other important reactions.

I have also involved in other research areas including the preparation of monodisperse MSNs with a variety of organic functional groups and chiral catalysis and chiral separation using predefined arrays of chiral mesopores. 


\section{ACKNOWLEDGEMENTS}

I would like to thank my parents and brothers for their encouragement and support in my life.

I appreciate my research advisor Dr. Victor S. $-\mathrm{Y}$. Lin and POS committee members for their invaluable guidance during my research.

I also thank Hung-Ting Chen, Weikua Deng, Dr. Jianguo Huang, other group members, and Korean friends for their friendship.

I also thank Dr. Marek Pruski, Dr. Jerzy W. Wiench, and Dr. Julien Trebosc for helping solid state NMR measurements. I thank Dr. Matthew J. Kramer, Mr. Francis C. Laabs, Dr. Seahn Song, and Ms. Tracey M. Pepper for TEM measurement. I also thank Mr. Jerry Amenson and Mr. Warren Straszheim for teaching me SEM measurement.

This work was performed at Ames Laboratory under Contract No. W-7405-Eng-82 with the U.S. Department of Energy. The United States government has assigned the DOE Report number IS-T 2397 to this thesis. 